\title{
BNREL
}
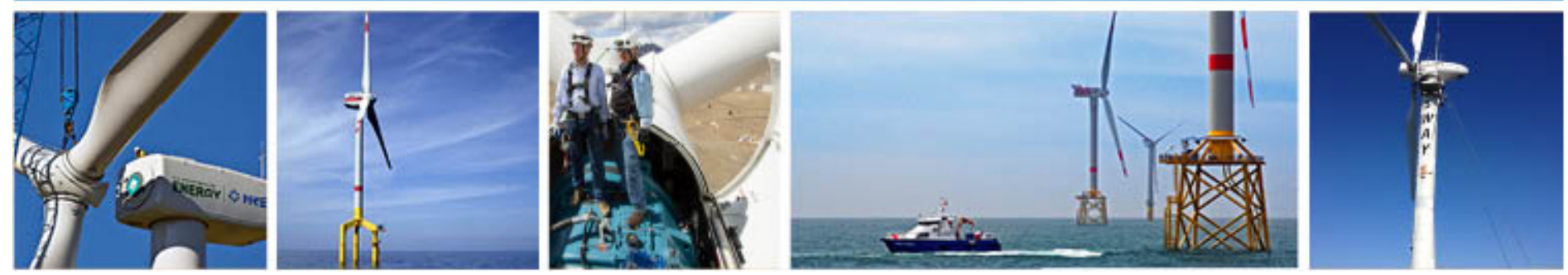

\section{An Assessment of the Economic Potential of Offshore Wind in the United States from 2015 to 2030}

Philipp Beiter, Walter Musial, Levi Kilcher, Michael Maness, and Aaron Smith National Renewable Energy Laboratory

Related Data: https://data.nrel.gov/submissions/67

NREL is a national laboratory of the U.S. Department of Energy Office of Energy Efficiency \& Renewable Energy Operated by the Alliance for Sustainable Energy, LLC

This report is available at no cost from the National Renewable Energy Laboratory (NREL) at www.nrel.gov/publications.

Technical Report

NREL/TP-6A20-67675

March 2017

Contract No. DE-AC36-08GO28308 


\section{An Assessment of the Economic Potential of Offshore Wind in the United States from 2015 to 2030}

Philipp Beiter, Walter Musial, Levi Kilcher, Michael Maness, and Aaron Smith National Renewable Energy Laboratory

Prepared under Task No. WE16.CA02

NREL is a national laboratory of the U.S. Department of Energy Office of Energy Efficiency \& Renewable Energy Operated by the Alliance for Sustainable Energy, LLC

This report is available at no cost from the National Renewable Energy Laboratory (NREL) at www.nrel.gov/publications.

National Renewable Energy Laboratory 15013 Denver West Parkway Golden, CO 80401 303-275-3000 • www.nrel.gov

\section{Technical Report}

NREL/TP-6A20-67675

March 2017

Contract No. DE-AC36-08G028308 


\section{NOTICE}

This report was prepared as an account of work sponsored by an agency of the United States government. Neither the United States government nor any agency thereof, nor any of their employees, makes any warranty, express or implied, or assumes any legal liability or responsibility for the accuracy, completeness, or usefulness of any information, apparatus, product, or process disclosed, or represents that its use would not infringe privately owned rights. Reference herein to any specific commercial product, process, or service by trade name, trademark, manufacturer, or otherwise does not necessarily constitute or imply its endorsement, recommendation, or favoring by the United States government or any agency thereof. The views and opinions of authors expressed herein do not necessarily state or reflect those of the United States government or any agency thereof.

This report is available at no cost from the National Renewable Energy Laboratory (NREL) at www.nrel.gov/publications.

Available electronically at SciTech Connect http:/www.osti.gov/scitech

Available for a processing fee to U.S. Department of Energy and its contractors, in paper, from:

U.S. Department of Energy

Office of Scientific and Technical Information

P.O. Box 62

Oak Ridge, TN 37831-0062

OSTI http://www.osti.gov

Phone: 865.576.8401

Fax: 865.576.5728

Email: reports@osti.gov

Available for sale to the public, in paper, from:

U.S. Department of Commerce

National Technical Information Service

5301 Shawnee Road

Alexandria, VA 22312

NTIS http://www.ntis.gov

Phone: 800.553 .6847 or 703.605 .6000

Fax: 703.605.6900

Email: orders@ntis.gov 


\section{Acknowledgments}

We thank the following individuals for their thoughtful reviews, comments, and suggestions: Jaquelin Cochran, Brian Smith, David Mooney, Maureen Hand, and Eric Lantz (National Renewable Energy Laboratory [NREL]); Catherine Bowes (National Wildlife Federation), Greg Matzat (New York State Energy Research and Development Authority), Stephanie McClellan (University of Delaware), Douglass Sims (Natural Resources Defense Council), Bruce Valpy and Giles Hundleby (BVG Associates Ltd.), and Ryan Wiser (Lawrence Berkeley National Laboratory). In addition, we thank Alana Duerr, Patrick Gilman, Gary Norton, Dan Beals, Rich Tusing, and Jose Zayas from the U.S. Department of Energy (DOE) for supporting this work. This work was supported by DOE under Contract Number DE-AC36-08GO28308 with NREL. Funding for the work was provided by the DOE Office of Energy Efficiency and Renewable Energy, Wind Energy Technologies Office. Any remaining errors or omissions are the sole responsibility of the authors. Editing was provided by Sheri Anstedt (NREL). 


\section{List of Abbreviations}

$\begin{array}{ll}\text { AEP } & \begin{array}{l}\text { annual energy production } \\ \text { capital expenditures } \\ \text { CapEx }\end{array} \\ \text { commercial operation date } \\ \text { EIA } & \begin{array}{l}\text { Energy Information Administration } \\ \text { fixed charge rate } \\ \text { gigawatt }\end{array} \\ \text { GW } & \text { gigawatt-hour } \\ \text { GWh } & \text { kilowatt } \\ \text { kW } & \text { kilowatt-hour } \\ \text { kWh } & \text { levelized avoided cost of energy } \\ \text { LACE } & \text { levelized cost of energy } \\ \text { LCOE } & \text { locational marginal price } \\ \text { LMP } & \text { meter } \\ \text { m } & \text { market marginal cost } \\ \text { MMC } & \text { megawatt } \\ \text { MW } & \text { megawatt-hour } \\ \text { MWh } & \text { North American Electric Reliability Corporation } \\ \text { NERC } & \text { National Renewable Energy Laboratory } \\ \text { NREL } & \text { operation and maintenance } \\ \text { O\&M } & \text { operational expenditures } \\ \text { OpEx } & \text { Regional Energy Deployment System } \\ \text { ReEDS } & \text { terawatt-hour } \\ \text { TWh } & \end{array}$




\section{Executive Summary}

This study describes an assessment of the site-specific variation of levelized cost of energy (LCOE) and levelized avoided cost of energy (LACE) to understand the economic potential of fixed-bottom and floating offshore wind technologies in major U.S. coastal areas ${ }^{1}$ between 2015 and 2030. The detailed methodology, assumptions, and context of this study are documented in $A$ Spatial-Economic Cost Reduction Pathway Analysis for U.S. Offshore Wind Energy Development from 2015-2030 (Beiter et al. 2016). ${ }^{2}$ This earlier report focused on the development of a geospatial cost model of the offshore wind technical resource area in the United States and the relationship of geospatial and temporal parameters on the cost of energy up to 2030. The present study builds on the Beiter et al. (2016) analysis to document in detail the variation in economic potential across more than 7,000 U.S. coastal locations by comparing sitespecific LCOE and LACE. In particular, this study offers insights into the available U.S. offshore wind resource by region at different levels of LCOE and an assessment of the present and future economic potential of that resource capacity out to 2030. The Crown Estate (2012) cost reductions assumed for this study should be considered in context of recent cost declines indicated by European offshore wind winning tenders. However, determining if and to what extent these recent European cost reductions will continue and how they can be translated to a U.S. market context is beyond the scope of this study.

LCOE is the total cost of generating a unit of electricity and is commonly expressed in dollars per megawatt-hour (MWh) over the expected lifetime of the offshore wind electricity-generating plant. It varies by location because of spatial differences in energy production (e.g., average wind speed variations) and capital expenditures (e.g., varying sea states ${ }^{3}$, distance from shore, water depth, soil and substructure suitability, and availability of critical infrastructure). However, LCOE alone is not sufficient to assess economic viability because it does not capture the electric system value that can be attributed to a generation source. Therefore, this analysis draws on a "simplified" version ${ }^{4}$ of LACE as a metric to capture the system value of a generation technology. LACE is a metric to approximate the electric system value of a generation technology over its expected lifetime and commonly expressed in dollars per-MWh as well. LACE varies by location because of differences in the system value of new electricity, which is determined by a range of factors, including the cost of competing generation technologies, the

\footnotetext{
${ }^{1}$ This analysis excludes Alaska. For Hawaii, estimates of LACE, net value, and economic potential were not calculated because of data limitations.

${ }^{2}$ Additional studies that this conceptual approach and methodology is based on include Brown et al. (2015), U.S. Department of Energy (2013), and Lopez et al. (2012).

3 Sea state has been defined as the "overall condition of the surface of a large area of open ocean or sea resulting from the combined effects of wind-generated waves, swells, and surface currents. It is described in terms of how rough the waters are based on wave height." (Canada Department of Environment and Climate Change 2017)

${ }^{4}$ The concept of avoided costs has long been used in utility and regulatory economics (see e.g., Public Utility Regulatory Act of 1978, Sec. 210, defining avoided costs as "the incremental cost to an electric utility of electric energy or capacity or both which [...] such utility would generate itself or purchase from another source"). This analysis applies a specification that does not necessarily reflect the same complexity that is used for other purposes. Limitations and caveats are discussed in Section 3.
} 
resource mix, demand patterns, and transmission constraints. The difference between LCOE and LACE at a given location (denoted in this report by "net value") can help inform an initial understanding of the economic potential of a new offshore wind project at a high geospatial resolution. For this analysis, policy-related factors that may influence LACE or LCOE (and hence, the "net value" of a renewable energy project) were not considered explicitly. For instance, renewable energy support mechanisms (e.g., the production tax credit, Renewable Portfolio Standards), energy sector and environmental regulations (e.g., carbon pricing), or benefits from portfolio diversification (Energy Information Administration [EIA] 2015) may increase the "net value" and economic potential. Conversely, regulatory uncertainty and market barriers (see e.g., DOE 2016) may decrease the "net value" and economic potential. 5

A series of data sources and reports were used to derive the assumptions and data for the underlying analysis documented in Beiter et al. (2016), including market reports (e.g., Moné et al. [2015]; Smith, Stehly, and Musial [2015]), U.S. electricity cost benchmark reports (e.g., EIA Annual Energy Outlook [AEO] 2014), offshore wind cost-reduction pathway studies (e.g., Beiter et al. (2016); Valpy et al. [2014]; Catapult [2015]; E.C. Harris [2012]; The Crown Estate [2012]; The Crown Estate [2015]), geospatial data layers, and expert elicitation.

Estimates of offshore wind costs were calculated for three focus years corresponding to commercial operation dates (CODs) ${ }^{6}$ of 2015, 2022, and 2027. In 2015, a baseline turbine rating of 3.4 megawatts (MW) was assumed as it reflects the average turbine size of installed offshore wind power projects globally in 2014 (Smith, Stehly and Musial 2015). Informed by recent industry trends, turbine ratings of $6 \mathrm{MW}$ and $10 \mathrm{MW}$ were assumed as representative technologies for years 2022 and 2027, respectively. ${ }^{7}$ Corresponding to this assumed growth trajectory in turbine size, a set of cost reductions and associated technology improvements were projected for 2015, 2022, and 2027 based on a recent assessment conducted by The Crown Estate, BVG Associates, and KIC InnoEnergy (The Crown Estate 2012; Valpy et al. 2014). Various assumptions were made to account for the nascent stage of the U.S. offshore wind industry and to project cost and technology parameters into the future. The first U.S. offshore wind power project came online for commercial operation in late 2016. As in this project, U.S. developers are expected to leverage European offshore wind technology, industry experience, and industrial capacity in early projects. Beiter et al. (2016) defined a scenario assuming that the U.S. offshore wind industry can leverage the recent European offshore wind technology and industry experience while addressing important physical, regulatory, and economic differences influencing U.S. projects. The cost-reduction pathway under this scenario applies projected cost reductions developed for European projects within the time frame from 2015 to 2027 and

\footnotetext{
${ }^{5}$ All data presented are assumed to be unsubsidized but consider accelerated depreciation (Modified Accelerated Cost Recovery [MACRS]).

${ }^{6}$ All years reported in commercial operation date (COD), unless indicated otherwise.

${ }^{7}$ The turbine size trajectory of 6 megawatts (MW) by 2022 and 10 MW by 2027 was informed by announced turbine supply agreements in 2015, indicating that by 2019/2020 a turbine size average of between 6 and 8 MW and by 2027 turbine sizes of 10-12 MW will be available in Europe. Because of current limitations associated with the Jones Act, the lower end of those ranges was chosen (Beiter et al. 2016). The same turbine sizes were assumed for the Great Lakes area without any consideration or adjustment for ship limitations because of locks in that area.
} 
assumes sufficient domestic deployment and supply chain maturity to support these cost reductions in the United States during the analysis period.

Based on the methodology and assumptions from Beiter et al. (2016), this analysis provides detailed outputs of the following:

- Maps showing spatial distribution of LCOE, LACE, and net value for five U.S. coastal regions including the Atlantic Coast, Pacific Coast, Gulf of Mexico, Great Lakes, and Hawaii for each of the focus years $(2015,2022$, and 2027)

- National and regional supply curves of offshore capacity ranked by LCOE for fixed-bottom and floating technology types

- Estimated LCOE plotted by different water depths and distance from shore for fixed-bottom and floating offshore wind technology.

The results presented in this study are intended to inform a broad set of stakeholders to enable an initial assessment of offshore wind as part of energy development and energy portfolio planning. It provides information that federal and state agencies and planning commissions may use to inform initial strategic decisions about offshore wind development in the United States. Although this analysis is the first of its kind to provide a comprehensive assessment of the economic potential for offshore wind at a high geospatial resolution across major U.S. coastal regions, more detailed site-specific assessments are needed to inform actual offshore wind project planning.

This study finds that estimated reductions in LCOE over the next decade coincide with relatively high levels of LACE in some U.S. regions. By 2027, a considerable amount of economic potential was estimated for the Northeast and the eastern shore of Virginia (see Table ES-1).

Table ES-1. Available Capacity with Economic Potential by State in 2027

\begin{tabular}{ll}
\hline \multicolumn{1}{c}{ State } & $\begin{array}{l}\text { Economic Potential } \\
\text { (in gigawatts [GW]) }\end{array}$ \\
\hline Maine & 65 \\
\hline Massachusetts & 55 \\
\hline Rhode Island & 16 \\
\hline Virginia & 4 \\
\hline New Hampshire & 2 \\
\hline New York & 1 \\
\hline Connecticut & 1 \\
\hline
\end{tabular}

Note: Values rounded to integers

viii 
It is also observed that the supply and net value curves were relatively flat, indicating that even a small change in LCOE or LACE has the potential to trigger significant changes in the amount of economic potential calculated. This effect resulting from relatively flat supply curves would be most relevant in regions that have a net value close to zero, such as the Northeast, mid-Atlantic, Great Lakes, and Gulf Coast in 2027, or in regions where policies are in place to incentivize renewable energy, such as California. The relatively high degree of sensitivity to changes in LCOE and LACE also indicates a moderate amount of uncertainty in the quantity of actual resource found to have "economic potential." As a result, the conclusions of this assessment should be re-evaluated as market conditions or costs change.

Some general observations include:

- Offshore wind sites with economic potential are located predominantly in the Northeast and eastern shore of Virginia

- Across all regions, the number of sites with a positive net value (or a value close to a positive net value) increase over the time period considered

- State policies have driven offshore wind development recently (e.g., in New York and Massachusetts); these policies may play a key role when assessing the economic viability of offshore wind but are not considered in this analysis

- Further technology improvements are needed to achieve the cost reductions of this assessment

- Some regions will likely require unique technology solutions (e.g., to address low wind speeds in the Gulf, icing in Great Lakes, and deep-water floating solutions in the Pacific and Hawaii)

- The value of offshore wind to the electric grid system under some high-penetration renewable energy scenarios may not be fully represented by net value as calculated in this study.

A number of limitations and opportunities for further work are indicated throughout this report. The results from the Beiter et al. (2016) assessment utilized in this study were produced with innovative models and assumptions, which may be refined as new tools and validation data become available. For this national-scale assessment, a number of simplifications and uncertainties exist that may affect the accuracy from reported results at any individual location. These simplifications and uncertainties range from the development of first-order tools that do not capture the entire set of parameters taken into account for a detailed site assessment, the suitability and availability of technology during the time period considered, and general uncertainty related to the formation of a domestic supply chain and macroeconomic factors. Limitations and corresponding caveats are discussed in Beiter et al. (2016). Some of the most important caveats from Beiter et al. (2016) include the following: 
- To achieve the modeled cost reductions in the United States, a key assumption is that there will be continued investments in technology innovation, developments, and the market visibility of a robust domestic supply chain commensurate with the established European offshore wind supply chains during the analysis period from 2015 to 2027 and sustained domestic offshore wind development (U.S. Department of Energy [DOE] 2015; Navigant 2012; European Commission 2016).

- The Crown Estate (2012) cost reductions assumed for this study should be considered in context of recent cost declines indicated by European offshore wind winning tenders. However, determining to what extent these recent reductions in European winning bids will continue in the future and how they translate to a U.S. context is beyond the scope of this study.

- This analysis includes a preliminary assessment of LACE limited by available data and a set of simplifying assumptions. It does not consider competition among technologies, dynamic feedback from increasing renewable deployment on wholesale electricity prices, export or import situations, or the alleviation of electricity system constraints (e.g., transmission constraints) over time. Further refinement and additional data could improve this indicator.

- In this study, LACE was estimated based on annual averages of marginal generation prices and a constant capacity value. This specification does not take into account the subhourly, hourly, or seasonal coincidence of offshore wind generation profiles with marginal generation prices or capacity value. For instance, if an offshore wind site produced electricity during times when it is in high demand (e.g., during peak load events in the late afternoon), the revenue opportunities (as represented by marginal generation prices or capacity value) would likely be higher. Such an assessment was not within the scope of this study.

- The validity of LACE varies by region because of spatial differences in data availability. As described in Section 2.2, a hierarchy of data sources was compiled to proxy marginal generation prices. This may be a particular concern in the Pacific Northwest coastal regions where neither locational margin price, market marginal cost, or partial locational margin price data were available and marginal generation prices were derived from neighboring regions in California and Nevada and regions in the Pacific Northwest with partial locational margin price data only.

- As applied here, policy-related factors that may influence LACE or LCOE (and hence, the "net value" of a renewable energy project) were not considered explicitly. For instance, renewable energy support mechanisms (e.g., the production tax credit, renewable portfolio standards), energy sector and environmental regulations (e.g., carbon pricing, loan guarantee programs), or benefits from portfolio diversification (Energy Information Administration [EIA] 2015) may increase the "net value" and economic potential. Conversely, regulatory uncertainty and market barriers (see e.g., DOE 2016) may decrease the "net value" and economic potential.

- As a result of how competing use areas were applied in Beiter et al. (2016) and Musial et al. (2016) (as a share of competing use and environmentally sensitive areas), some of the leastcost LCOE sites identified in this study may not be available in practice for offshore wind 
development because of human use trade-offs (e.g., conflicting use related to viewshed concerns, shipping lines, marine protected areas and fishing [see e.g., DOE 2016]).

- The calculation of economic potential should not be used as a prediction for actual project deployment. Economic potential indicates that the revenue at a given site may exceed its costs in the local energy market, but it does not guarantee that the technology will be selected. Conversely, a negative net value indicating the lack of economic potential at a given site does not necessarily imply that economic viability is not achievable because of general modeling uncertainty related to the development of future costs, electricity prices, policy, and renewable targets (see Section 2.3).

- This study only assesses the economic potential of offshore wind and is not a metric of profitability. For a full sectorwide assessment of economic competitiveness, the economic potential from all competing technologies would have to be taken into consideration (see e.g., EIA 2014). For instance, another generation technology may exhibit a net value that is greater than the estimates for offshore wind at any of the assessed sites. 


\section{Table of Contents}

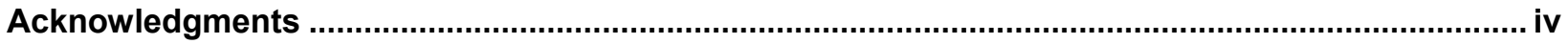

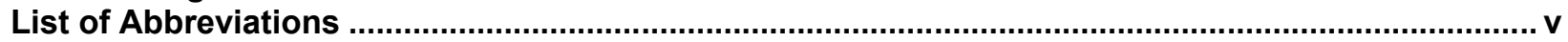

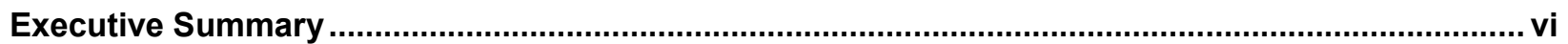

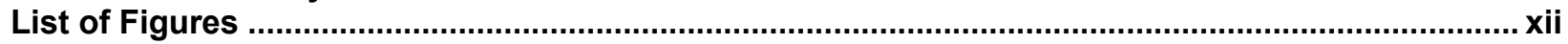

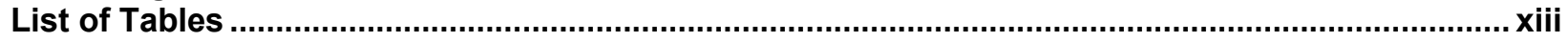

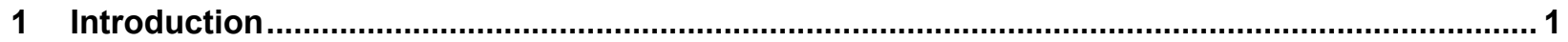

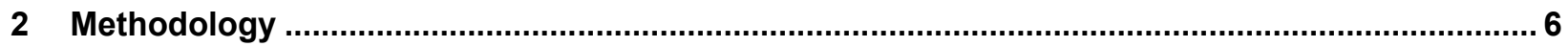

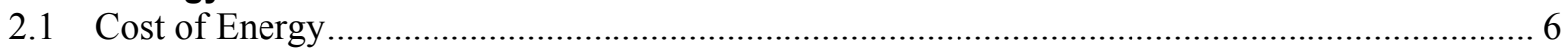

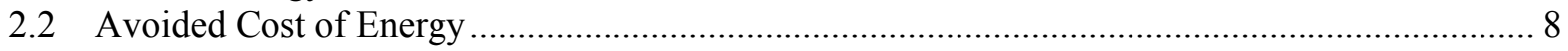

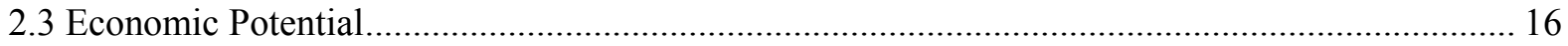

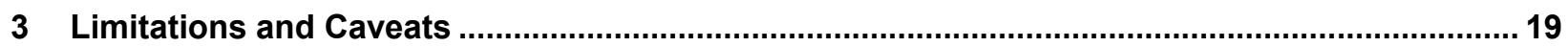

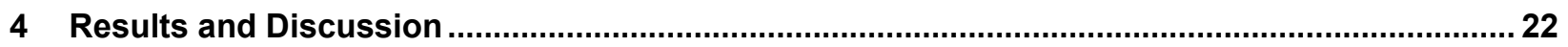

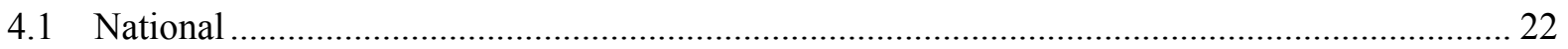

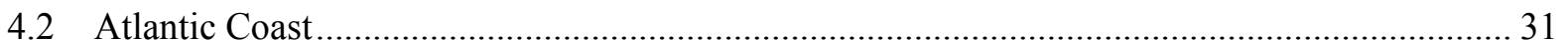

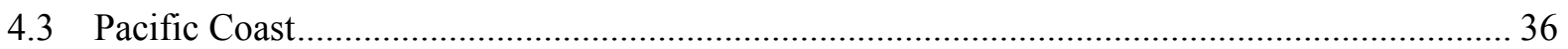

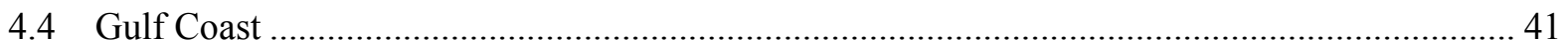

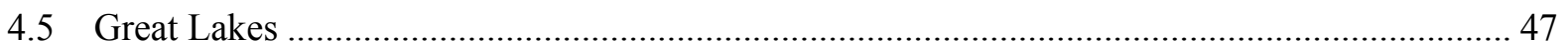

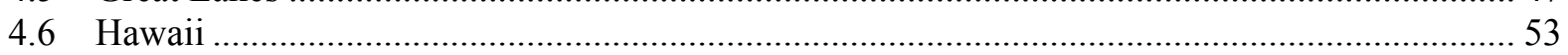

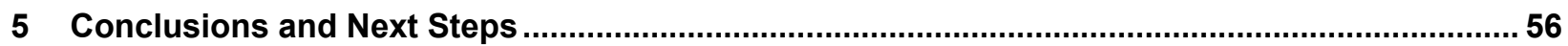

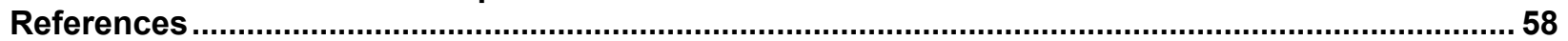

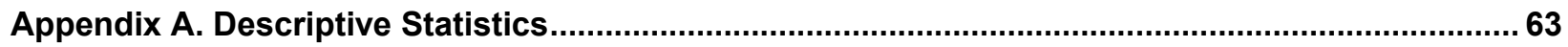

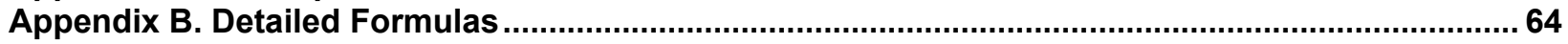

\section{List of Figures}

Figure 1. Recent strike prices of European offshore wind winning tenders adjusted to U.S. dollars, with grid cost, development cost, and contract length adders ................................................... 4

Figure 2. Regions in the ReEDS model.............................................................................. 10

Figure 3. Data sources used for marginal generation price estimates across all U.S. regions ....... 11

Figure 4. Marginal generation price estimates.............................................................................. 14

Figure 5. Electricity generation price projections by region (EIA AEO 2014).................................. 15

Figure 6. U.S. offshore wind resource terminology framework indicating estimated resource potential and classification criteria ........................................................................................... 17

Figure 7. Levelized cost of electricity for potential offshore wind projects from 2015 to 2030 over

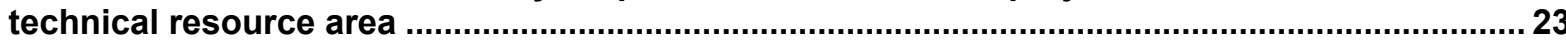

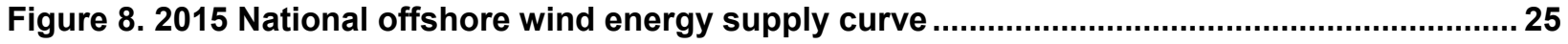

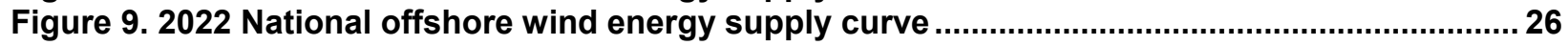

Figure 10. 2027 National offshore wind energy supply curve ..................................................... 27

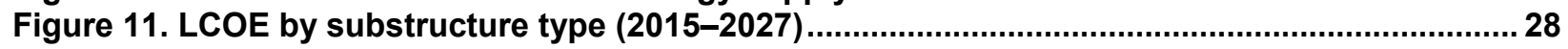

Figure 12. LCOE by substructure type and water depth (2015-2030) ............................................. 28

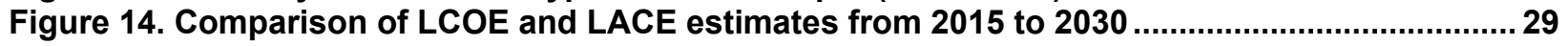

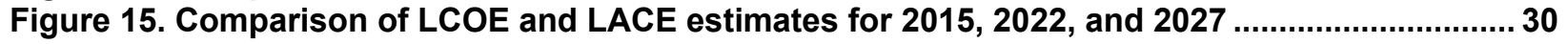

Figure 16. Atlantic Coast spatial LCOE distribution (2015-2027) ..................................................... 31

Figure 17. 2015 Atlantic Coast offshore wind energy supply curve .......................................... 32

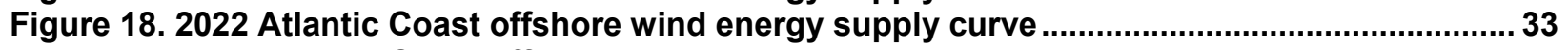

Figure 19. 2027 Atlantic Coast offshore wind energy supply curve .................................................. 33

Figure 20. Atlantic Coast spatial LACE distribution (2015-2027) .................................................... 34

Figure 21. Atlantic Coast spatial net value distribution (2015-2027) ................................................. 35

Figure 22. Pacific Coast spatial LCOE distribution (2015-2027) ...................................................... 37 


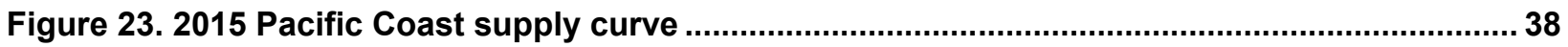

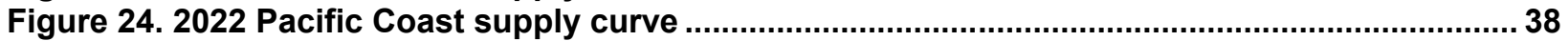

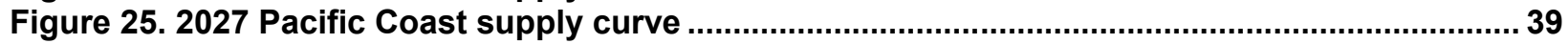

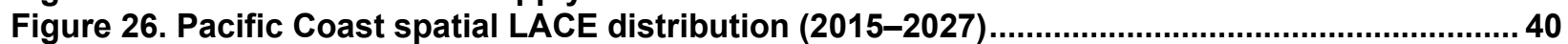

Figure 27. Pacific Coast spatial net value distribution (2015-2027) ............................................. 41

Figure 28. Gulf Coast spatial LCOE distribution (2015-2027) ......................................................... 42

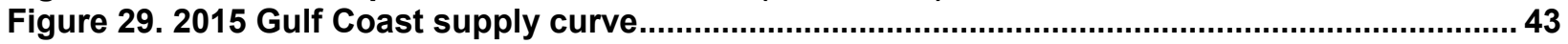

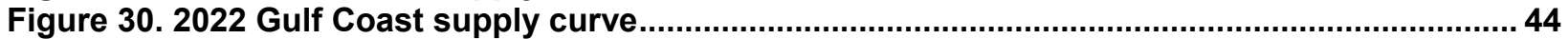

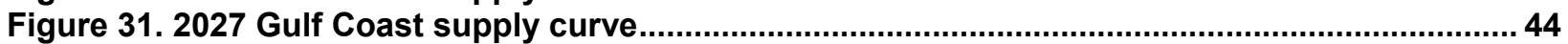

Figure 32. Gulf Coast spatial LACE distribution (2015-2027) ..................................................... 45

Figure 33. Gulf Coast spatial net value distribution (2015-2027) .................................................. 46

Figure 34. Great Lakes spatial LCOE distribution (2015-2027) ....................................................... 48

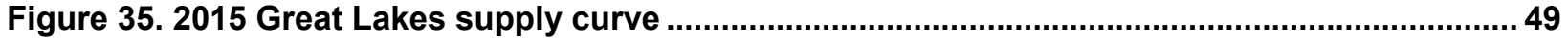

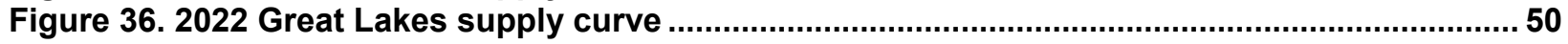

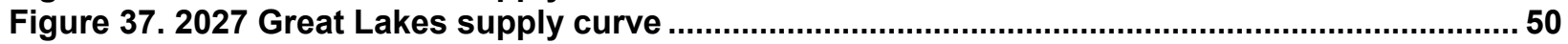

Figure 38. Great Lakes spatial LACE distribution (2015-2027) .................................................. 51

Figure 39. Great Lakes spatial net value distribution (2015-2027) ............................................. 52

Figure 40. Hawaii spatial LCOE distribution (2015-2027) ............................................................... 53

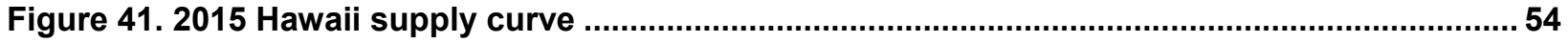

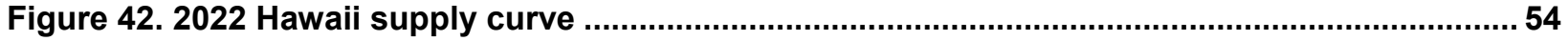

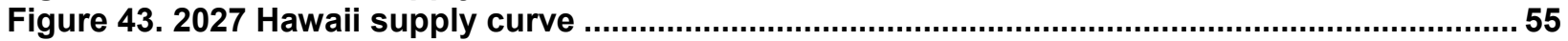

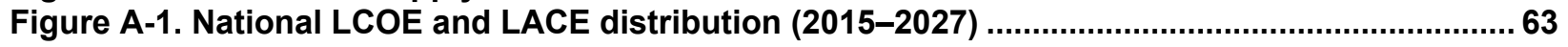

\section{List of Tables}

Table ES-1. Available Capacity with Economic Potential by State in 2027.................................... viii

Table 1. Summary of Key Assumptions for the Spatial-Economic Assessment ............................... 7

Table 2. Description of Types of Marginal Generation Price Data Used for Calculating LACE........ 12

Table 3. Available Capacity with Unsubsidized Economic Potential by State in 2027 .................... 35 


\section{Introduction}

This study describes an assessment of the site-specific variation of levelized cost of energy (LCOE) and levelized avoided cost of energy (LACE) to understand the economic potential of fixed-bottom and floating offshore wind technologies in major U.S. coastal areas ${ }^{8}$ between 2015 and 2030. The detailed methodology, assumptions, and context of this study are documented in $A$ Spatial-Economic Cost Reduction Pathway Analysis for U.S. Offshore Wind Energy Development from 2015-2030 (Beiter et al. 2016). ${ }^{9}$ This earlier report focused on the development of a geospatial cost model of the offshore wind technical resource area in the United States and the relationship of geospatial and temporal parameters on the cost of energy up to 2030. The present study builds on the Beiter et al. (2016) analysis to document in detail the variation in economic potential across the U.S. offshore wind resource by comparing sitespecific LCOE and LACE. In particular, this study offers insights into the available U.S. offshore wind resource by region at different levels of LCOE and an assessment of the present and future economic potential of that resource capacity up to 2030 .

Beiter et al. (2016) compared LCOE and LACE, the two cost metrics used to assess economic potential, at more than 7,000 potential U.S. offshore wind sites. The offshore wind capacity associated with different LCOE and LACE levels was not reported in Beiter et al. (2016). ${ }^{10}$ LCOE is the total cost of generating a unit of electricity and is commonly expressed in dollarsper-megawatt-hour (MWh) over the expected lifetime of the offshore wind electricity-generating plant. It varies by location because of spatial differences in energy production (e.g., average wind speed variations) and capital expenditures (e.g., varying sea states, distance from shore, water depth, soil and substructure suitability, and availability of critical infrastructure). For example, sites that are closer to shore may benefit from lower electric transmission, construction, and operation and maintenance (O\&M) costs, whereas sites farther from shore may realize lower LCOE as a result of higher energy production. The lower the LCOE at a given offshore wind site, the more likely it is for the site to be economically viable. However, LCOE alone is not sufficient to assess economic viability because it does not capture the electric system value that can be attributed to a generation source.

Electric system value is defined in this analysis as the revenue that an offshore wind generator can earn (reflecting its marginal economic value) without considering subsidies. The system value of offshore wind is affected by its location (i.e., coincidence with load patterns and available transmission), uncertainty (i.e., forecasting errors), and variability (i.e., generation profile) (Hirth 2013). The focus of this study is on the locational aspects of system value. This

\footnotetext{
${ }^{8}$ This analysis excludes Alaska. For Hawaii, estimates of levelized avoided cost of energy (LACE), net value, and economic potential were not calculated because wholesale electric price data and LACE were not readily available. ${ }^{9}$ Additional studies that this conceptual approach and methodology is based on include Brown et al. (2015), U.S. Department of Energy (DOE) (2013), and Lopez et al. (2012).

${ }^{10}$ The identification of potential U.S. offshore wind sites and associated resource assessment is documented in Musial et al. (2016).
} 
analysis draws on a "simplified" version ${ }^{11}$ of LACE as a metric to capture the system value of a generation technology. LACE is a metric to approximate the electric system value of a generation technology over its expected lifetime and commonly expressed in dollars per MWh, similar to LCOE. It estimates the cost to generate the electricity that is displaced by a new generation project (Energy Information Administration [EIA] 2015; Namovicz 2013; EIA 2013) and can be thought of as the potential revenue available to procure new generation. LACE varies by location because of differences in the system value of new electricity, which is determined by a range of factors, including the cost of competing generation technologies, the resource mix, demand patterns, and transmission constraints. Higher LACE values are indicative of higher local electricity prices or higher compensation for providing (firm) capacity. The higher LACE is at a given offshore wind site, the more likely it is for this site to be economically viable, all else equal. The difference between LCOE and LACE at a given location (denoted in this report by "net value") can help inform an initial understanding of the economic potential of a new offshore wind project at a high geospatial resolution. For this analysis, policy-related factors that may influence LACE or LCOE (and hence, the "net value" of a renewable energy project) were not considered explicitly. For instance, renewable energy support mechanisms (e.g., the production tax credit, Renewable Portfolio Standards), energy sector and environmental regulations (e.g., carbon pricing), or benefits from portfolio diversification (Energy Information Administration [EIA] 2015) may increase the "net value" and economic potential. Conversely, regulatory uncertainty and market barriers (see e.g., DOE 2016) may decrease the "net value" and economic potential. $^{12}$

A series of data sources and reports were used to derive the assumptions and data for this analysis, including market reports (e.g., Moné et al. [2015] and Smith, Stehly, and Musial [2015]), U.S. electricity cost benchmark reports (e.g., EIA Annual Energy Outlook [AEO] 2014), offshore wind cost-reduction pathway studies (e.g., Beiter et al. (2016); Valpy et al. [2014]; Catapult [2015]; E.C. Harris [2012]; The Crown Estate [2012]; The Crown Estate [2015]), geospatial data layers, and expert elicitation.

This report builds on the Beiter et al. (2016) study, which considered the impact on LCOE and LACE from a variety of spatial and temporal parameters for fixed-bottom and floating offshore wind technologies. Estimates of offshore wind costs were calculated for three focus years corresponding to commercial operation dates (CODs) ${ }^{13}$ of 2015,2022 , and 2027. In 2015, a baseline turbine rating of 3.4 megawatts (MW) was assumed as it reflects the average turbine size of installed offshore wind power projects globally in 2014 (Smith, Stehly and Musial 2015). Informed by recent industry trends, turbine ratings of $6 \mathrm{MW}$ and $10 \mathrm{MW}$ were assumed as

\footnotetext{
${ }^{11}$ The concept of avoided costs has long been used in utility and regulatory economics (see e.g., Public Utility Regulatory Act of 1978, Sec. 210, defining avoided costs as "the incremental cost to an electric utility of electric energy or capacity or both which [...] such utility would generate itself or purchase from another source"). This analysis applies a specification that does not necessarily reflect the same complexity that is used for other purposes. Limitations and caveats are discussed in Section 3.

${ }^{12}$ All data presented are assumed to be unsubsidized but consider accelerated depreciation (Modified Accelerated Cost Recovery [MACRS]).

${ }^{13}$ All years reported in commercial operation date (COD), unless indicated otherwise.
} 
representative technologies for years 2022 and 2027, respectively. ${ }^{14}$ Corresponding to this assumed growth trajectory in turbine size, a set of cost reductions and associated technology improvements were projected for 2015, 2022, and 2027 based on a recent assessment conducted by The Crown Estate, BVG Associates, and KIC InnoEnergy (The Crown Estate 2012; Valpy et al. 2014). Various assumptions were made to account for the nascent stage of the U.S. offshore wind industry and to project cost and technology parameters into the future. The first U.S. offshore wind power project came online for commercial operation in late 2016. As in this project, U.S. developers of the first few domestic projects are expected to leverage existing European offshore wind technology, industry experience, and industrial capacity. Beiter et al. (2016) defined a scenario assuming that the U.S. offshore wind industry can leverage the recent European offshore wind technology and industry experience while addressing important physical, regulatory, and economic differences influencing U.S. projects. The cost-reduction pathway under this scenario applies projected cost reductions developed for European projects within the time frame from 2015 to 2027 and assumes sufficient domestic deployment and supply chain maturity to support these cost reductions in the United States during the analysis period. However, these deployment levels have not yet been quantified. As shown in Figure 1, the Crown Estate (2012) cost reductions assumed for this study should be considered in context of recent cost declines indicated by European offshore wind winning tenders. However, determining if and to what extent these recent European offshore wind cost reductions will continue and how they might translate to a U.S. market context is beyond the scope of this study.

\footnotetext{
${ }^{14}$ The turbine size trajectory of 6 megawatts (MW) by 2022 and 10 MW by 2027 was informed by announced turbine supply agreements in 2015, indicating that by 2019/2020 a turbine size average of between 6 and 8 MW and by 2027 turbine sizes of 10-12 MW will be available in Europe. Because of current limitations associated with the Jones Act, the lower end of those ranges was chosen (Beiter et al. 2016). The same turbine sizes were assumed for the Great Lakes area without any consideration or adjustment for ship limitations because of locks in that area.
} 


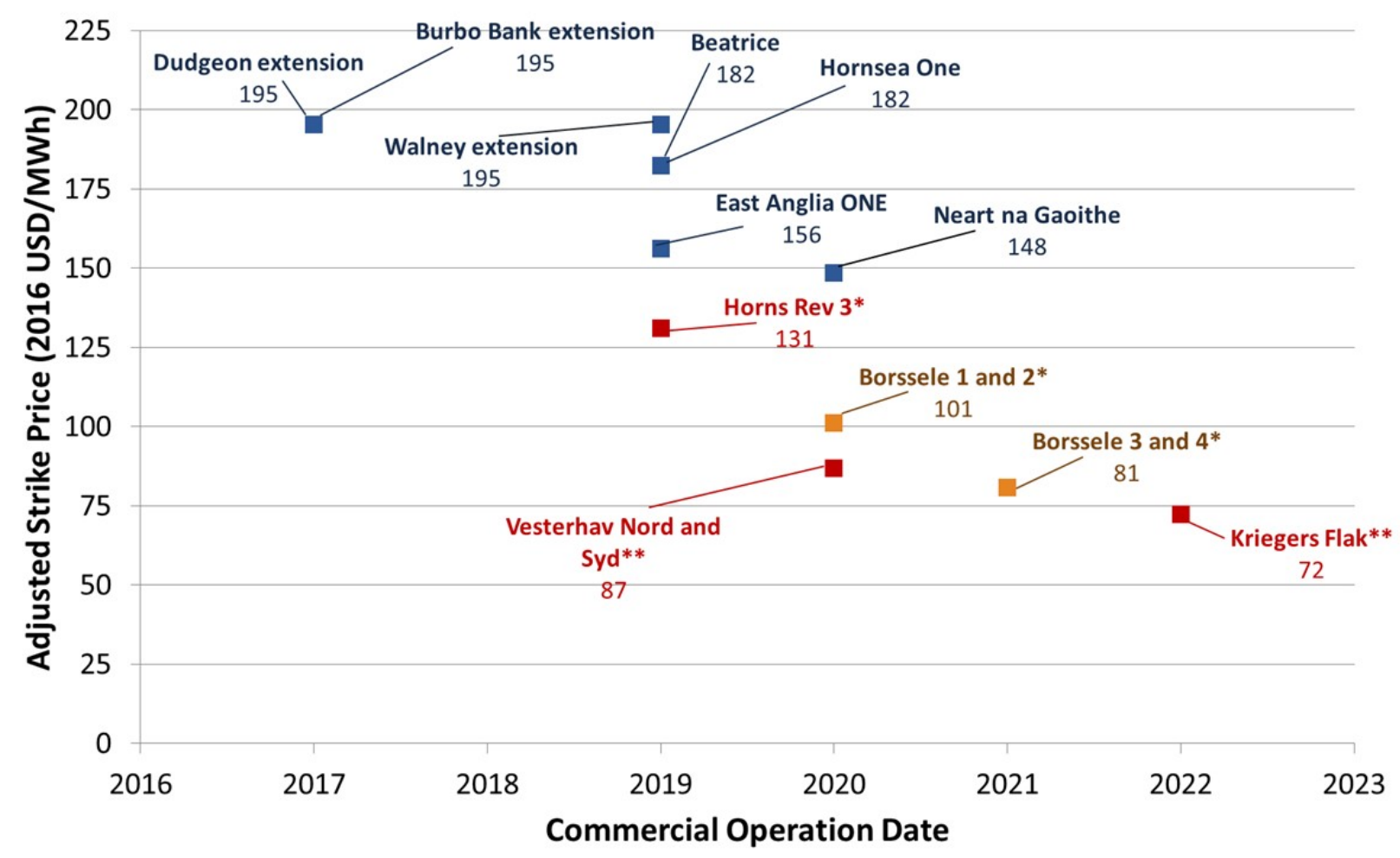

United Kingdom $\square$ Netherlands Denmark

Figure 1. Recent strike prices of European offshore wind winning tenders adjusted to U.S. dollars, with grid cost, development cost, and contract length adders

Notes: *Grid and development costs added; ${ }^{* *}$ Grid costs and contract length adjusted; Source: Data derived from 4C Offshore (2017)

Estimates of offshore wind LACE were intended to reflect the electric system value and calculated using prevailing electricity prices and capacity value. The corresponding data were collected for 2014, averaged by region, ${ }^{15}$ and projected for the years between 2015 and 2027 based on EIA's 2014 AEO electricity generation prices.

Based on the methodology and assumptions from Beiter et al. (2016), this analysis provides detailed outputs of the following:

- Maps showing spatial distribution of LCOE, LACE, and net value for five U.S. coastal regions including the Atlantic Coast, Pacific Coast, Gulf of Mexico, Great Lakes, and Hawaii for each of the focus years $(2015,2022$, and 2027)

\footnotetext{
15 The regions used correspond to those applied in the National Renewable Energy Laboratory’s Regional Energy Deployment System (ReEDS).
} 
- National and regional supply curves of offshore capacity ranked by LCOE for fixedbottom and floating technology types

- Estimated LCOE plotted by different water depths and distance from shore for fixedbottom and floating offshore wind technology.

The results presented in this study are intended to inform a broad set of stakeholders to enable an initial assessment of offshore wind as part of energy development and energy portfolio planning. It provides information that federal and state agencies and planning commissions may use to inform initial strategic decisions about offshore wind developments in the United States. Although this analysis is the first of its kind to provide a comprehensive assessment of the economic potential for offshore wind at a high geospatial resolution across major U.S. coastal regions, more detailed site-specific assessments are needed to inform actual offshore wind project planning.

This report is organized as follows:

- Section 2: Methodology

- Section 3: Limitations and Caveats

- Section 4: Results and Discussion

- Section 5: Conclusions and Next Steps. 


\section{Methodology}

This section provides an overview of the core analytical methodology applied in Beiter et al. (2016), which is identical to the approach used in this report. Further details on the methodology, data, and limitations may be found in Beiter et al. (2016). This report focuses on the additional analysis, data sources, and documentation for LACE used in this investigation.

\subsection{Cost of Energy}

\subsubsection{Levelized Cost of Energy Across U.S. Coastal Areas}

LCOE is the total cost of generating a unit of electricity commonly expressed on a dollars-per$\mathrm{kWh}$ basis over the expected lifetime of the project. ${ }^{16}$ The discounted cash flow of future project expenditures and the discounted energy production is approximated through the use of annualized values and calculated at the point of interconnection with the existing electricity grid. Following Short et al. (1995), LCOE in general form, was calculated as shown below (Eq. 1):

$$
\mathrm{LCOE}=\frac{\left(F C R^{*} C a p E x\right)+\mathrm{OpEx}}{A E P_{\text {net }}}
$$

where:

LCOE $=$ levelized cost of energy $(\$ / \mathrm{kWh})$

$\mathrm{FCR}=$ fixed charge rate $(\%)$

CapEx $=$ capital expenditures $(\$ / \mathrm{kW})$

$\mathrm{AEP}_{\text {net }}=$ net annual energy production $(\mathrm{kWh} / \mathrm{kW} / \mathrm{yr})$

$\mathrm{OpEx}=$ annual operational expenditures $(\$ / \mathrm{kW} / \mathrm{yr})$

LCOE varies by location because of differences in site conditions (e.g., average wind speed, varying sea states, distance from shore, water depth, substructure suitability, and availability of critical infrastructure) that influence turbine technology requirements. For example, sites that are closer to shore may benefit from lower electric transmission, construction, O\&M costs; sites farther from shore may benefit from lower costs as a result of higher wind speeds resulting in increased energy production. A number of parameters related to modeling energy performance, capital cost, operating cost, and finance cost as well as numerous spatial characteristics were considered to estimate the LCOE components from Eq. 1 at more than 7,000 U.S. coastal sites. The set of spatial parameters considered include:

- Water depth

- Average wind speed

- Sea state severity

- Seabed conditions

- Location and characteristics of prospective staging ports

\footnotetext{
${ }^{16}$ In this analysis, 20 years were assumed for an offshore wind project lifetime. Extending the lifetime of offshore wind projects can considerably lower the levelized cost of energy (LCOE).
} 
- Location and characteristics of possible inshore assembly areas

- Existing grid features and proximity to potential connection points

- Environmentally sensitive areas

- Competitive-use areas.

Detailed information on the parameter studies that were conducted to inform the spatial-cost relationships and assumptions applied in this analysis are discussed in Beiter et al. (2016). For instance, Beiter et al. (2016) includes information on the relationship between primary substructure components and water depth, installation costs scaling and distance from project site to staging port, and O\&M costs and the distance between the project and maintenance facilities. Various substructure types were assessed in this analysis, including monopile and jacket foundations for fixed-bottom offshore wind technology, and semisubmersible and spar buoy substructures for floating offshore wind technology. Depending on the spatial parameters listed above, the least-cost substructure type was chosen for each of the U.S. coastal sites.

A cost-reduction pathway related to technology advancement and market development was assumed for this study. The cost reduction trajectory is closely linked to the assumed turbine-size growth scenario that is shown in Table 1. The turbine technology indicated in Table 1 was assigned in the beginning of each focus year and held constant at all sites until the next focus year. Among the drivers of these time-dependent cost reductions are technology advancements that lower the cost for capital expenditures (CapEx) (e.g., turbine, substructures, electrical infrastructure), operational expenditures (OpEx), financing, and factors that increase the annual energy output of the turbines. For this study, all technology advancements are assumed to be equally available to all regions in the United States; however, some regions may require unique technology solutions that are beyond the scope of this work (e.g., hurricane turbine design).

Table 1. Summary of Key Assumptions for the Spatial-Economic Assessment

\begin{tabular}{lccc}
\hline Financial Close & $\mathbf{2 0 1 3}$ & $\mathbf{2 0 2 0}$ & $\mathbf{2 0 2 5}$ \\
Commercial Operation Date & $\mathbf{2 0 1 5}$ & $\mathbf{2 0 2 2}$ & $\mathbf{2 0 2 7}$ \\
\hline Turbine Rated Power (MW) & 3.4 & 6 & 10 \\
Plant Size (MW) & 600 & 600 & 600 \\
Turbine Hub Height (m) & 85 & 100 & 125 \\
Turbine Rotor Diameter (m) $_{\text {Turbine Specific Power }}^{\mathrm{a}}(\mathrm{W} / \mathrm{m} 2)$ & 115 & 155 & 205 \\
\hline
\end{tabular}

${ }^{a} \mathrm{~A}$ wind turbine's specific power is the ratio of its nameplate capacity rating to its rotor-swept area. All else equal, a decline in specific power should lead to an increase in capacity factor.

\subsubsection{Data Sources}

A variety of input data sources were used in this study, including, but not limited to, market reports (e.g., Moné et al. [2015] and Smith, Stehly, and Musial [2015]), cost-reduction pathway studies (e.g., Valpy et al. [2014]; Catapult [2015]; E.C. Harris [2012]; The Crown Estate [2012, 2015]), spatial data layers, and industry collaboration. These data are combined with a resource 
assessment (Musial et al. 2016), ${ }^{17}$ performance modeling, and spatial cost relationships documented in Beiter et al. (2016) to estimate LCOE at more than 7,000 sites across U.S. coastal regions (excluding Alaska).

The cost reductions assumed for years 2015-2027 were based on a cost model assessment conducted by The Crown Estate, BVG Associates, and KIC InnoEnergy (The Crown Estate 2012; Valpy et al. 2014) for fixed-bottom technology and an initial assessment of floating offshore wind technology following a similar methodology as applied in Valpy et al. (2014). ${ }^{18}$

\subsection{Avoided Cost of Energy}

\subsubsection{Levelized Avoided Cost of Energy in U.S. Coastal Areas}

LACE, as a metric to determine the value of new generation projects, was developed to complement the well-established LCOE metric (e.g., EIA 2015; Namovicz 2013; EIA 2013). According to EIA (2013), "LCOE is not a useful tool to compare the cost of different generation options, unless the options being compared have substantially similar operational profiles and system values." LACE can be particularly useful when assessing the economic competitiveness of "unconventional" resources like wind and solar (EIA 2013). LACE and LCOE are complementary in the sense that LCOE comprises a measure for revenue requirements (based on the cost required to generate electricity), whereas LACE captures the revenues available to that generating source. The two metrics can be compared to provide an indicator of economic attractiveness (EIA 2013). LACE is a metric to approximate the electric system value of a generation technology over its expected lifetime and commonly expressed on a per-MWh basis. Electric system value is defined in this analysis as the revenue that an offshore wind generator can earn (reflecting its marginal economic value) without consideration for subsidies. The system value of offshore wind is affected by its location (i.e., coincidence with load patterns and available transmission), uncertainty (i.e., forecasting errors), and variability (i.e., generation profile) (Hirth 2013). Because of these technological properties, LACE may vary by technology and location (see e.g., EIA 2016 for a comparison of LACE by technology). The metric can be interpreted as the amount a generation project, such as an offshore wind project at a U.S. coastal location, would be paid for the electrical energy and capacity it could potentially provide, or alternatively, what a utility or other entity would not have to purchase from other sources.

In this study, LACE is calculated based on prevailing regional marginal generation prices and capacity values. Marginal generation price and capacity are presented in terms of average (avoided) costs per MWh of generation. The discounted revenues from regional marginal generation prices and capacity value are approximated through the use of levelized values. Marginal generation price is the cost of serving load to meet the demand in a specified time period, which is determined by the variable cost of the most expensive generating unit that is

\footnotetext{
${ }^{17}$ The Musial et al. (2016) resource assessment takes into account conflicting use areas.

${ }^{18}$ As shown in Figure 1, the Crown Estate (2012) cost reductions assumed for this study should be considered in context of recent cost declines indicated by European offshore wind winning tenders. However, determining to what extent these recent reductions in European winning bids will continue in the future and how they translate to a U.S. context is beyond the scope of this study.
} 
needed to be dispatched to meet energy demand (EIA 2013). Capacity value can be defined as "a generator's ability to help reliably serve load [...] - the firm capacity that a generating unit is able to provide during reliability-critical periods" (Sigrin et al. 2014).

The following general formula (Eq. 2) was used to estimate LACE (see Appendix B for a more detailed version):

$$
\mathrm{LACE} \quad=\frac{M P * A E P_{n e t}+C P * C C}{A E P_{\text {net }}}
$$

where:

$\mathrm{MP}=$ Average marginal generation price $(\$ / \mathrm{kWh})$

$\mathrm{AEP}_{\text {net }}=$ Net annual energy production $(\mathrm{kWh} / \mathrm{kW} / \mathrm{yr})$

$\mathrm{CP}=$ Capacity payment $(\$ / \mathrm{kW} / \mathrm{yr})$

$\mathrm{CC} \quad=$ Capacity credit $(\%)$

In estimating marginal generation prices for sites across the continental United States, this analysis relies on a range of 2014 market prices (see Section 2.2.2) that were adopted for Regional Energy Deployment System (ReEDS) price regions (see Figure 1) (Short et al. 1995). Capacity values were calculated based on a technology-specific capacity credit and the overnight capital $\operatorname{cost}^{19}$ of an advanced, natural-gas-fired combustion turbine plant as proxy for capacity payment.

${ }^{19}$ Overnight capital costs represent capital expenditures, excluding construction period financing. 


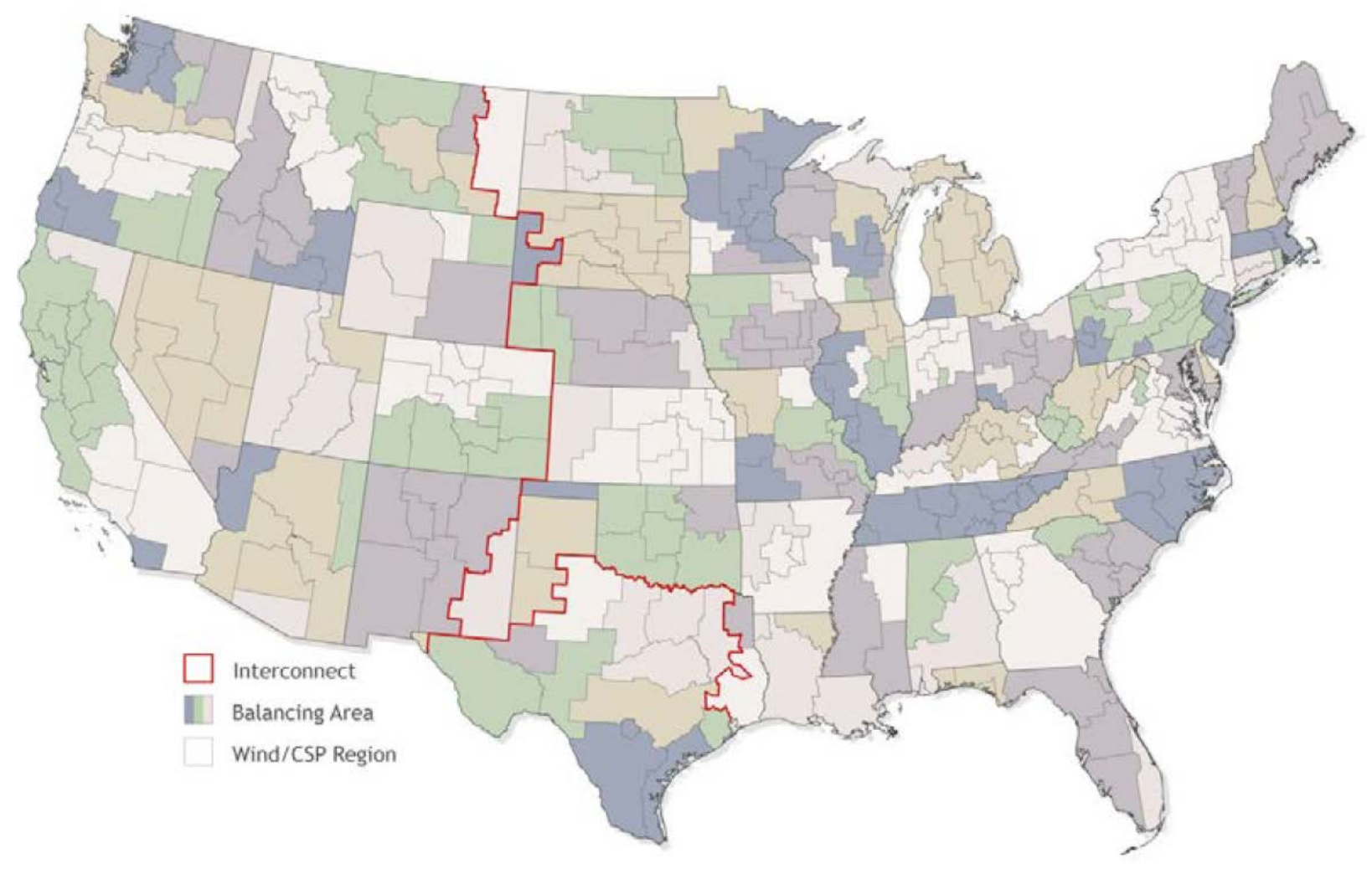

Figure 2. Regions in the ReEDS model

Source: Reprinted from Eurek et al. (2016); only coastal regions are relevant for this analysis

LACE was estimated for each ReEDS region and for each year between 2015 (COD) and 2030 (COD) using the generation price projection from EIA (2014) described earlier. The LACE metric can vary by location because of differences in prevailing electricity prices. These differences may exist for various reasons, including, but not limited to, the number of load congestion events, load fluctuation, available electricity generation types and profiles, and weather events. Spatial and temporal differences in capacity value are not considered in this analysis. LACE is generally predicted to increase gradually among U.S. coastal areas over time as a result of increasing power generation and delivery costs (EIA 2015). The magnitudes of these LACE increases vary by region. Although EIA (2015) and other sources generally predict an increase in power generation and electricity delivery costs, a range of factors may influence future electricity costs, some of which are challenging to predict. These factors may include, but are not limited to, future developments in the energy efficiency, transportation, and storage sectors; changes in fuel prices and generation technologies; market structures; and macroeconomic factors. For this study, Hawaii and Alaska were excluded in the calculation of LACE because the underlying wholesale electricity price data for these states were not available.

\subsubsection{LACE Components and Data Sources}

This initial assessment of LACE is based on a combination of regional marginal generation price and capacity value (see Eq. 2). Following the methodology from Namovicz (2014) and Brown et al. 
(2015), this analysis uses prevailing locational marginal prices (LMP) and market marginal cost (MMC) to proxy marginal generation prices. A technology-specific capacity credit and generic capacity value $^{20}$ are applied to approximate the value of firm capacity from offshore wind. Net annual energy production was derived from U.S. site-specific capacity factors published in a recent offshore wind resource assessment (Musial et al. 2016).

\section{Marginal Generation Prices}

Because of limitations related to the availability of regional data, various data sources were used to estimate marginal generation prices across all major U.S. coastal regions. These prices are depicted by region in Figure 3 and summarized in Table 2. The selection of data sources follow a hierarchy that is depicted in Table 2 (from top to bottom).

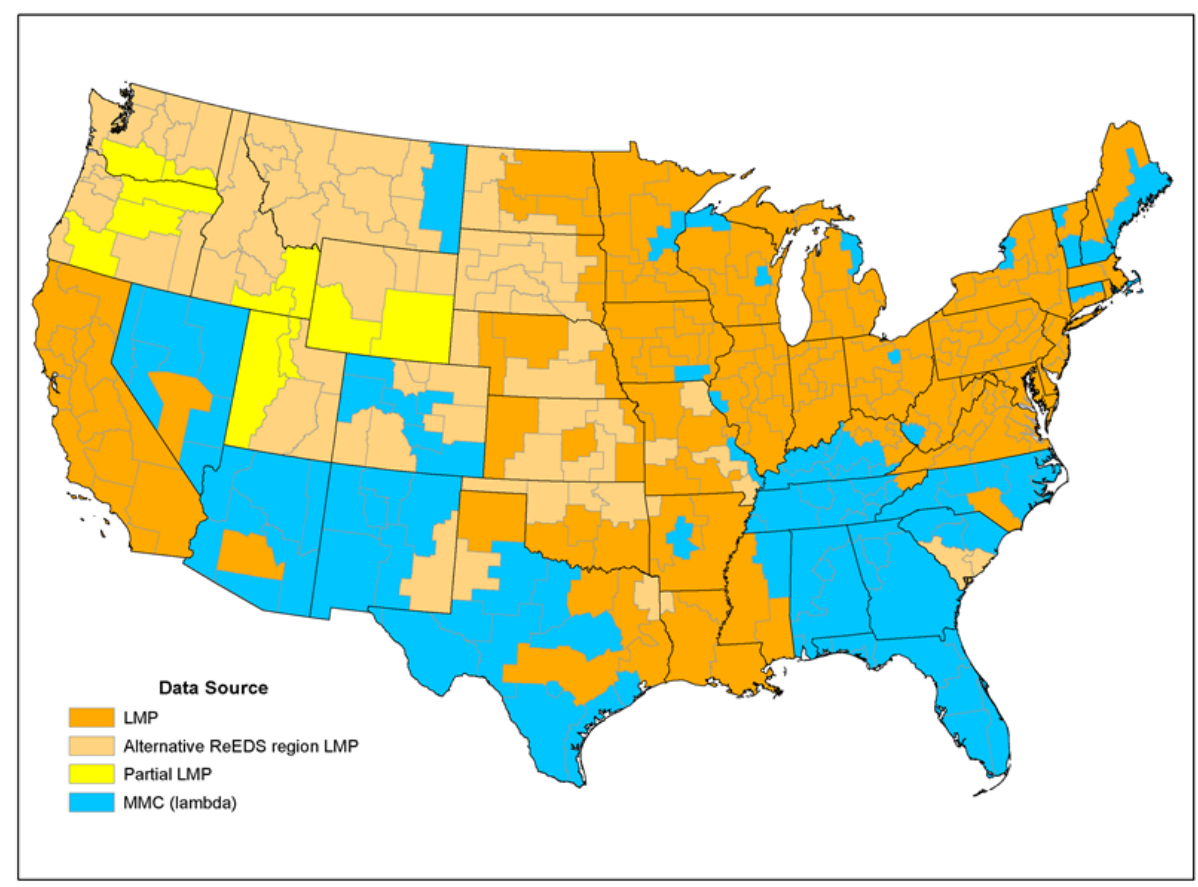

Figure 3. Data sources used for marginal generation price estimates across all U.S. regions

Source: Reprinted from Brown et al. (2015); only coastal regions are relevant for this analysis

\footnotetext{
${ }^{20}$ Capacity markets are implemented in the PJM, MISO, Independent System Operator-New England, New York Independent System Operator, and California Independent System Operator market regions but do not encompass the Electric Reliability Council of Texas (ERCOT) and the Southwest Power Pool (SPP). An approximation of capacity value is included in this analysis to capture the revenue plant owners receive for being ready to supply power when needed (Jenkin, Beiter, and Margolis 2016).
} 
Table 2. Description of Types of Marginal Generation Price Data Used for Calculating LACE

Source: Reprinted from Brown et al. (2015)

\begin{tabular}{|c|c|c|}
\hline Available Data & Definition & Source \\
\hline $\begin{array}{l}\text { Locational Marginal Prices } \\
\text { (LMP) }\end{array}$ & $\begin{array}{l}\text { LMP reflects the value of } \\
\text { generation at different locations, } \\
\text { accounting for load patterns, } \\
\text { generation, and the physical limits } \\
\text { of the transmission system. For } \\
\text { this analysis, LMPs have been } \\
\text { curtailed at the highest generation } \\
\text { cost from regional bid stack } \\
\text { curves. Hourly LMPs below zero } \\
\text { were also excluded from this } \\
\text { analysis. }\end{array}$ & $\begin{array}{l}\text { Independent system operator } \\
\text { real-time day-ahead LMP pricing } \\
\text { from New York Independent } \\
\text { System Operator, PJM, } \\
\text { Independent System Operator- } \\
\text { New England, Independent } \\
\text { Electricity System Operator } \\
\text { (Ontario), California Independent } \\
\text { System Operator, Electric } \\
\text { Reliability Council of Texas, } \\
\text { Alberta Electric System Operator, } \\
\text { MISO, Southwest Power Pool, } \\
\text { New Brunswick System Operator } \\
\text { (ABB/Ventyx) }\end{array}$ \\
\hline $\begin{array}{l}\text { Market Marginal Costs } \\
\text { (Lambda) (MMC) }\end{array}$ & $\begin{array}{l}\text { System lambda is the incremental } \\
\text { cost of energy of the marginal unit } \\
\text { assuming no system constraints } \\
\text { exist. }\end{array}$ & $\begin{array}{l}\text { Federal Energy Regulatory } \\
\text { Commission Form } 714 \text { Hourly } \\
\text { System Lambda by Balancing } \\
\text { Authority Area (ABB/Ventyx) }\end{array}$ \\
\hline $\begin{array}{l}\text { Partial Locational Marginal } \\
\text { Prices }\end{array}$ & $\begin{array}{l}\text { Some regions, particularly those } \\
\text { covered by Energy Imbalance } \\
\text { Market, have no LMP data series } \\
\text { that cover the entire year. Partial } \\
\text { LMP is based on the reported } \\
\text { subset of LMPs. }\end{array}$ & Same as LMP \\
\hline $\begin{array}{l}\text { Alternative ReEDS Region } \\
\text { Locational Marginal Prices }\end{array}$ & $\begin{array}{l}\text { For some regions, neither LMP } \\
\text { nor MMC is reported. Alternative } \\
\text { ReEDS region LMP is based on } \\
\text { LMP price data from nodes that } \\
\text { are located closest to the missing } \\
\text { regions. }\end{array}$ & Same as LMP \\
\hline
\end{tabular}

\section{Locational Marginal Prices}

Consistent with the Brown et al. (2015) study, this analysis follows the methodology from Namovicz (2013) in using LMPs as the best available proxy for marginal generation prices, whenever available. LMPs reflect "the value of generation at different locations, accounting for load patterns, generation, and the physical limits of the transmission system" (Independent System Operator (ISO)-New England 2013). They are reported by independent system operators on an hourly basis. For the purpose of this analysis, real-time, day-ahead LMPs were curtailed at the highest generation cost within a North American Electric Reliability Corporation (NERC) region in 2014, as determined by NERC region bid stack curves (Ventyx 2015). Hourly LMPs below zero were also excluded from this analysis. These adjustments serve the purpose of excluding price outliers reflected in the hourly LMPs that would reduce the validity of LMPs to 
serve as a proxy for marginal generation costs. ${ }^{21}$ These "adjusted" LMPs were averaged by ReEDS region (Balancing Authority level).

\section{Market Marginal Costs}

Because LMP data are not available for every coastal region of the country, market marginal cost data (MMCs or system lambdas) were used whenever LMP was not available. In choosing between LMP and MMC prices there is a trade-off: MMC presumably has closer alignment with marginal generation prices, whereas LMP has better geographic price resolution. Though conceptually MMC prices may be considered to align closer with marginal generation prices, these prices were only available at the Balancing Authority level. On the other hand, ISOreported LMPs can be identified at several hundred price nodes across the continental United States. Preference was given to the higher geographic price resolution provided by LMPs because of the spatial focus of this analysis ( $>7,000$ offshore wind sites were analyzed).

System lambda is the incremental cost of energy of the marginal unit assuming no system constraint exists (Federal Energy Regulatory Commission [FERC] 2010). MMC price data are reported hourly at the Balancing Authority level. For the purpose of this analysis, MMC (lambda) data were weighted by the number of hours in each ReEDS time slice and averaged by ReEDS region.

\section{Partial Locational Marginal Prices}

In some regions, including parts of the recently established Energy Imbalance Market, an LMP data series was not available for the entire year. Partial LMP is based on the reported subset of wholesale generation prices for a portion of a given year. Whenever neither (full series) LMP nor MMC (lambda) were available, these partial LMP data were assigned to a ReEDS region.

\section{Alternative ReEDS Region Locational Marginal Prices}

In some regions, neither LMP, MMC (lambda), or partial LMP were reported for 2014, particularly in the Pacific Northwest and the Southeast. For these regions, price estimates were derived based on ReEDS regions with price data that were located closest to the region with missing price data.

As shown in Figure 3, LMPs are predominant in ISO market regions; MMC price estimates were used as proxies of marginal generation price mainly in the Southeast and Southwest/Mountain regions. Neither LMPs nor MMC estimates were available in large parts of the Pacific Northwest and Mountain regions, therefore, this analysis relies on LMP price data from nodes that are located closest to these regions. Future revisions of this analysis for the entire continental United States could yield more accurate price estimates, particularly for the Pacific Northwest and Mountain regions.

\footnotetext{
${ }^{21}$ Upper and lower thresholds were implemented to exclude effects due to bidding behavior, transmission constraints, and so on, so that they better meet the proxy objective (and to distinguish from the value reflected in capacity payments).
} 
Figure 4 features marginal generation price estimates for 2014 from the various sources listed in Table 2. New England, Nevada, and parts of Texas and South Carolina comprise regions with relatively high prices. Large parts of the Midwest, Southeast, and Arizona are generally among zones with lower prices. For this analysis, only marginal generation prices from coastal ReEDS regions are considered.

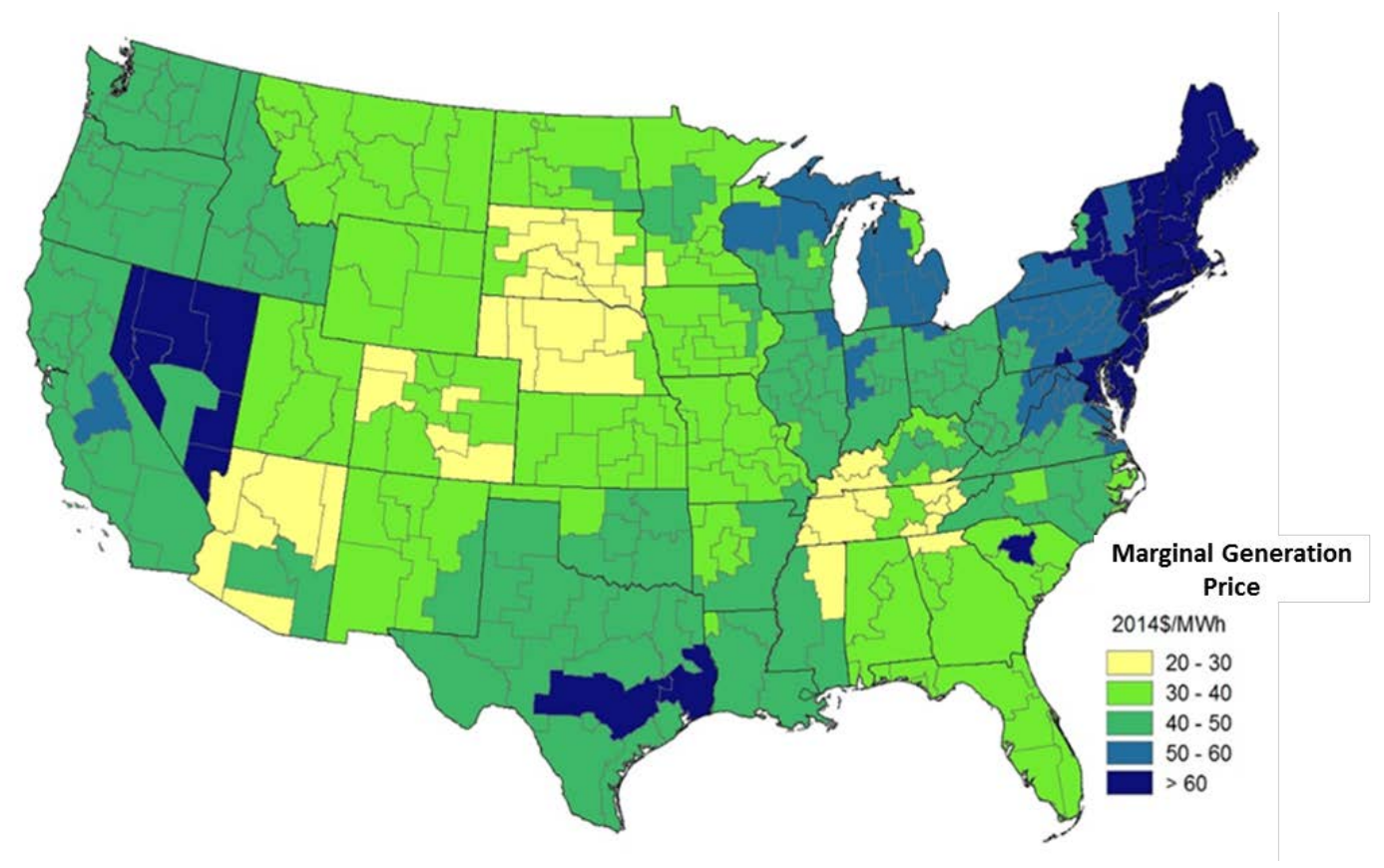

Figure 4. Marginal generation price estimates

Source: Reprinted from Brown et al. (2015); only coastal regions are relevant for this analysis

The marginal generation prices estimated for this analysis take into account projected generation price changes that occur between 2014 and the focus year by means of an annual escalation factor. These price changes were based on regional projections from the EIA AEO (2014) Reference Case in EIA (2014) (Figure 5). 


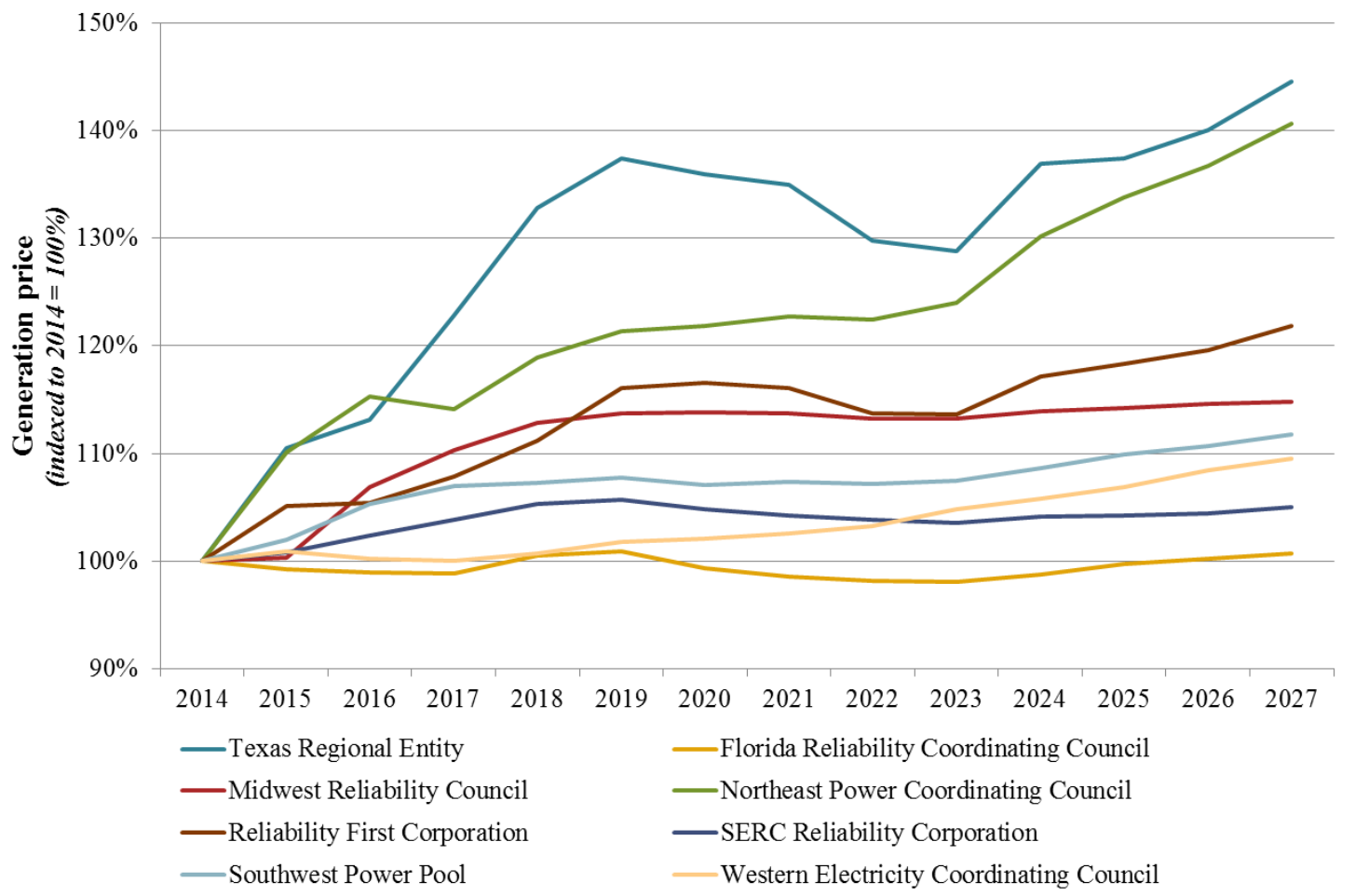

Figure 5. Electricity generation price projections by region (EIA AEO 2014)

Note: For visualization purposes, data shown represent the NERC region level; the analysis used subregion NERC data available from EIA AEO 2014

\section{Capacity Value}

The second LACE component comprises a capacity payment and a technology-specific capacity credit. The product of these two components approximates the capacity value of a generation project. The capacity payment captures the value a generation project can offer to the system in meeting reliability reserve margins, and can be determined by estimating the payment necessary to "incentivize the last unit of capacity needed to satisfy a regional reliability reserve requirement" (EIA 2013). The capacity credit captures "the ability of a unit to provide system reliability reserves" (EIA 2013) and depends upon the dispatchability of a generation project. For the purpose of this analysis and consistent with Brown et al. (2015), the overnight capital cost of a new advanced natural-gas combustion turbine plant (AEO 2015 Table 8.2) of \$682/kilowatt $(\mathrm{kW})$ serves as a proxy of capacity payment. A capacity credit of $25 \%$ was assumed for offshore wind in this assessment based on land-based wind capacity credit estimates from Milligan and Porter (2008) because of the limited regional data for offshore wind. ${ }^{22}$ Spatial and temporal differences in capacity value are not considered in this analysis. The LACE estimation was based on annual averages and did not consider the coincidence of the offshore wind energy production

${ }^{22}$ A full assessment is necessary to estimate a capacity credit for U.S. offshore wind. 
profile with temporal patterns of marginal generation prices. The calculation of annual energy production for LCOE and LACE is identical (see Eq. 1 and 2).

This preliminary approach to quantifying capacity value has some caveats and limitations that are listed in Section 3. Among these caveats and limitations are the exclusion of any spatial and temporal variation in capacity payment and capacity credit, which may vary significantly based on factors such as the local generation mix and load patterns. The capacity credit of $25 \%$ assumed for this study is intended to reflect the average capacity credit across U.S. offshore wind sites. This value was informed by estimates derived for land-based wind because offshore wind specific estimates were not available for the entire set of regions assessed in this study. Future spatial studies will need to assess the local coincidence of offshore wind generation and load patterns across U.S. coastal sites and over time to derive a more accurate estimate for an offshore wind capacity credit. There is some evidence that the capacity credit for offshore wind may be significantly higher than the $25 \%$ assumed for this study (see, e.g., Ensslin et al. 2008, Stoutenburg et al. 2010, and GE Power 2010 for some site-specific assessments). Some factors that contribute to a higher capacity credit include (but are not limited to) typically more energetic and less turbulent winds offshore and production characteristics of offshore wind that tend to be less variable and better coincide with local load peaks (e.g., sea breeze effects) (see e.g., DOE 2016).

\subsection{Economic Potential}

There are many ways to estimate the economic potential of renewable energy projects (e.g., Massachusetts Institute of Technology 2015; Hirth 2013). Economic potential, expressed in terms of MWh or MW, as defined for this analysis can be understood by comparing it to other forms of resource potential. Musial et al. (2016) used the framework depicted in Figure 6 to classify types of offshore wind resources based on specific criteria. Technical resource potential (green ellipse) comprises the subset of gross recoverable resource potential that can be considered recoverable under available technological and turbine performance conditions while considering reductions for land-use and environmental siting constraints. It takes into account technical limits of offshore wind, including system performance and losses, real-world geographic conflicting use and environmental constraints, and turbine spacing criteria. ${ }^{23}$

\footnotetext{
${ }^{23}$ The technical resource potential is a resource class that is quantified in Musial et al. (2016) by considering any available offshore wind resource at a water depth less than 1,000 meters $(\mathrm{m})$ and wind speeds greater than 7 meters per second $(\mathrm{m} / \mathrm{s})$. It also excludes ice regions of the Great Lakes where depths are greater than $60 \mathrm{~m}$, because floating wind technology has not yet been developed to survive freshwater ice floes (Musial et al. 2016).
} 


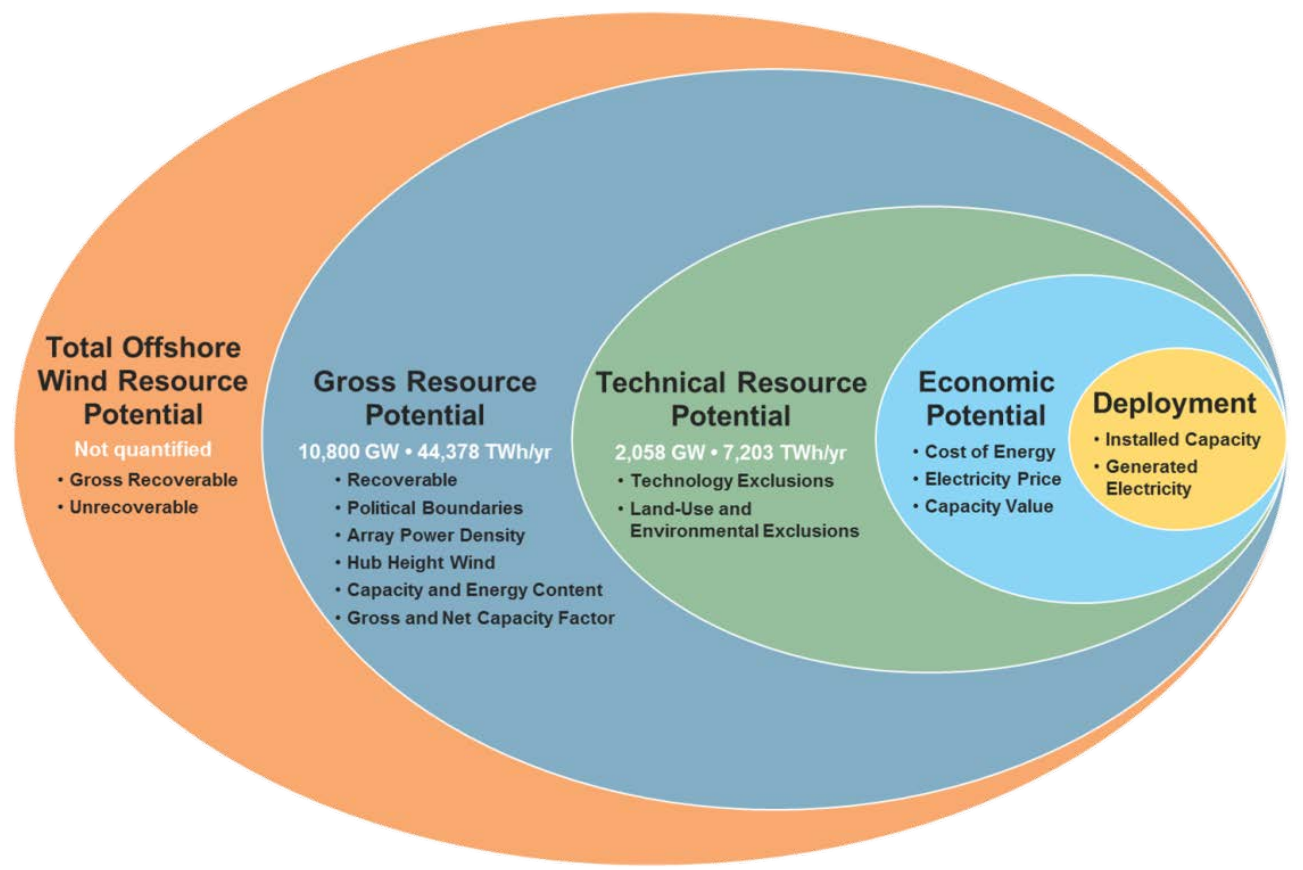

Figure 6. U.S. offshore wind resource terminology framework indicating estimated resource potential and classification criteria

Source: Image adapted from Musial et al. (2016)

For the purpose of this analysis, economic potential is defined as the subset of sites within the technical resource potential (in MWh or MW) (Musial et al. 2016), in which net value is greater than zero. Net value at a given site, $\mathrm{i}$, is defined as follows:

$$
\text { Net value }(\$ / M W h)_{i}=L_{A C E}-L_{i} C_{i}
$$

In other words, for an offshore wind site to be economic under the definitions of this analysis, LACE will need to be greater than the LCOE. LCOE is calculated at more than 7,000 coastal sites and is compared to a LACE value that is estimated for each coastal ReEDS region. The assignment of potential offshore wind site LCOE with LACE values is determined by the point of cable landfall that minimizes the direct distance to the centroid of the site.

For the purpose of this analysis, economic potential for a region, $\mathrm{j}$, with the number of sites, $n$, is defined as:

\section{Economic potential (MWh or MW) $)_{j}=\sum_{i=1}^{n}$ Technical Resouce Potential $_{i}$; where Net value ${ }_{i}>0$}

Economic potential, as defined in Eq. 4, can be helpful as a high-level indicator of economic viability to inform energy planners about new generation at a relatively high geospatial resolution. 
In the specification of economic potential as applied in this report, policy-related factors that may influence LACE or LCOE were not considered explicitly. For instance, renewable energy support mechanisms (e.g., the production tax credit), energy sector and environmental regulations (e.g., carbon pricing), or benefits from portfolio diversification (EIA 2015) may increase the "net value" and economic potential. It also does not include any considerations related to local economic development (see e.g., Tegen et al. 2015) or the attainment of state renewables portfolio standards and offshore wind targets (e.g., a requirement to procure 1,600 MW of offshore wind in Massachusetts, [The General Court of the Commonwealth of Massachusetts (2017)] a 50\% renewables portfolio standard by 2030 in New York [New York State Governor's Office (2016)] and California [California Energy Commission (2017)]). Conversely, regulatory uncertainty and market barriers (see e.g., DOE 2016) may decrease the "net value" and economic potential. 


\section{Limitations and Caveats}

The results from the Beiter et al. (2016) assessment utilized in this study were produced with first-of-its kind models and assumptions, which may be further refined as new tools, data, and validation become available. For this national-scale assessment, a number of simplifications and uncertainties exist that may affect the accuracy from reported results at any individual location. These simplifications and uncertainties range from the development of first-order tools that do not capture the entire set of parameters taken into account for a detailed site assessment, the suitability and availability of technology during the time period considered, and general uncertainty related to the formation of a domestic supply chain and macroeconomic factors. Limitations and corresponding caveats are discussed in detail in Beiter et al. (2016). Some of the most important caveats from Beiter et al. (2016) are listed here.

\section{Levelized Cost of Energy}

- To achieve the modeled cost reductions in the United States, a key assumption is that there will be continued investments in technology innovation, developments, and the market visibility of a robust domestic supply chain commensurate with the established European offshore wind supply chains during the analysis period from 2015 to 2027 and sustained domestic offshore wind development (DOE 2015; Navigant 2012; European Commission 2016).

- This analysis defines cost reduction scenarios that assume that the U.S. offshore wind industry can leverage the recent European offshore wind technology and industry experiences while accounting for some significant physical, regulatory, and economic differences (e.g., hurricanes, deeper water, Jones Act requirements), including the development of U.S.-based labor skills and ocean-based infrastructure (e.g., assembly ports or vessels) (Navigant 2012; Valpy et al. 2014; McClellan et al. 2015; Moné et al. 2015).

- As shown in Figure 1, the Crown Estate (2012) cost reductions assumed for this study should be considered in context of recent cost declines indicated by European offshore wind winning tenders. However, determining if and to what extent these recent European cost reductions will continue and how they might be translated to a U.S. context is beyond the scope of this study.

\section{Levelized Avoided Cost of Energy}

- This analysis includes a preliminary assessment of LACE limited by available data and a set of simplifying assumptions. It does not consider competition among technologies, dynamic feedback from increasing renewable deployment on wholesale electricity prices, export or import situations, or the alleviation of electricity system constraints (e.g., transmission constraints) over time. Further refinement and additional data could improve this indicator.

- In this study, LACE was estimated based on annual averages of marginal generation prices and a constant capacity value. This specification does not take into account the subhourly, hourly, or seasonal coincidence of offshore wind generation profiles with marginal generation prices or capacity value. For instance, if an offshore wind site produced electricity during times when it is in high demand (e.g., during peak load events in the late afternoon), 
the revenue opportunities (as represented by marginal generation prices or capacity value) would likely be higher. Such an assessment was not within the scope of this study.

- The validity of LACE varies by region because of spatial differences in data availability. As described in Section 2.2, a hierarchy of data sources was compiled to proxy marginal generation prices. This method of approximation may be of particular concern in the Pacific Northwest coastal regions where neither LMP, MMC, or partial LMP data were available and marginal generation prices were derived from neighboring regions in California and Nevada and regions in the Pacific Northwest with partial LMP data only.

- There is inherent uncertainty about the escalation factors that were applied by region from the AEO 2014 (EIA 2014) to project marginal generation prices for the 20-year lifetime of projects. Generation prices are determined by a range of factors, including, but not limited to, economic growth, load, energy efficiency, availability of competing generation technologies, congestion events, and weather. These factors are hard to predict and inherently uncertain.

- As applied here, LACE does not consider policy-related factors or subsidies, either nationally or in individual states, such as renewable energy support mechanisms (e.g., the production tax credit, carbon pollution and other greenhouse gas regulations, state renewable portfolio standards, and loan guarantee programs), energy sector and environmental regulations, regulatory uncertainty, or benefits from portfolio diversification (EIA 2015).

- Integration costs of offshore wind (see, e.g., Bird et al. 2013 for general discussion) are not considered in this study.

- A decline in LACE as a result of higher penetration from offshore wind (see, e.g., Mills and Wiser 2012) is not implemented in the model developed for this analysis.

- The capacity credit of $25 \%$ assumed for this study is intended to reflect the average capacity credit across U.S. offshore wind sites. This value was informed by estimates derived for land-based wind because offshore wind specific estimates were not available for the entire set of regions assessed in this study. Future spatial studies will need to assess the local coincidence of offshore wind generation and load patterns across U.S. coastal sites and over time to derive a more accurate estimate for an offshore wind capacity credit. There is some evidence that the capacity credit for offshore wind may be significantly higher than the $25 \%$ assumed for this study (see, e.g., Ensslin et al. 2008, Stoutenburg et al. 2010, and GE Power 2010 for some site-specific assessments). Some factors that contribute to a higher capacity credit include (but are not limited to) typically more energetic and less turbulent winds offshore and production characteristics of offshore wind that tend to be less variable and better coincide with local load peaks (e.g., sea breeze effects) (see e.g., DOE 2016).

\section{Economic Potential}

- The calculation of economic potential should not be used as a prediction for actual project deployment. Economic potential indicates that the revenue at a given site may exceed its costs in the local energy market, but it does not guarantee that the technology will be selected. Conversely, a negative net value indicating the lack of economic potential at a given site does not necessarily indicate that economic viability is not achievable because of general 
modeling uncertainty related to the development of future costs, electricity prices, policy, and renewable targets (see Section 2.3).

- This study only assesses the economic potential of offshore wind and is not a metric of profitability. For a full sectorwide assessment of economic competitiveness, the economic potential from all competing technologies would have to be taken into consideration (see e.g., EIA 2014). For instance, another generation technology may exhibit a net value that is greater than the estimates for offshore wind at any of the assessed sites. 


\section{Results and Discussion}

In this section, results are presented in various formats:

- Maps showing spatial distribution of LCOE, LACE, and net value of offshore wind for five U.S. coastal regions, including the Atlantic Coast, Pacific Coast, Gulf of Mexico, Great Lakes, and Hawaii for each of the focus years $(2015,2022$, and 2027)

- National and regional supply curves of offshore wind capacity ranked by LCOE for fixed-bottom and floating technology types

- Scatterplots of LCOE and LACE for fixed-bottom and floating offshore wind technology nationally, and for individual U.S. coastal regions.

Results are shown at the national level in Section 4.1, and for U.S. coastal regions, including the Atlantic (Section 4.2), Pacific (Section 4.3), Gulf of Mexico (Section 4.4), Great Lakes (Section 4.5), and Hawaii ${ }^{24}$ (Section 4.6).

\subsection{National}

\subsubsection{Levelized Cost of Energy}

Figure 7 depicts the variance of LCOE estimated across all U.S. coastal sites (indicated by the vertical blue two-way arrow) and over time (along the horizontal time axis). The lower range of LCOE estimates among all U.S. offshore wind sites indicates a decline from \$130/MWh in 2015 to $\$ 95 / \mathrm{MWh}$ in 2022 , to $\$ 80 / \mathrm{MWh}$ in 2027 and $\$ 60 / \mathrm{MWh}$ in 2030 . The upper range of $\mathrm{LCOE}^{25}$ estimates among U.S. offshore wind sites shows a decline from \$450/MWh in 2015 to approximately $\$ 300 / \mathrm{MWh}$ in 2022, $\$ 220 / \mathrm{MWh}$ in 2027, and $\$ 190 / \mathrm{MWh}$ in 2030. Figure 7 also includes two offshore wind cost-reduction reference scenario sites for fixed-bottom and floating technologies, respectively. The characteristics of these generic reference scenarios are specified in Beiter et al. (2016) ${ }^{26}$ to represent typical spatial conditions of existing Bureau of Ocean Energy Management lease areas. However, these generic reference scenario sites represent averages but not any specific Bureau of Ocean Energy Management lease area or site. The two reference scenarios follow the same general cost-reduction trend that is reflected in the upper and lower boundary of LCOE. Based on this analysis, although the LCOE for floating technology is significantly higher in 2015, fixed-bottom and floating technologies are expected to converge over time.

Some of the drivers that lead to lower LCOE at certain sites include:

- Strong wind resources, ranging from 8.5 to $10 \mathrm{~m} / \mathrm{s}$, which result in net capacity factors between $40 \%$ and $60 \%$

\footnotetext{
${ }^{24}$ Only LCOE reported for Hawaii.

${ }^{25}$ LCOE was calculated for all sites, regardless of whether they are likely to attain economic potential in a near-term timeframe.

${ }^{26}$ The fixed-bottom cost-reduction scenario site assumes a water depth of $30 \mathrm{~m}$ and a distance from shore of $30 \mathrm{~km}$. The floating cost-reduction scenario site assumes a water depth of $100 \mathrm{~m}$ and a distance from shore of $30 \mathrm{~km}$.
} 
- Close proximity to the onshore grid interconnect, which minimizes the electrical infrastructure and maintenance costs

- Proximity to an inshore assembly area

- Close to shore-based port facilities, which minimizes installation, maintenance, and export system costs

- Shallower water depths, which minimize substructure costs.

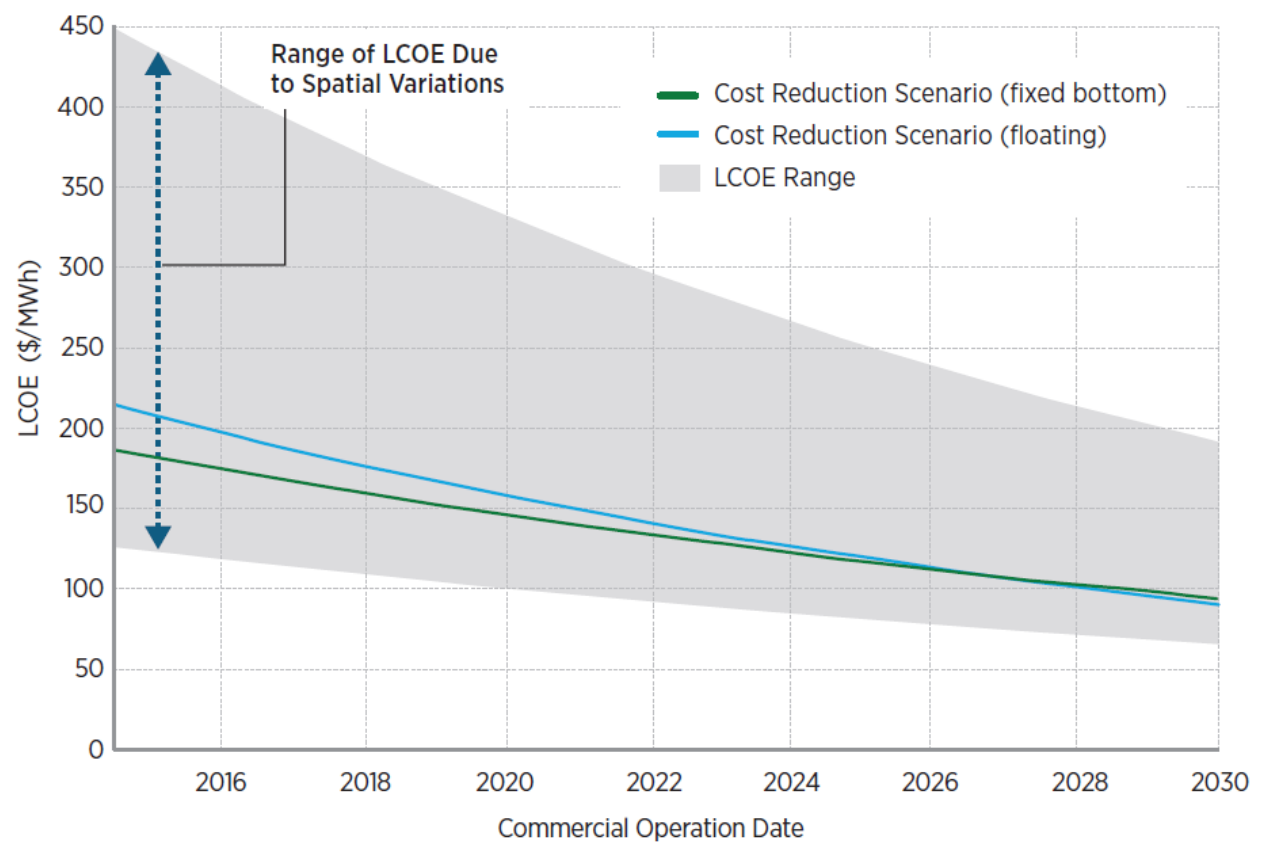

Figure 7. Levelized cost of electricity for potential offshore wind projects from 2015 to 2030 over technical resource area

Source: Beiter et al. (2016)

Note: Data plotted are an exponential curve fit through the modeled LCOE values $(2015,2022$, and 2027 COD)

\subsubsection{Supply Curves}

Supply curves depict the relationship between LCOE levels and available capacity. A total of approximately 2,060 gigawatts (GW) of offshore wind technical resource potential were estimated by Musial et al. (2016) for all major U.S. coastal regions (excluding Alaska). In comparison, a total of $82 \mathrm{GW}$ of land-based wind was installed in the United States by the end of 2016 (American Wind Energy Association [AWEA] 2017). Figures 8 through 10 are a set of national offshore wind supply curves for years 2015,2022 , and 2027, respectively. ${ }^{27}$ The

${ }^{27}$ See Beiter et al. (2016) for more details on methodology and limitations. 
adjacent tables indicate the available capacity at different levels of LCOE by increments of \$25/MWh.

The inverse S-shape form of these supply curves indicate that any global reduction in LCOE (or conversely, increase in LCOE) can trigger a relatively smaller amount of available capacity at low (e.g., between 0 and $100 \mathrm{GW}$ of cumulative capacity in 2015) and high (>1,700 GW of cumulative capacity in 2015) levels of LCOE than at moderate LCOE intervals (e.g., between 100 and $1,700 \mathrm{GW}$ of cumulative capacity in 2015).

In 2015, approximately $40 \mathrm{GW}$ of offshore wind technical resource capacity was estimated to be available below \$150/MWh, $620 \mathrm{GW}$ below \$200/MWh, and 1,720 GW below \$300/MWh. The lowest cost sites $(<\$ 150 / \mathrm{MWh})$ are entirely comprised of offshore wind plants with fixedbottom substructure technology. Floating technology is still in a nascent stage and has arguably not yet realized a significant portion of its cost-reduction potential. The least-cost fixed-bottom location was estimated at just above $\$ 125 / \mathrm{MWh}$. Total capacity within the lowest-cost bin of $\$ 125 / \mathrm{MWh}-\$ 135 / \mathrm{MWh}$ amounts to approximately $4 \mathrm{GW}$. The least-cost floating technology substructure site in 2015 is estimated at cost levels of approximately $\$ 160 / \mathrm{MWh}$. The share of capacity supply using floating technology increases with higher LCOE levels and reaches 50\% of cumulative national offshore wind energy capacity at all sites where cost levels are approximately $\$ 280 / \mathrm{MWh}$ or less. ${ }^{28}$ The average net capacity factors for locations with LCOE of $<\$ 150 /$ MWh ranged from $43 \%$ to $47 \%$.

\footnotetext{
${ }^{28}$ Note that the fraction of resource where floating technology was deployed as the least-cost option was approximately 58\%, if only the sites with LCOE $<\$ 300 / \mathrm{MWh}$ were considered.
} 


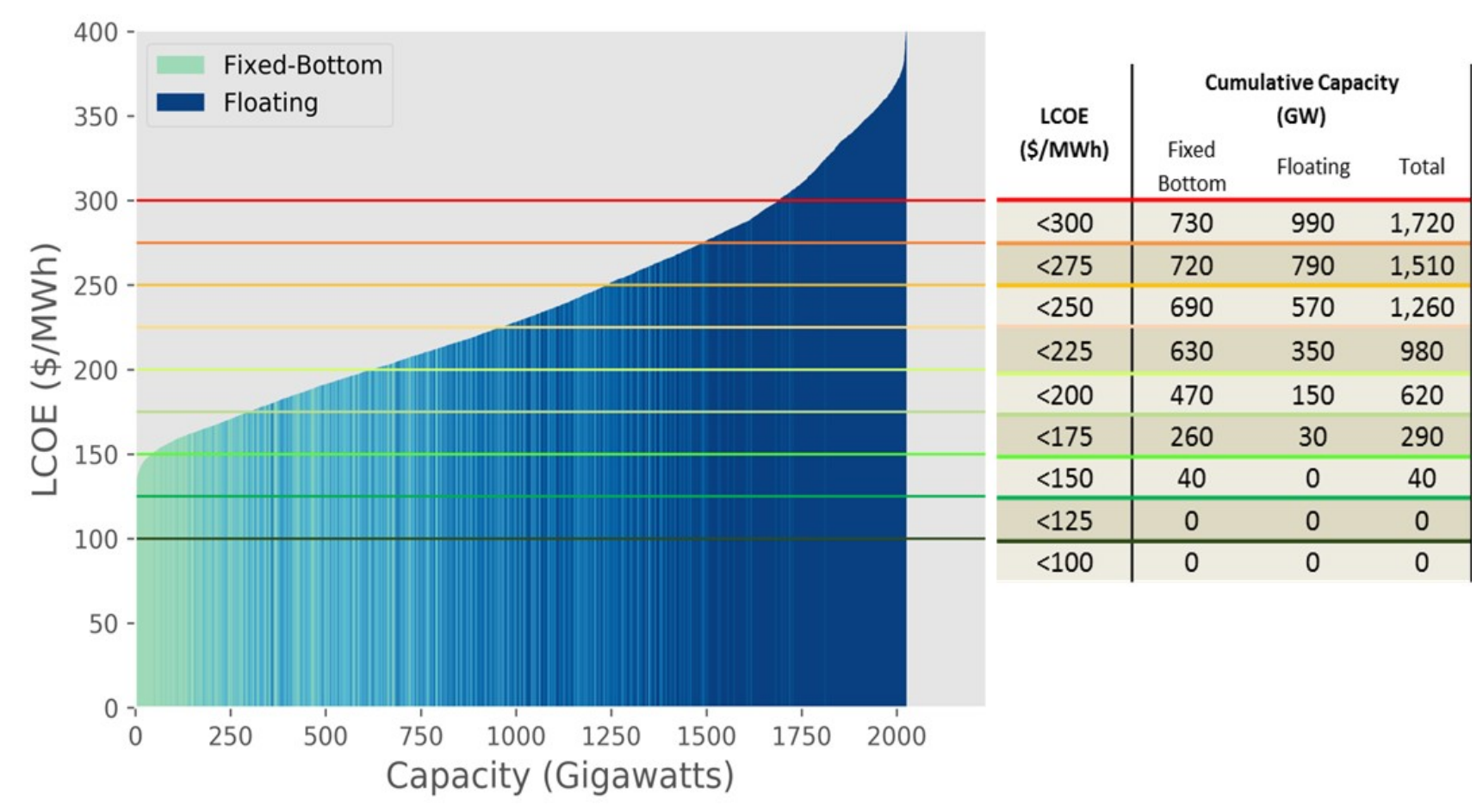

Figure 8. 2015 National offshore wind energy supply curve

Note: Cumulative capacity supply in the table is rounded to the nearest 10; includes Hawaii

By 2022, technology innovation and cost savings have led to a downward shift of the supply curve. In 2022, approximately $4 \mathrm{GW}$ is estimated to be available below $\$ 100 / \mathrm{MWh}, 290 \mathrm{GW}$ below $\$ 125 / \mathrm{MWh}, 870 \mathrm{GW}$ below $\$ 150 / \mathrm{MWh}$, and 1,700 GW below $\$ 200 / \mathrm{MWh}$. The lowestcost fixed-bottom technology sites are estimated to be less than $\$ 95 / \mathrm{MWh}$, and the least-cost floating sites are estimated at nearly $\$ 105 / \mathrm{MWh}$. Compared to 2015, a greater fraction of floating offshore wind capacity is expected to be present among low LCOE sites by 2022. The share of cumulative capacity comprised of floating technology increases from approximately $10 \%$ at LCOE levels below \$110/MWh to 50\% at LCOE levels below \$170/MWh. The average net capacity factors for locations with LCOE if $<\$ 120 / \mathrm{MWh}$ ranged from $46 \%$ to $50 \%$. 


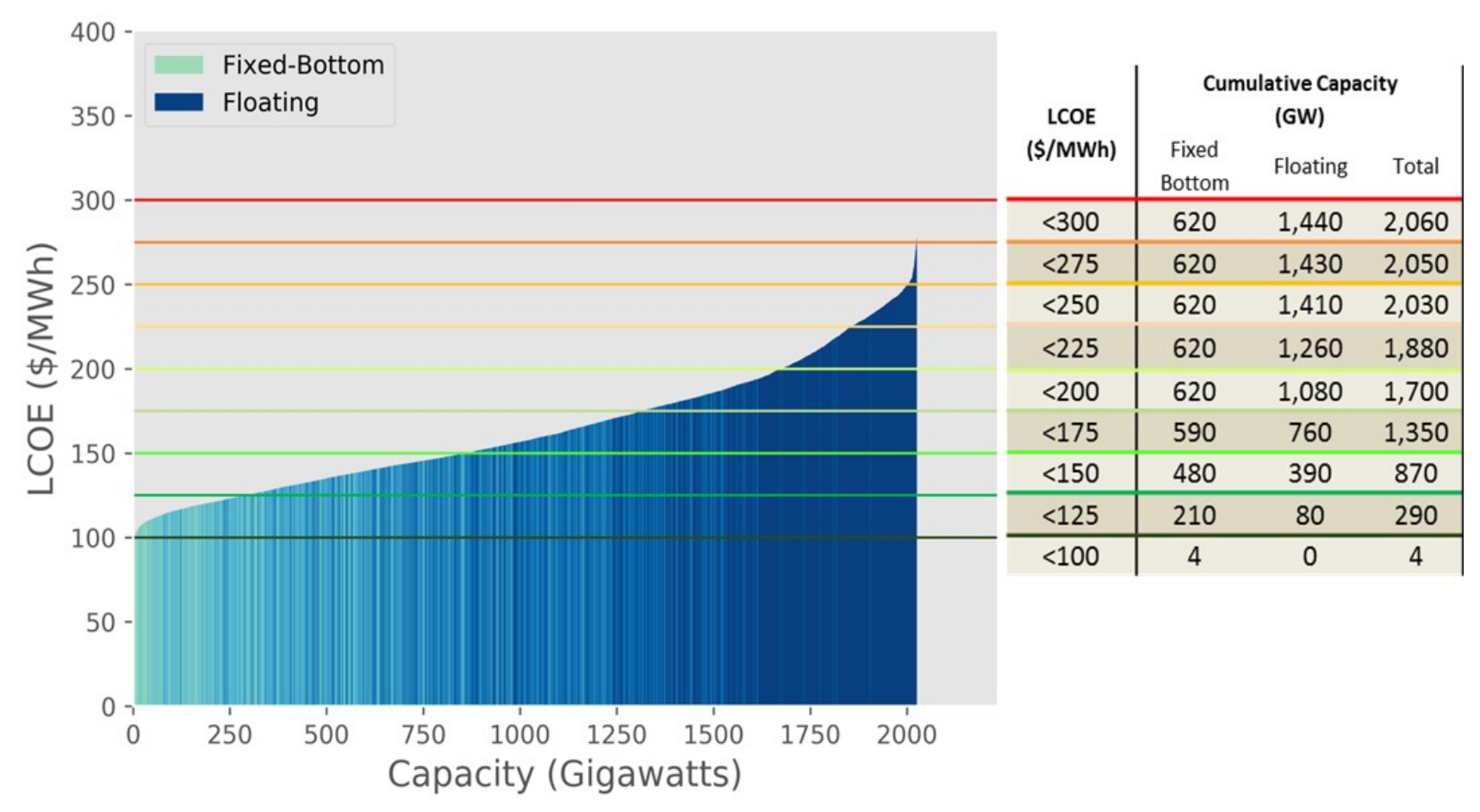

Figure 9. 2022 National offshore wind energy supply curve

Note: Cumulative capacity in the table is rounded to the nearest $10(\mathrm{LCOE}<\$ 300 / \mathrm{MWh})$ and one (LCOE<100\$/MWh); includes Hawaii

Consistent with the declining cost trend shown in Figure 7, the supply curve shifts further downward by 2027 (Figure 10). Approximately $450 \mathrm{GW}$ of cumulative offshore wind capacity was estimated to be available below \$100/MWh, 1,280 GW below $\$ 125 / \mathrm{MWh}$, and 1,790 GW below $\$ 150 / \mathrm{MWh}$. The lowest LCOE among both fixed-bottom and floating locations in 2027 is just above $\$ 75 / \mathrm{MWh}$. A total capacity of $6 \mathrm{GW}$ is available at LCOE levels of $<\$ 80 / \mathrm{MWh}$. The share of cumulative capacity comprised of floating technology among locations with an LCOE $<$ $\$ 80 / \mathrm{MWh}$ is approximately $43 \%$ and increases to more than $50 \%$ at LCOE levels greater than $\$ 110 / \mathrm{MWh}$. The average net capacity factor ranges from $53 \%$ to $58 \%$ among sites with LCOE levels of $<\$ 100 / \mathrm{MWh}$. 


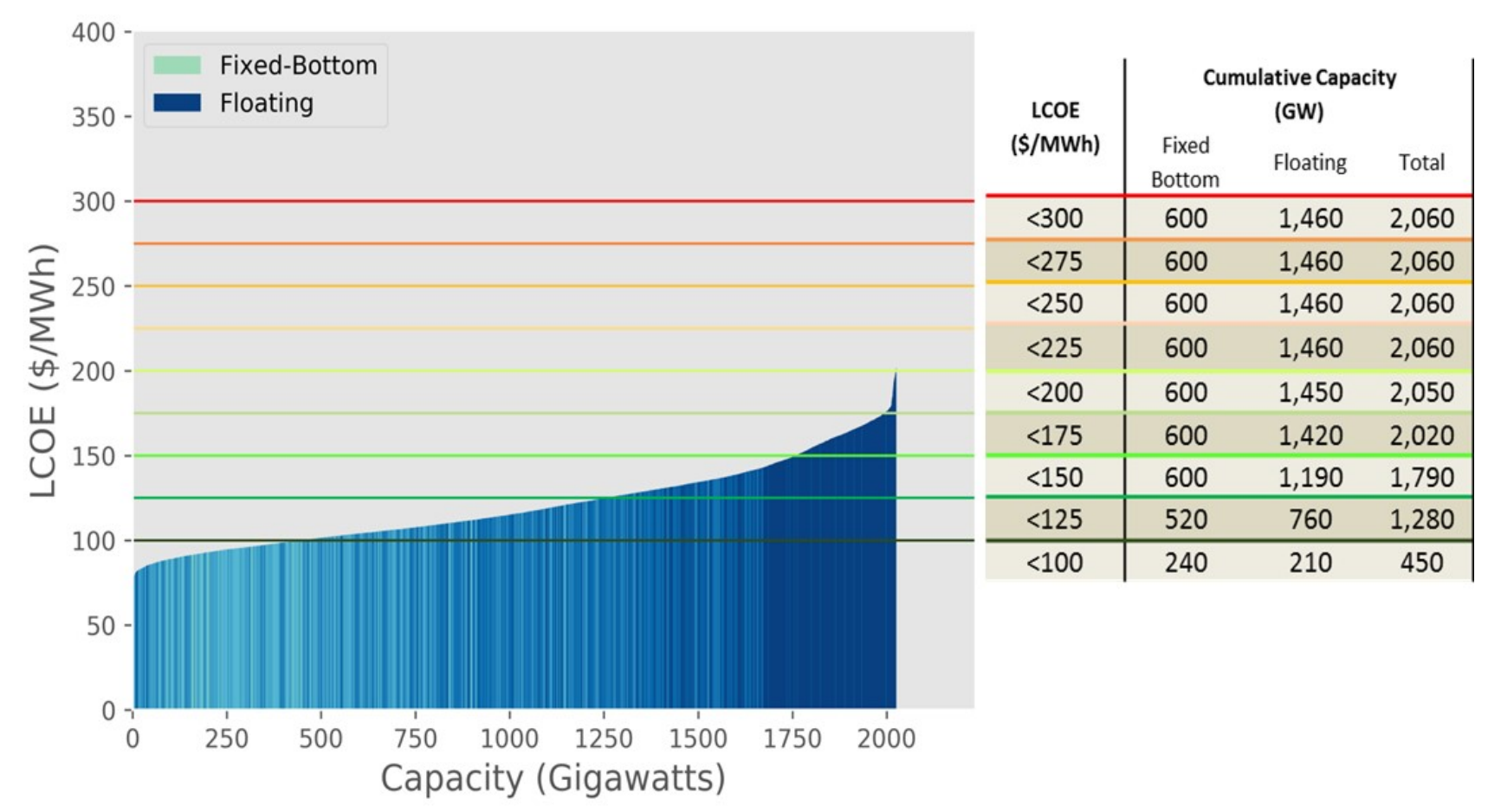

Figure 10. 2027 National offshore wind energy supply curve

Note: Cumulative capacity in table is rounded to the nearest 10; includes Hawaii

Note that by 2027, floating technology has matured substantially, and the total fraction of offshore wind capacity $(1,460 \mathrm{GW})$ that the model calculates for floating technology is $70 \%$ of the total offshore wind resource capacity $(2,060 \mathrm{GW})$ in the U.S. technical resource area.

\subsubsection{Substructure Types}

The distribution of LCOE varies by the two principal offshore wind substructure types considered in this analysis: fixed-bottom and floating. These technologies were estimated to have different baseline costs in 2015 and cost-reduction trajectories, subject to their respective technological and commercial maturity. As shown in Figure 11, among the entire set of locations considered, fixed-bottom substructure technology generally has a lower median and smaller spread than floating technology. This is a result of various factors, including the spatial conditions they are suitable for and the associated baseline costs and cost-reduction scenarios, as well as the number of locations. Floating technology is suitable at a greater variety of spatial conditions, such as at a water depth ranging from $60 \mathrm{~m}$ to $1,000 \mathrm{~m}$ (with a minimum water depth of $38 \mathrm{~m}$ in 2027) (Figure 12) and distance from shore between $30 \mathrm{~km}$ to $370 \mathrm{~km}$. Whereas in 2015 , the minimum cost of fixed-bottom technology is lower than floating technology; by 2027 , these costs are nearly the same at just below $\$ 100 / \mathrm{MWh}$. 

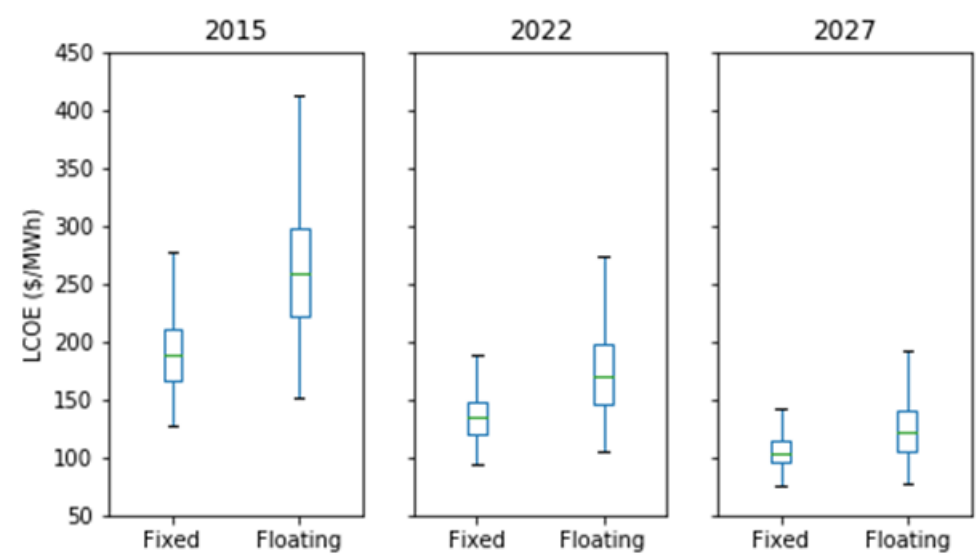

Figure 11. LCOE by substructure type (2015-2027)

Note: the box plot spans the first quartile (bottom) to the third quartile (top); the segment inside the rectangle shows the median (in green); the "whiskers" above and below the box indicate the minimum and maximum LCOE.

In this analysis, the cost-optimal choice between fixed-bottom and floating technology depends on geospatial variables, such as water depth or distance from shore. The range of these variables wherein the cost-optimal choice transcends from one technology to the other is denoted as the economic "break point." Figure 12 shows the LCOE of the two substructure types by water depth (Figure 12). The model results indicate that the "break point" for the least-cost choice between fixed-bottom and floating technology ranges between 50 and $70 \mathrm{~m}$ deep.
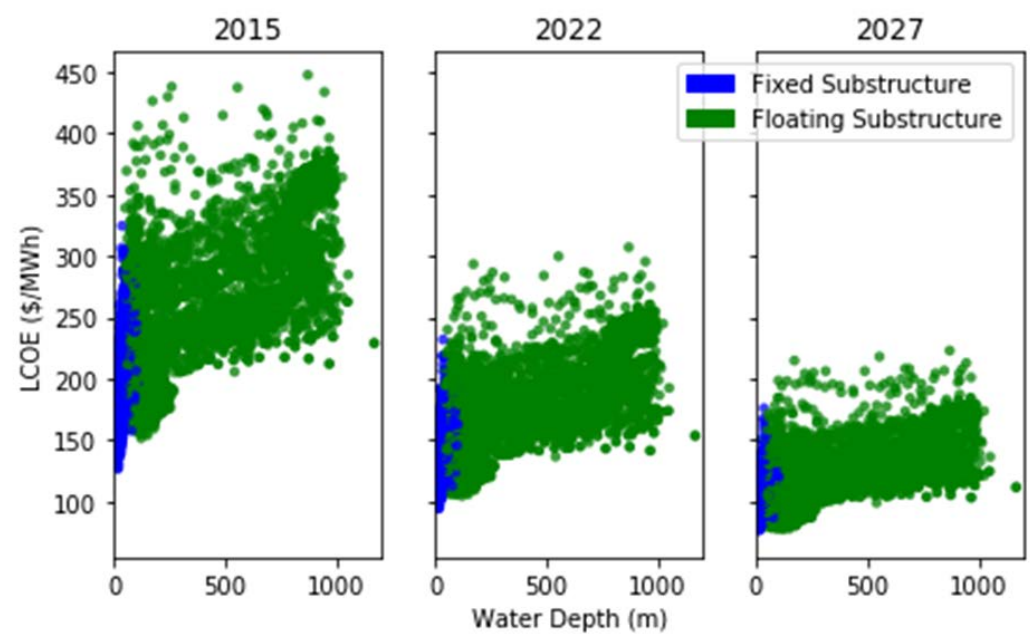

Figure 12. LCOE by substructure type and water depth (2015-2030)

\subsubsection{Economic Potential}

Economic potential was defined in this report as the subset of sites from the technical resource potential for which net value (LACE/LCOE) is greater than zero. In other words, the generation or capacity associated with a potential offshore wind location is considered economic when its available revenue (LACE) exceeds its costs (LCOE). Economic potential is expressed in terms of energy generation (MWh) or installed capacity (MW). 
Figure 14 shows the LCOE costs from Figure 7 with the corresponding LACE estimates added for U.S. coastal sites. The figure indicates that as LCOE decreases and LACE grows gradually, the possibility for economic potential at some U.S. offshore wind sites grows over time. It should be noted that the overlap between LCOE and LACE shown in Figure 14 does not satisfy the conditions for economic potential (net value $>0$ ) because LACE must exceed LCOE at a specific site. To illustrate this point, Figure 14 shows an assessment of economic viability for two contrasting offshore wind locations in Massachusetts using floating technology. A set of markers (stars and dots) included for focus year 2027 (COD) show site-specific LCOE and LACE estimates. The first site, indicated by dots, has a water depth of $926 \mathrm{~m}$ and a distance to cable landfall of $264 \mathrm{~km}$. Its LACE of \$93/MWh (green dot) compares to an LCOE of \$122/MWh (blue dot) in 2027 (COD); therefore, this location lacks economic potential. On the other hand, the second site, indicated by stars, has a water depth of $221 \mathrm{~m}$ and a distance of $72 \mathrm{~km}$ from site to cable landfall. Its LACE of \$103/MWh (green star) compares to an LCOE of \$92/MWh (blue star) by 2027 (COD); because LACE is greater than LCOE, this location is considered to have economic potential by 2027 (COD). This site-independent data is shown again in Appendix A-1 in terms of frequency distributions.

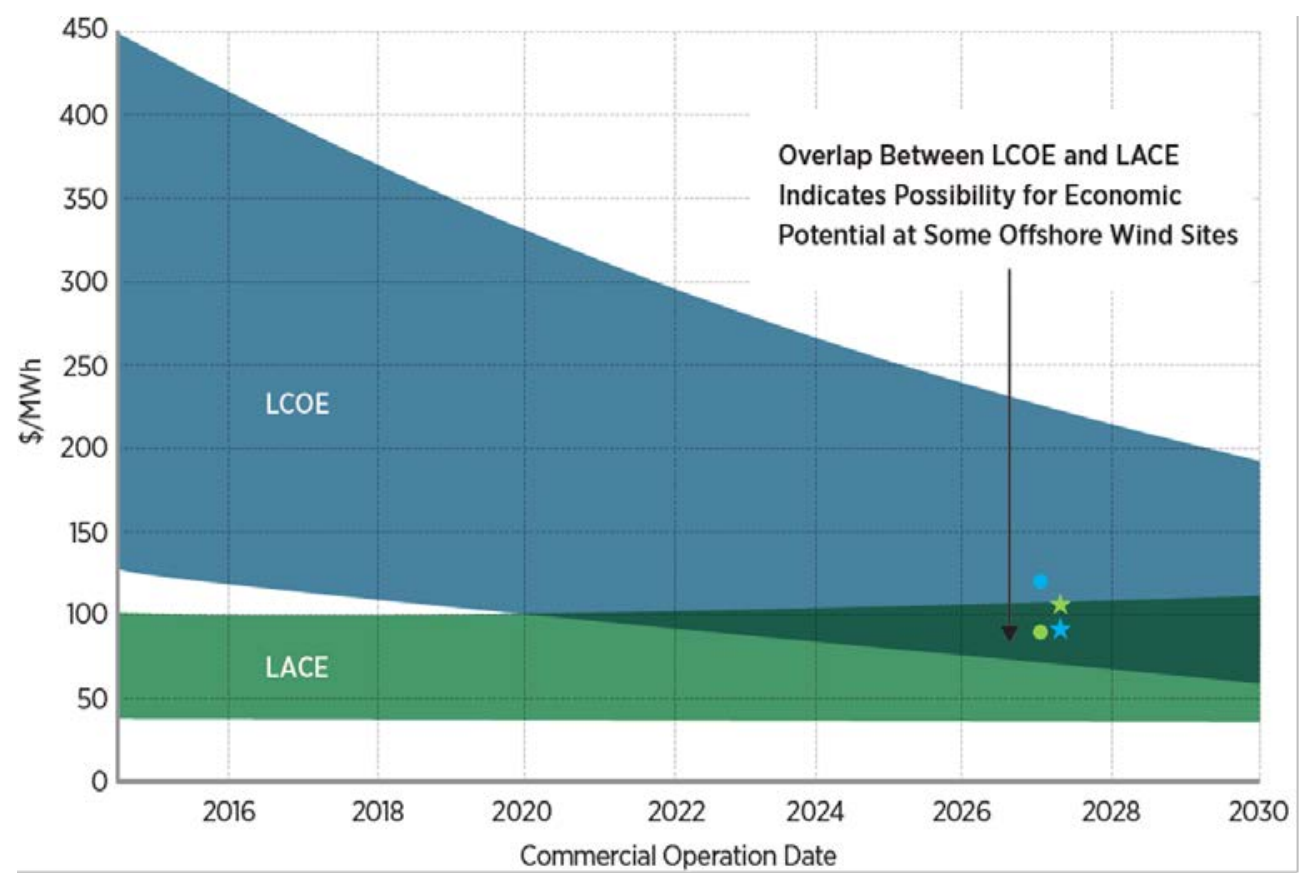

Stars illustrate an economically viable location in Massachusetts where LACE (green) is greater than LCOE (blue) in 2027 (COD)
Dots illustrate an economically unviable location in Massachusetts where LACE (green) is less than LCOE (blue) in 2027 (COD)

Figure 14. Comparison of LCOE and LACE estimates from 2015 to 2030

Note: Reprinted from Beiter et al. (2016); Data plotted are an exponential curve fit through the modeled LCOE values (2015, 2022, and 2027 COD); the overlap between LCOE and LACE shown in Figure 14 does not satisfy the conditions for economic potential (net value $>0$ ) because LACE must exceed LCOE at a specific site. 
Figure 15 depicts the relationship between the site-specific net value (LACE/LCOE) and available capacity. The subset of capacity with a net value $>0$ is considered economic potential. Corresponding to the trend of declining LCOE and increasing LACE, the net value curves are shifted upwards between 2015, 2022, and 2027. Although the net value curves for years 2015 and 2022 fall below zero (indicated by the dashed line in black), a total of $144 \mathrm{GW}$ of capacity has economic potential by 2027 as the associated sites have a net value $>0$. Figure 15 also illustrates that even a relatively small difference in either LCOE or LACE can have a considerable effect in terms of the available economic potential because of a relatively shallow slope of the net value curve. Therefore, it is important to interpret these results carefully because modeling uncertainties coupled with regulatory, technological, market, and policy factors can induce large impacts on the quantity of economic potential estimated.

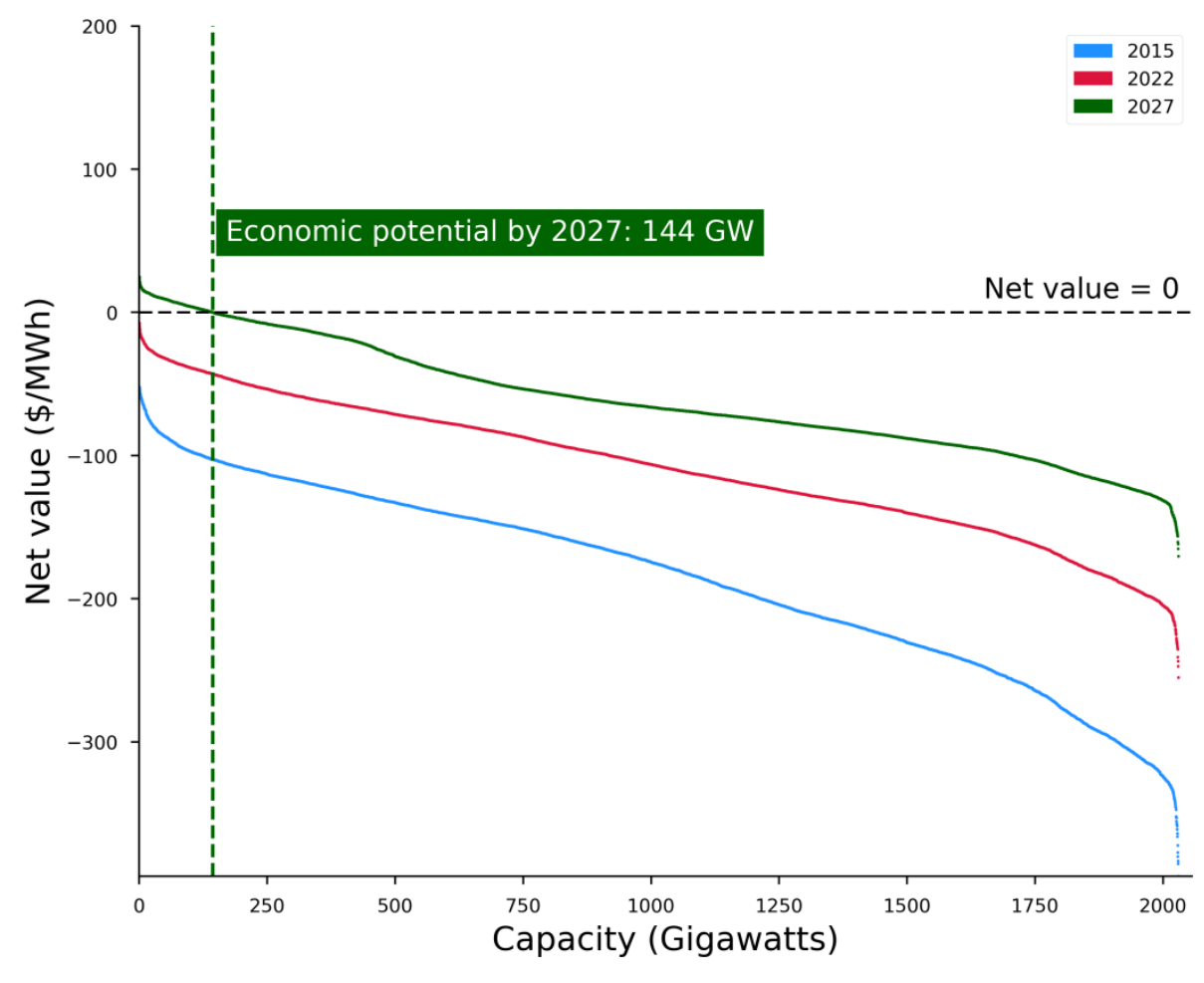

Figure 15. Comparison of LCOE and LACE estimates for 2015, 2022, and 2027

Note: Net value is defined as the difference between LACE and LCOE. Capacity associated with positive net value indicates economic potential. 


\subsection{Atlantic Coast}

\subsubsection{Levelized Cost of Energy}

\subsubsection{Spatial Distribution}

In 2015, along the Atlantic Coast, the LCOE was estimated to range from approximately $\$ 125$ $270 / \mathrm{MWh}$ in the Northeast, ${ }^{29} \$ 145-315 / \mathrm{MWh}$ in the mid-Atlantic regions, ${ }^{30}$ and $\$ 150-385 / \mathrm{MWh}$ in the Southeast, ${ }^{31}$ respectively (Figure 16). These ranges decrease to $\$ 95-180 / \mathrm{MWh}$ (Northeast), \$110-210/MWh (mid-Atlantic), and \$115-260/MWh (Southeast) by 2022, respectively. By 2027, the LCOE range in the Northeast was estimated to decline to $\$ 80-130 / \mathrm{MWh}$ (Northeast), $\$ 85-$ 150/MWh (mid-Atlantic), and \$90-185/MWh (Southeast).

The Atlantic Coast has some of the lowest LCOE sites across U.S coastal areas. These sites are generally near shore and in relatively shallow waters. Some of the lowest-cost sites are located in Massachusetts, Maine, Rhode Island, and New York. As shown in Figure 16, areas of relatively low LCOE extend far from shore in Massachusetts, New Hampshire, Maine, and Rhode Island because of shallow waters. Along the coast of Florida, LCOE tends to be significantly higher as a result of relatively low wind speeds (see Musial et al. 2016).
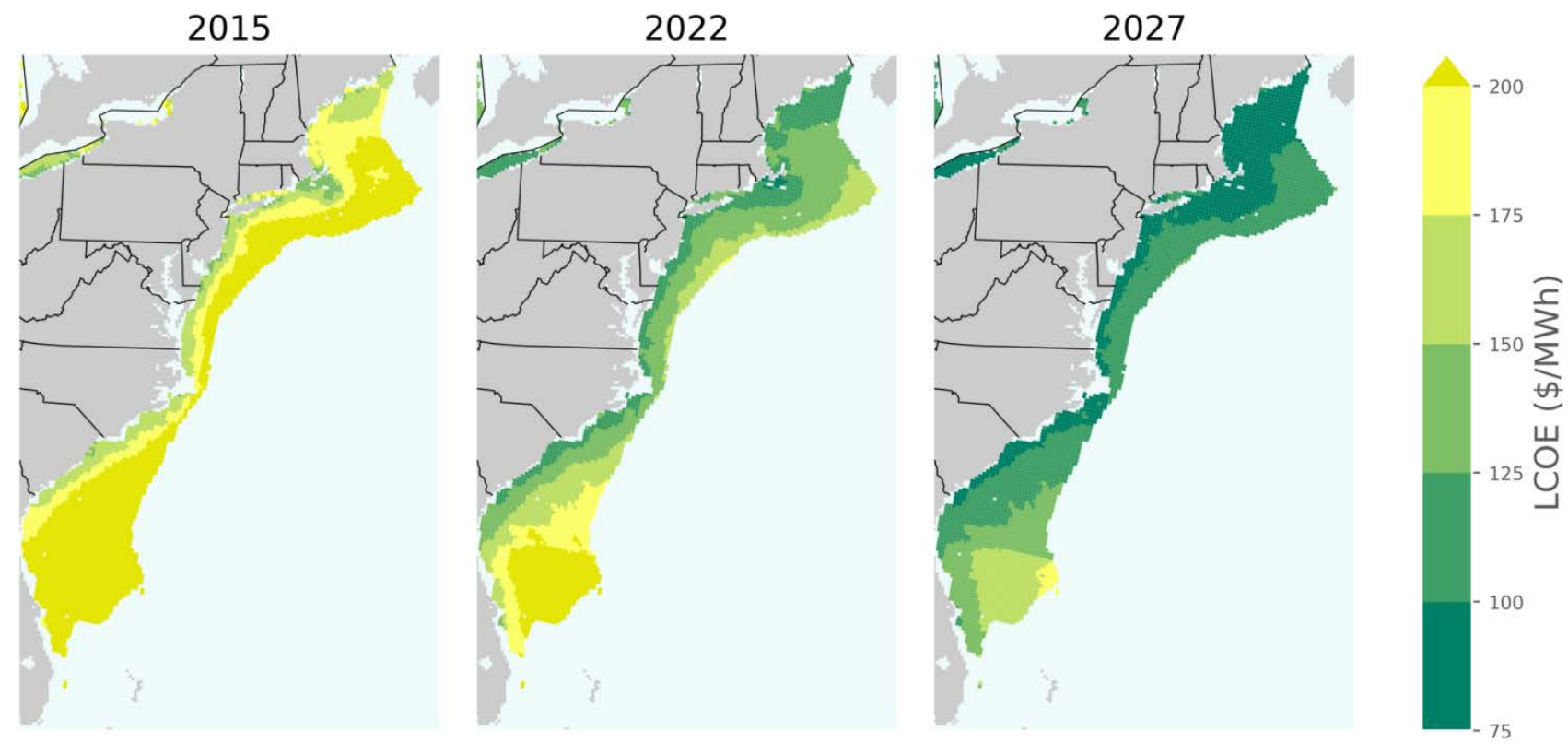

Figure 16. Atlantic Coast spatial LCOE distribution (2015-2027)

\footnotetext{
${ }^{29}$ The Northeast region includes Maine, New Hampshire, Massachusetts, Rhode Island, Connecticut, and New York.

${ }^{30}$ The mid-Atlantic region includes Delaware, Maryland, Virginia, North Carolina, and South Carolina.

31 The Southeast region includes Georgia and Florida.
} 


\subsubsection{Supply Curves}

As depicted in Figures 17 through 19, the Atlantic Coast possesses a total offshore wind technical resource of approximately $1,100 \mathrm{GW}$. This is the largest resource potential among all U.S. coastal areas. ${ }^{32}$ Yet, in 2015 , there is no offshore wind capacity below LCOE levels of $\$ 100 / \mathrm{MWh}$. By 2022, nearly $4 \mathrm{GW}$ of capacity is available below $\$ 100 / \mathrm{MWh}$, and by 2027 approximately $340 \mathrm{GW}$ of capacity reaches costs below $\$ 100 / \mathrm{MWh}$. In the same timeframe, the share of floating offshore wind sites increases from $0 \%$ at LCOE levels of $<\$ 150 / \mathrm{MWh}$ in 2015 to nearly $60 \%$ at LCOE levels of $<\$ 100 / \mathrm{MWh}$ in 2027 . By 2027 , the Northeast region alone comprises more than $260 \mathrm{GW}$ of the $340 \mathrm{GW}$ of capacity at LCOE levels below $\$ 100 / \mathrm{MWh}$ in 2027. Approximately $200 \mathrm{GW}$ of this amount are located off the coast of Maine, Massachusetts, and Rhode Island. Note that in the Atlantic Coast region, approximately $74 \%$ of the sites favor floating wind technology as the least-cost solution by 2027.

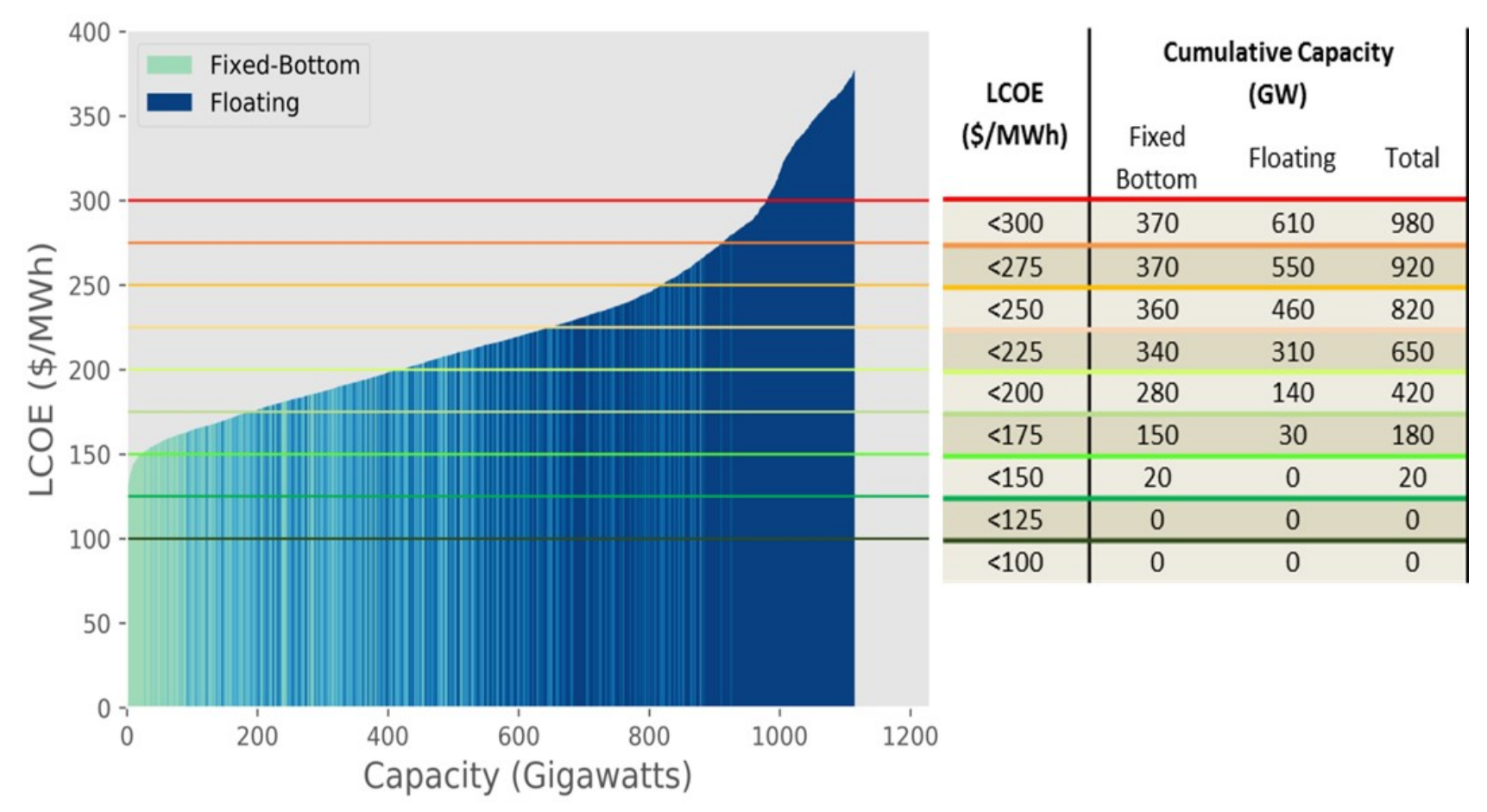

Figure 17. 2015 Atlantic Coast offshore wind energy supply curve

Note: Cumulative capacity in table rounded to the nearest 10.

\footnotetext{
${ }^{32}$ As indicated above, Alaska is excluded from this analysis.
} 


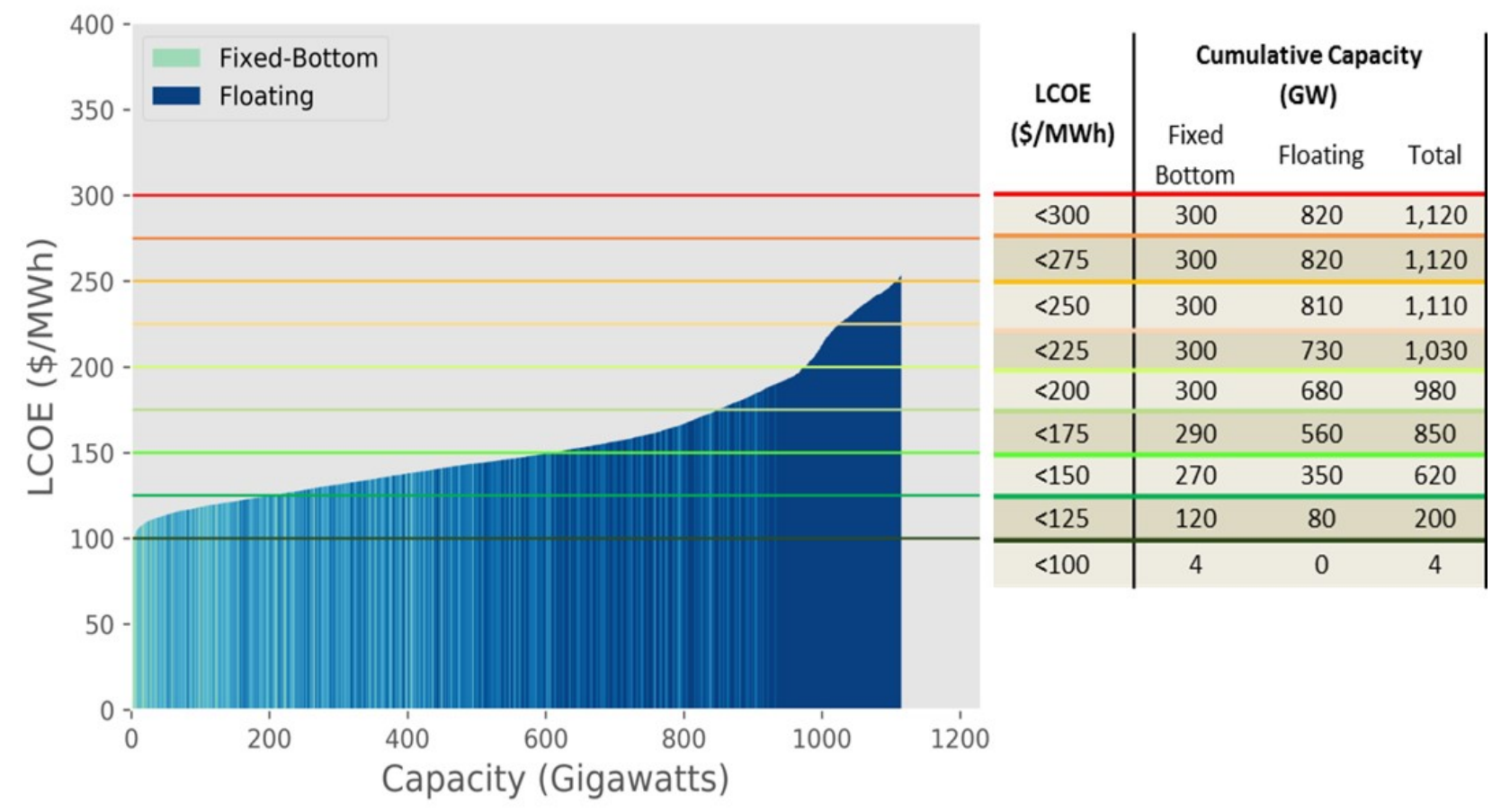

Figure 18. 2022 Atlantic Coast offshore wind energy supply curve

Note: Cumulative capacity in table rounded to the nearest $10 \quad$ (LCOE $<\$ 300 / \mathrm{MWh}$ ) and one (LCOE<100\$/MWh).

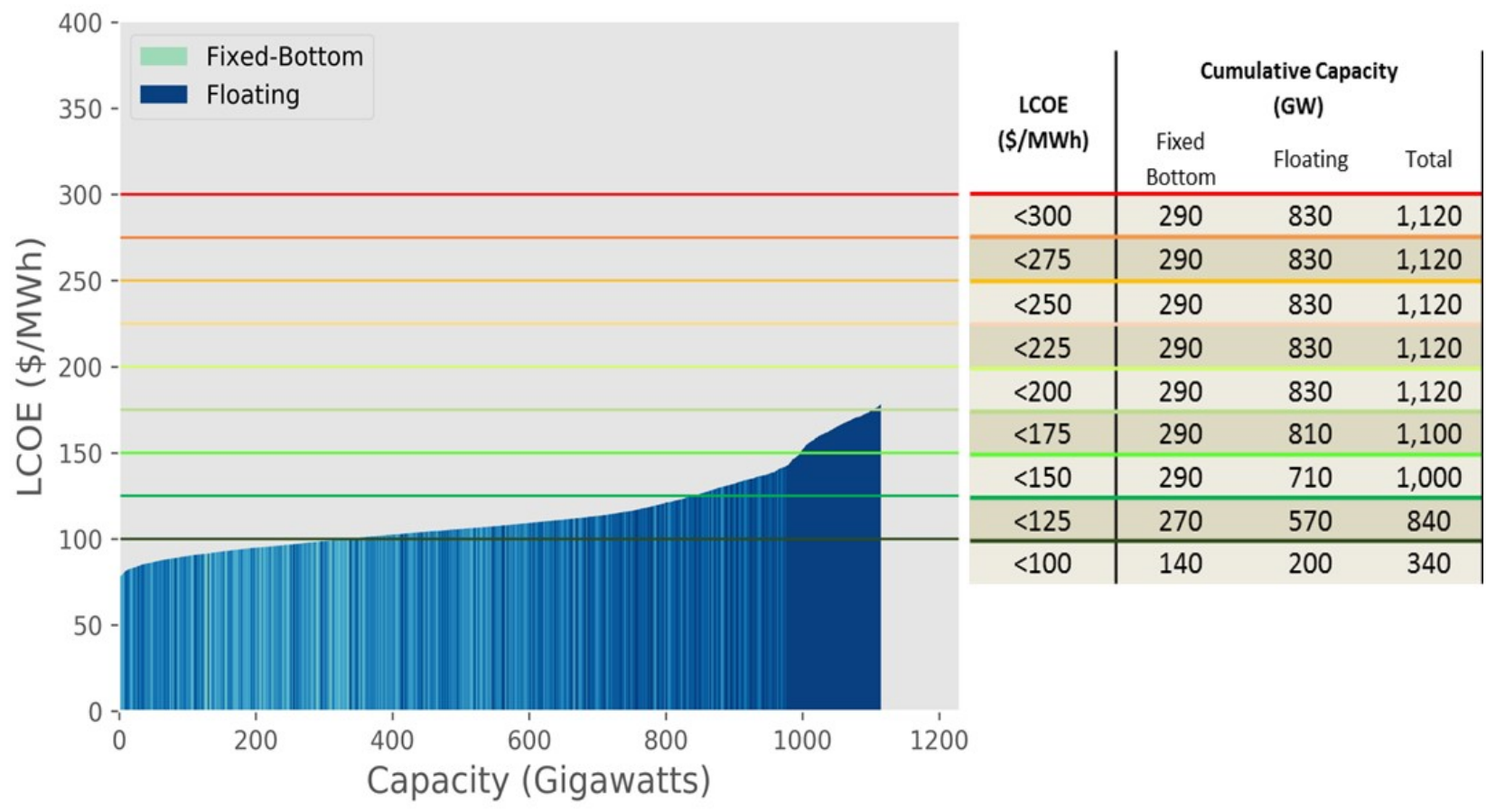

Figure 19. 2027 Atlantic Coast offshore wind energy supply curve

Note: Cumulative capacity in table rounded to the nearest 10.

This report is available at no cost from the National Renewable Energy Laboratory at www.nrel.gov/publications. 


\subsubsection{Levelized Avoided Cost of Energy}

The variance in LACE is relatively high in the Atlantic Coast region when compared to the other coastal regions. The highest levels of LACE are generally found off the coast of Virginia, Connecticut, Rhode Island, Massachusetts, and Maine, largely because of comparatively high electricity price levels. Comparatively low levels of LACE were estimated on the Southeast coast along Florida, North Carolina, and South Carolina where electricity price levels are generally lower than in the coastal population centers in the Northeast. LACE increases incrementally from 2015 to 2027 as shown by the increasingly dark color scheme and estimated by the AEO generation price forecasts (EIA 2014).
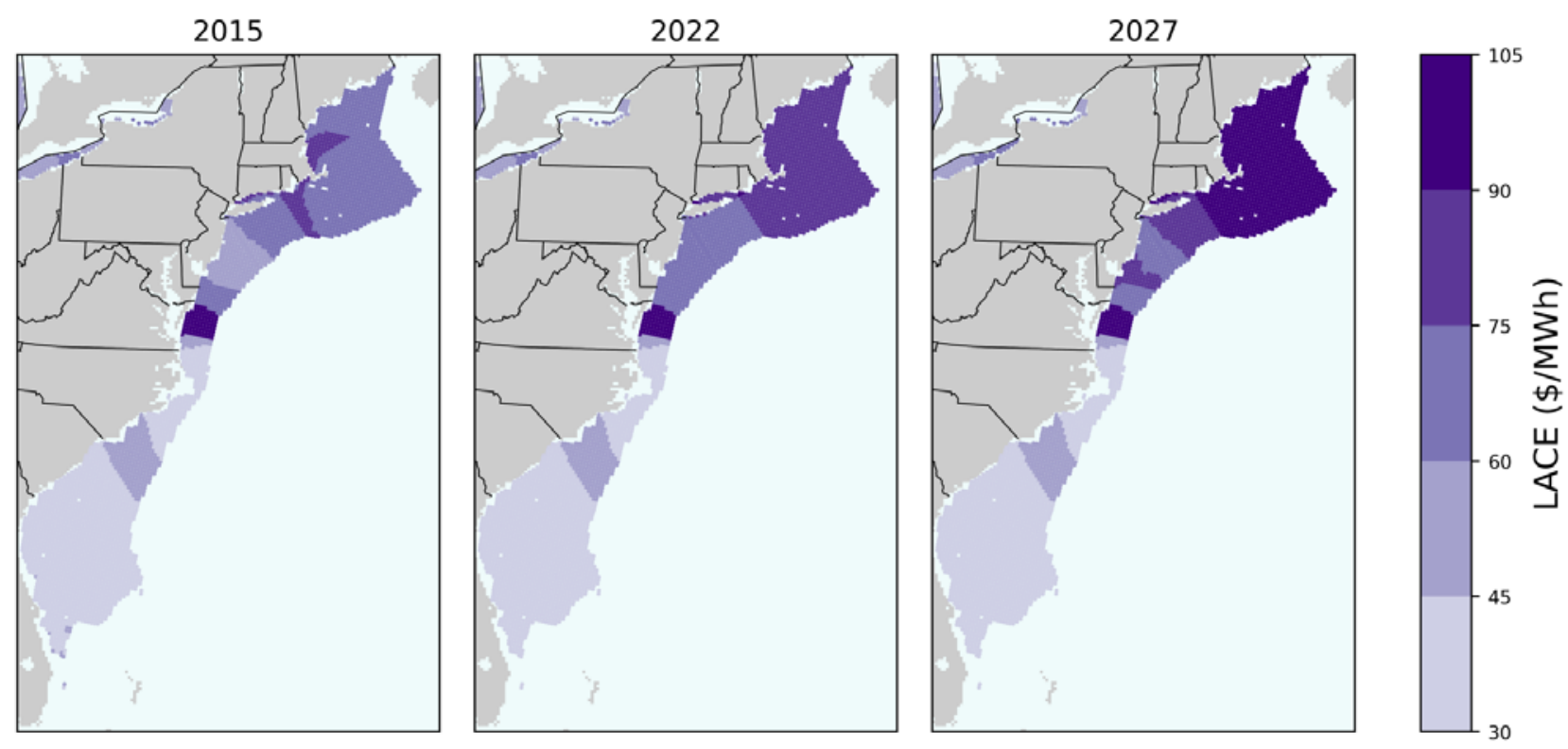

Figure 20. Atlantic Coast spatial LACE distribution (2015-2027)

\subsubsection{Net Value and Economic Potential}

As depicted in Figure 21, net value along the Atlantic Coast is below zero in years 2015 and 2022. By 2027, coastal areas in the Northeast and the Eastern shore of Virginia (southern part of the Delmarva Peninsula) show a net value greater than zero, indicating there is economic potential for offshore wind. The model indicates economic potential in the following states (listed in descending order by the amount of economic potential): Maine, Massachusetts, Rhode Island, Virginia, New Hampshire, New York, and Connecticut (Table 3). In these areas, a relatively low LCOE coincides with a relatively high level of LACE by 2027. There is also a subset of sites (approximately $9 \mathrm{GW}$ of economic potential) in Massachusetts and Rhode Island where the net value was found to be greater than $\$ 15 / \mathrm{MWh}$. Although $9 \mathrm{GW}$ comprises less than $1 \%$ of the total resource estimated for the Atlantic Coast region, it exceeds the combined installed capacity of land-based wind and photovoltaics in the Northeast in 2015 (Beiter and Tian 2016). These sites are predicted to have the highest net value in the United States. A considerable band of coastal areas with a net value between $-\$ 50 / \mathrm{MWh}$ and $\$ 0 / \mathrm{MWh}$ in 2027 spans from far distance locations off the coast of the New England states down to the coast of 
Virginia. Because of higher LCOE and lower LACE, offshore locations in the Southeast show a net value in the range of $-\$ 50 / \mathrm{MWh}$ to $-\$ 140 / \mathrm{MWh}$.

Table 3. Available Capacity with Unsubsidized Economic Potential by State in 2027

\begin{tabular}{ll}
\hline \multicolumn{1}{c}{ State } & $\begin{array}{c}\text { Economic Potential } \\
\text { (in GW) }\end{array}$ \\
\hline Maine & 65 \\
Massachusetts & 55 \\
Rhode Island & 16 \\
Virginia & 4 \\
New Hampshire & 2 \\
New York & 1 \\
Connecticut & 1 \\
\hline
\end{tabular}

Note: Values rounded to integers
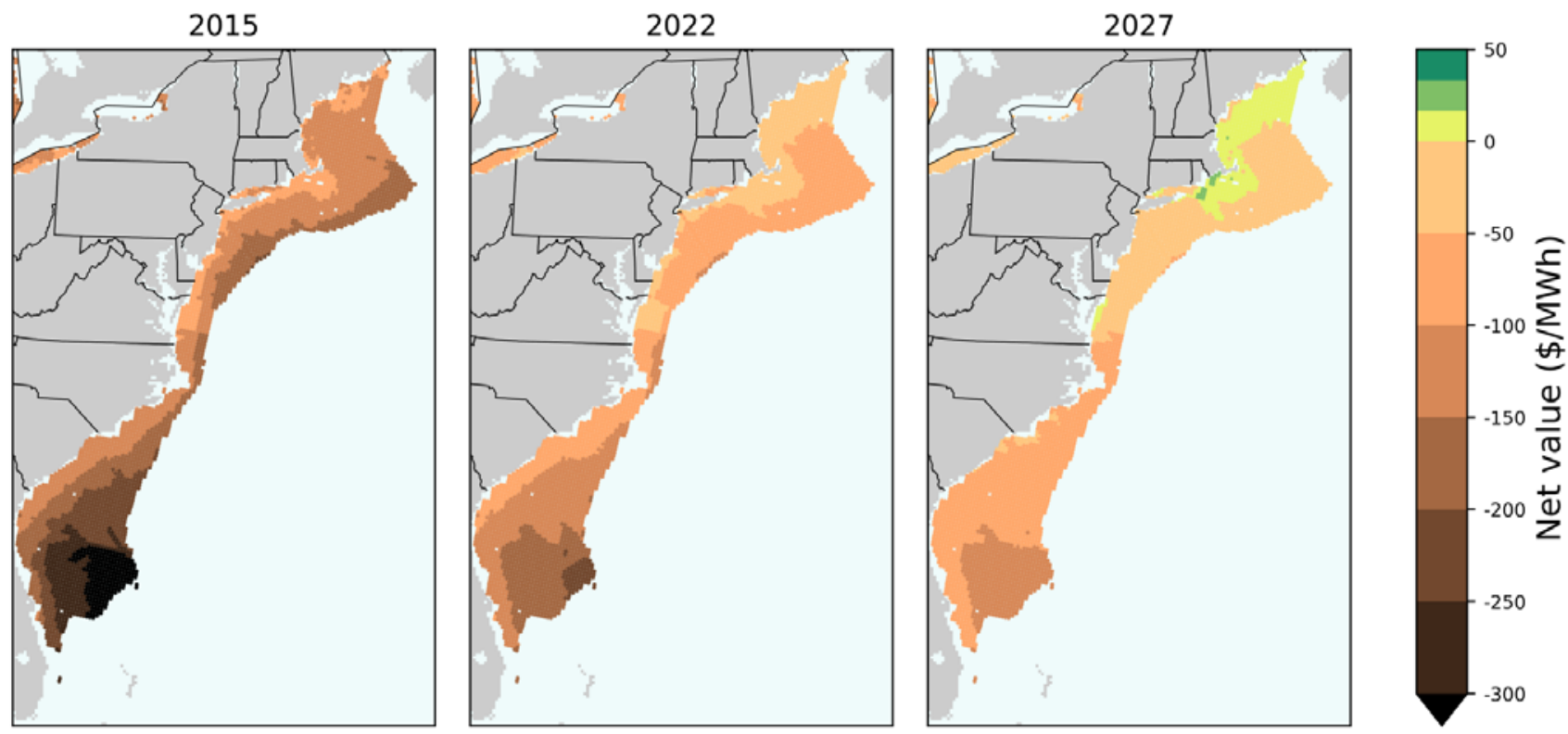

Figure 21. Atlantic Coast spatial net value distribution (2015-2027)

Note: Sites with economic potential (net value $>0$ ) are depicted in shades of green 


\subsection{Pacific Coast}

\subsubsection{Levelized Cost of Energy}

\subsubsection{Spatial Distribution}

LCOE in the Pacific Coast region is generally higher than along the Atlantic Coast. In 2015, LCOE in this region ranges from approximately $\$ 180 / \mathrm{MWh}$ to $\$ 450 / \mathrm{MWh}$ (Figure 22). By 2022, the LCOE range along the Pacific Coast declines from $\$ 130$ to $310 / \mathrm{MWh}$ by 2022 , and to $\$ 95-220 / \mathrm{MWh}$ by 2027. The lowest LCOEs in 2027 are found predominately along the southern coast of Oregon (nearly $3 \mathrm{GW}$ below $\$ 100 / \mathrm{MWh}$ ). Although Oregon and Washington were estimated to have a relatively larger share of low LCOE sites in 2015 and 2022, the LCOE along California's baseline is reduced significantly by 2027 as floating technology is estimated to make considerable cost improvements. The Pacific Coast is generally characterized by strong winds ${ }^{33}$ and deep water that is close to the shore-attributes that are favorable for floating offshore wind technology. The prevalence of floating technology is shown in Figures 23-25. The wave climate in the Pacific Coast region is, however, much more challenging than the climate experienced by the offshore wind industry in the North and Baltic Seas in Europe. These conditions, in which the 1-year significant wave heights average $2.5 \mathrm{~m}$, suggest that a high percentage of weather downtime ${ }^{34}$ happens during marine operations. This weather downtime has implications for installation CapEx, OpEx, and availability losses, and can lead to higher costs for Pacific Coast sites relative to similar sites in the Atlantic Coast or Great Lakes regions. Although it is beyond the scope of this study, technical advancements in vessel design may be able to address the challenges associated with severe meteorological ocean conditions and reduce the LCOE premium for Pacific Coast sites.

\footnotetext{
${ }^{33}$ Note that sites that are south and east of the Channel Islands generally exhibit wind speeds of less than $7.0 \mathrm{~m} / \mathrm{s}$, therefore they have been excluded from the offshore wind technical potential underpinning this analysis as this is generally unsuitable for offshore development.

${ }^{34}$ Weather downtime relates to costs incurred that are associated with "unsafe installation conditions caused by weather" (Maness, Maples, and Smith 2017) and wave conditions.
} 


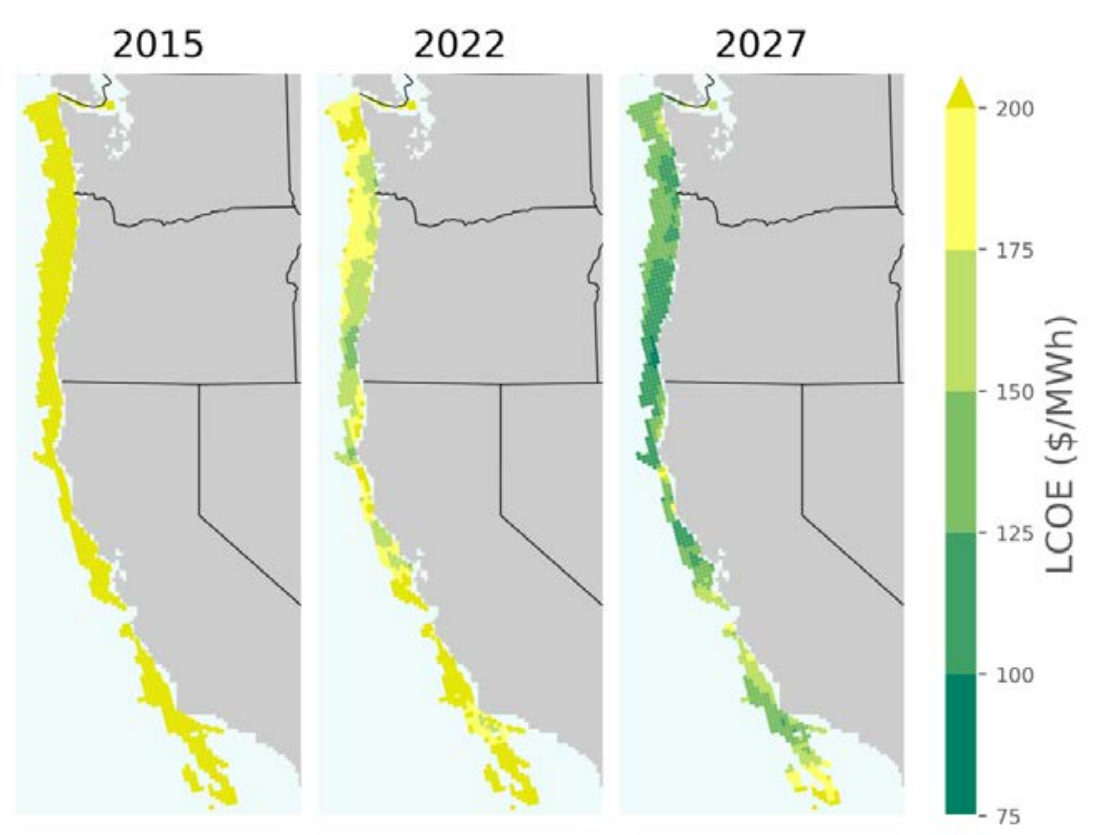

Figure 22. Pacific Coast spatial LCOE distribution (2015-2027)

\subsubsection{Supply Curves}

Despite its vast coastline, the technical resource potential of the Pacific Coast region was estimated at $220 \mathrm{GW}$, which is considerably smaller than the potential calculated for the Atlantic and Gulf Coast regions. This outcome is a result of a rapid increase in water depth in this area (Musial et al. 2016) with respect to distance from shore. The maximum water depth of $1,000 \mathrm{~m}$, assumed for the technical offshore wind resource assessment, is reached at a relatively close distance from shore, thereby limiting the number of sites to a relatively narrow strip in deeper water that is $20 \mathrm{~km}$ to $60 \mathrm{~km}$ from shore (Musial et al. 2016). Note that $210 \mathrm{GW}$ out of $220 \mathrm{GW}$ of this resource capacity in 2015 is in water depths where floating technology was selected by the model applied for this study.

A total of $10 \mathrm{GW}$ of capacity was estimated to be available by 2015 at an LCOE below \$225/MWh and $40 \mathrm{GW}$ below \$250/MWh. Although these LCOE levels are high compared to the Atlantic Coast, they represent the initial baseline costs for nascent floating technology derived from European prototypes. The model shows that floating technology is the least-cost option for a vast majority of viable sites along the Pacific Coast. The decline in cost for floating technology is calculated to be steeper than fixed-bottom technology over the same period because of greater opportunities for innovation, supply chain, risk reduction, and infrastructure development that will spur decreases for floating technology. By 2022, approximately $10 \mathrm{GW}$ of capacity is estimated to be available below $\$ 150 / \mathrm{MWh}$, and in 2027 , nearly $3 \mathrm{GW}$ of capacity was calculated to be available below $\$ 100 / \mathrm{MWh}$ with $70 \mathrm{GW}$ below $\$ 125 / \mathrm{MWh}$. By 2027 , California's available capacity between $\$ 100$ and $\$ 115 / \mathrm{MWh}$ is estimated to be more than 4 GW. In Oregon, a total of $15 \mathrm{GW}$ is expected to become available by 2027 at an LCOE between $\$ 95$ and $\$ 115 / \mathrm{MWh}$, whereas the state of Washington only has one site that reaches $\$ 115 / \mathrm{MWh}$ by 2027. 


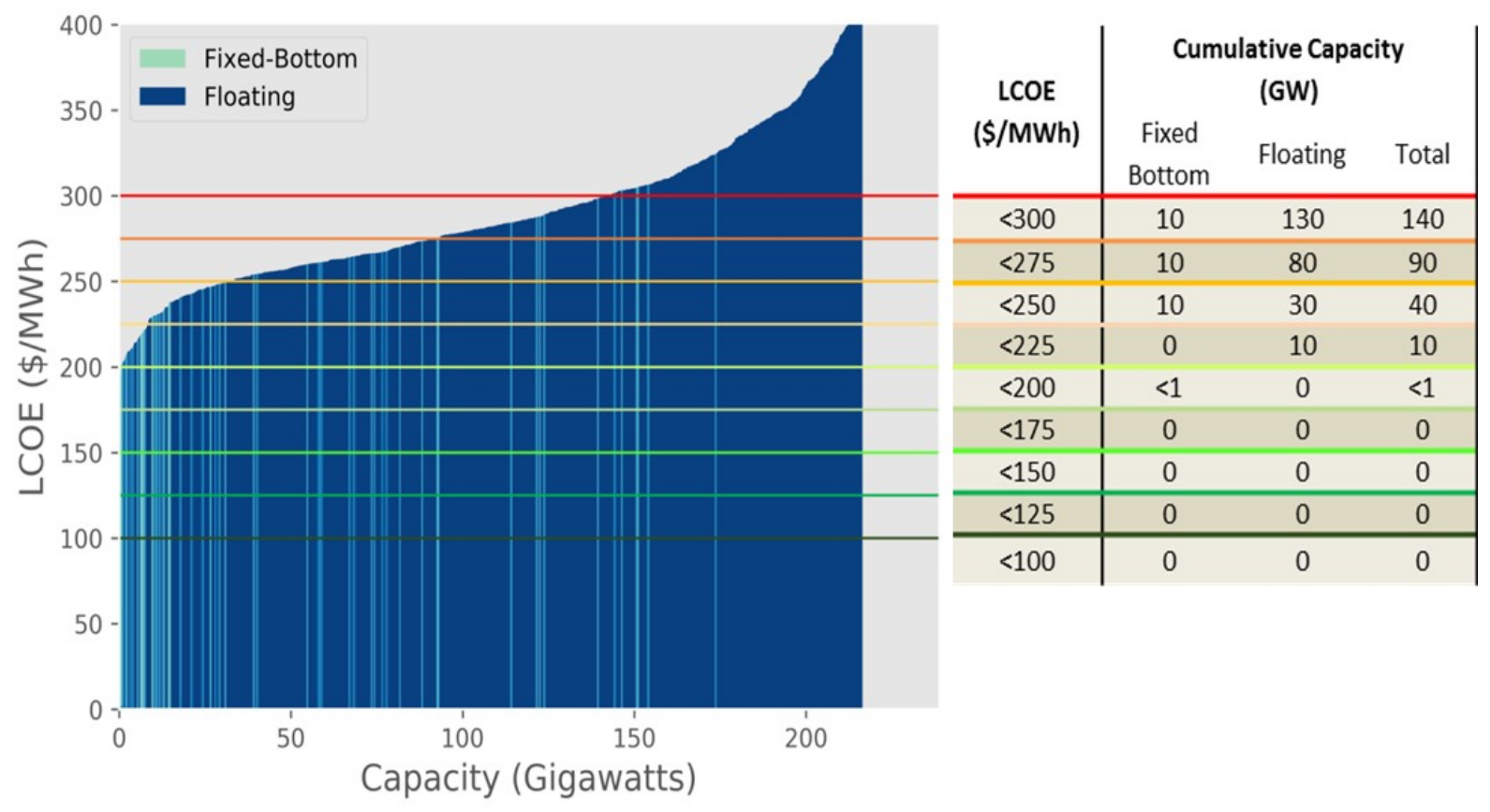

Figure 23. 2015 Pacific Coast supply curve

Note: Cumulative capacity in table rounded to the nearest $10(\mathrm{LCOE}<\$ 300 / \mathrm{MWh})$ and one (LCOE<200\$/MWh).

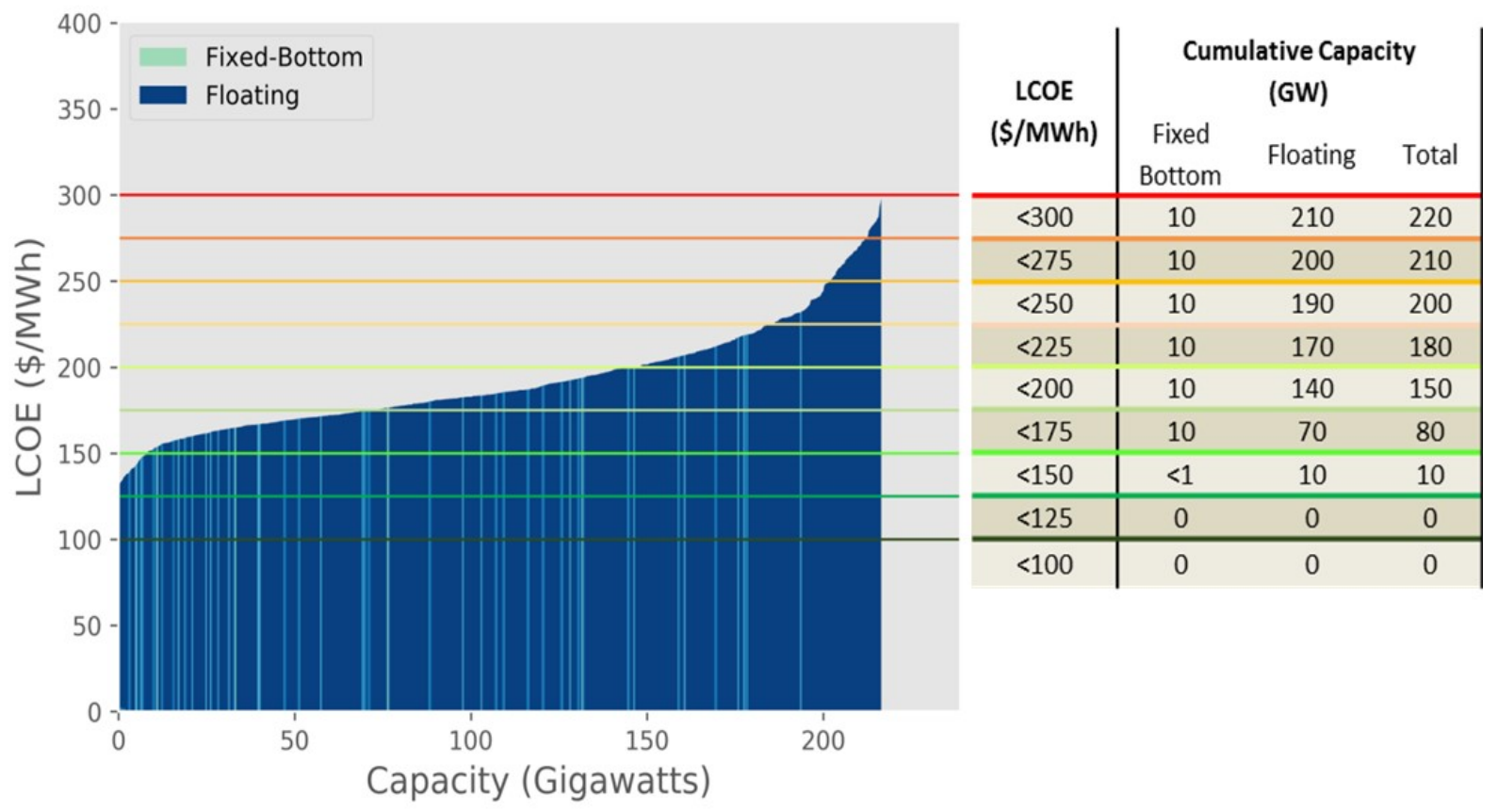

Figure 24. 2022 Pacific Coast supply curve

Note: Cumulative capacity in table rounded to the nearest 10 (LCOE $<\$ 300 / \mathrm{MWh})$ and one (LCOE<150\$/MWh).

This report is available at no cost from the National Renewable Energy Laboratory at www.nrel.gov/publications. 


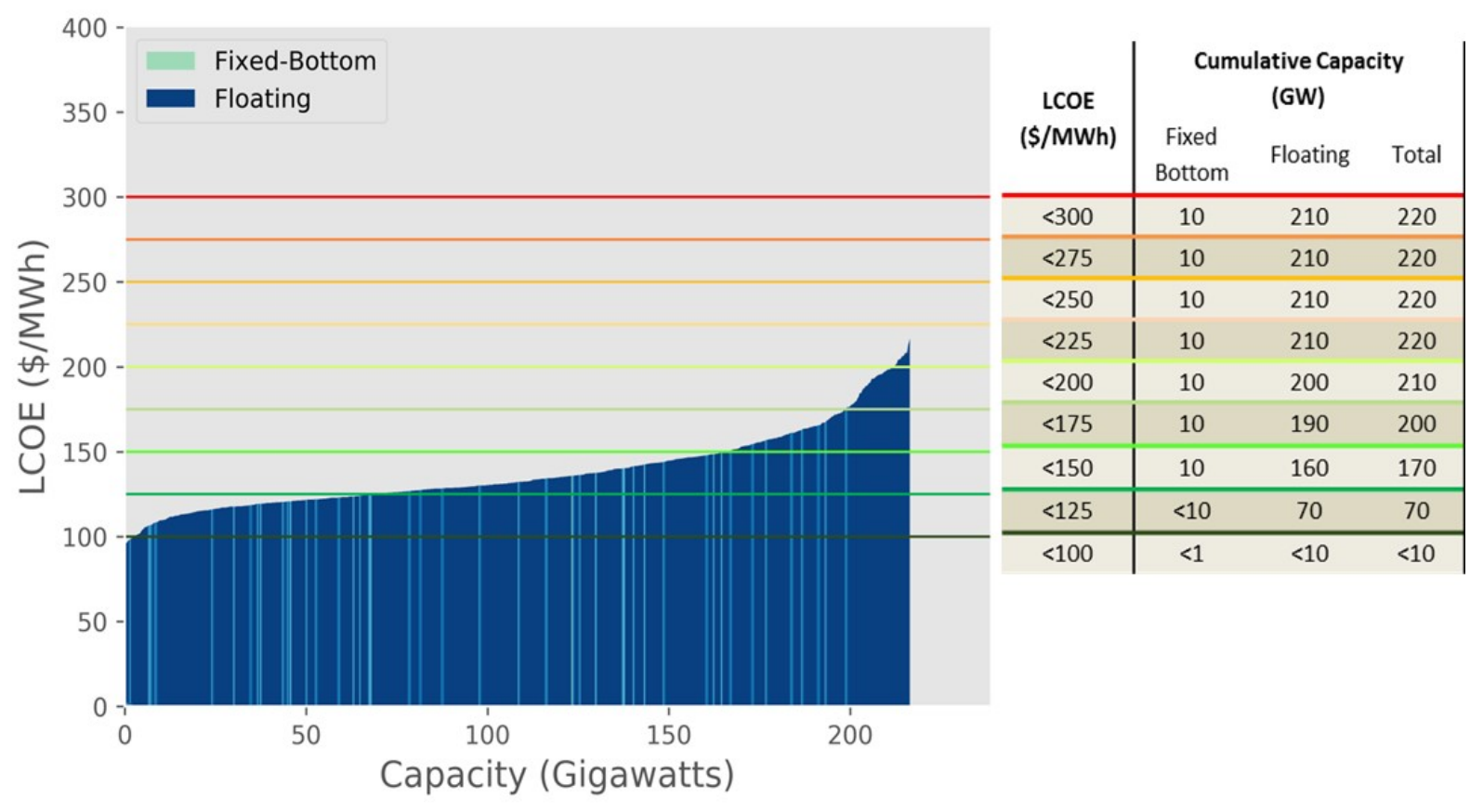

Figure 25. 2027 Pacific Coast supply curve

Note: Cumulative capacity in table rounded to the nearest 10 (LCOE $<\$ 300 / \mathrm{MWh}$ ) and one (LCOE<100\$/MWh).

\subsubsection{Levelized Avoided Cost of Energy}

As indicated in Section 3, the variation in estimated LACE among the Pacific Coast sites is relatively small, ranging from $\$ 45-54 / \mathrm{MWh}$ in 2015 , $\$ 49-52 / \mathrm{MWh}$ in 2022 , and $\$ 45-60 \$ / \mathrm{MWh}$ in 2027. This is likely the result of limited availability of wholesale electricity data in the Pacific Northwest (see Section 3 for more details) and relatively flat generation price projections by EIA (2014) (e.g., a compound annual growth rate of $-0.2 \%$ in the Western Electricity Coordinating Council California region and $2.1 \%$ compound annual growth rate for the Western Electricity Coordinating Council Northwest region between 2015 and 2027). 

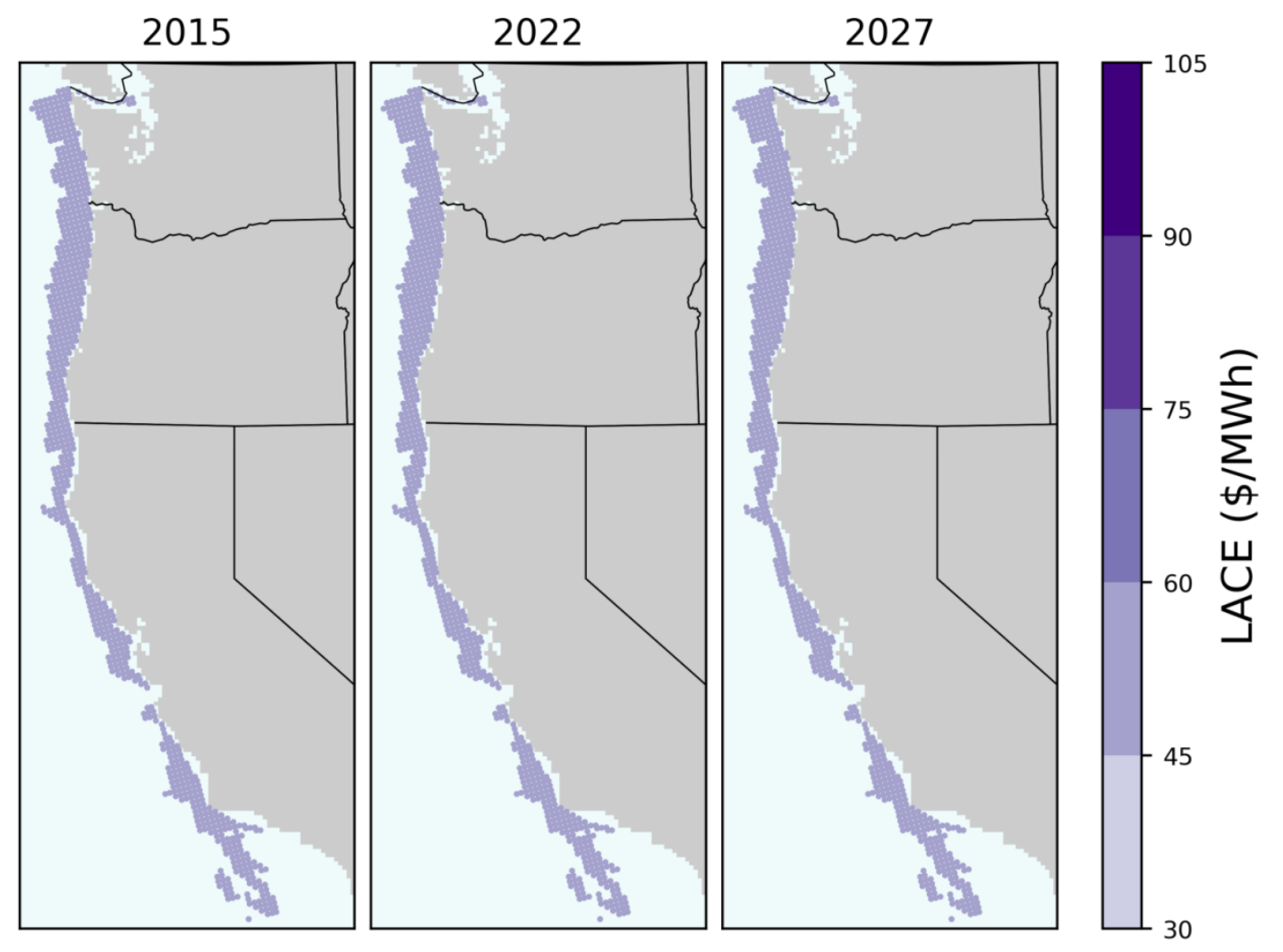

Figure 26. Pacific Coast spatial LACE distribution (2015-2027)

\subsubsection{Net Value and Economic Potential}

In 2015, the Pacific Coast has a large difference between LACE and LCOE (a net value below zero), and this gap narrows through 2027. By that year, without considering any additional state or federal policy incentives, large areas along the Pacific Coast are estimated to have a net value between $-\$ 50$ and $-\$ 100 / \mathrm{MWh}$. The highest net value is calculated for an area in southern Oregon (off the coast of Port Orford) with a net value range of $-40 \$$ to $-50 \$ / \mathrm{MWh}$ in 2027. 

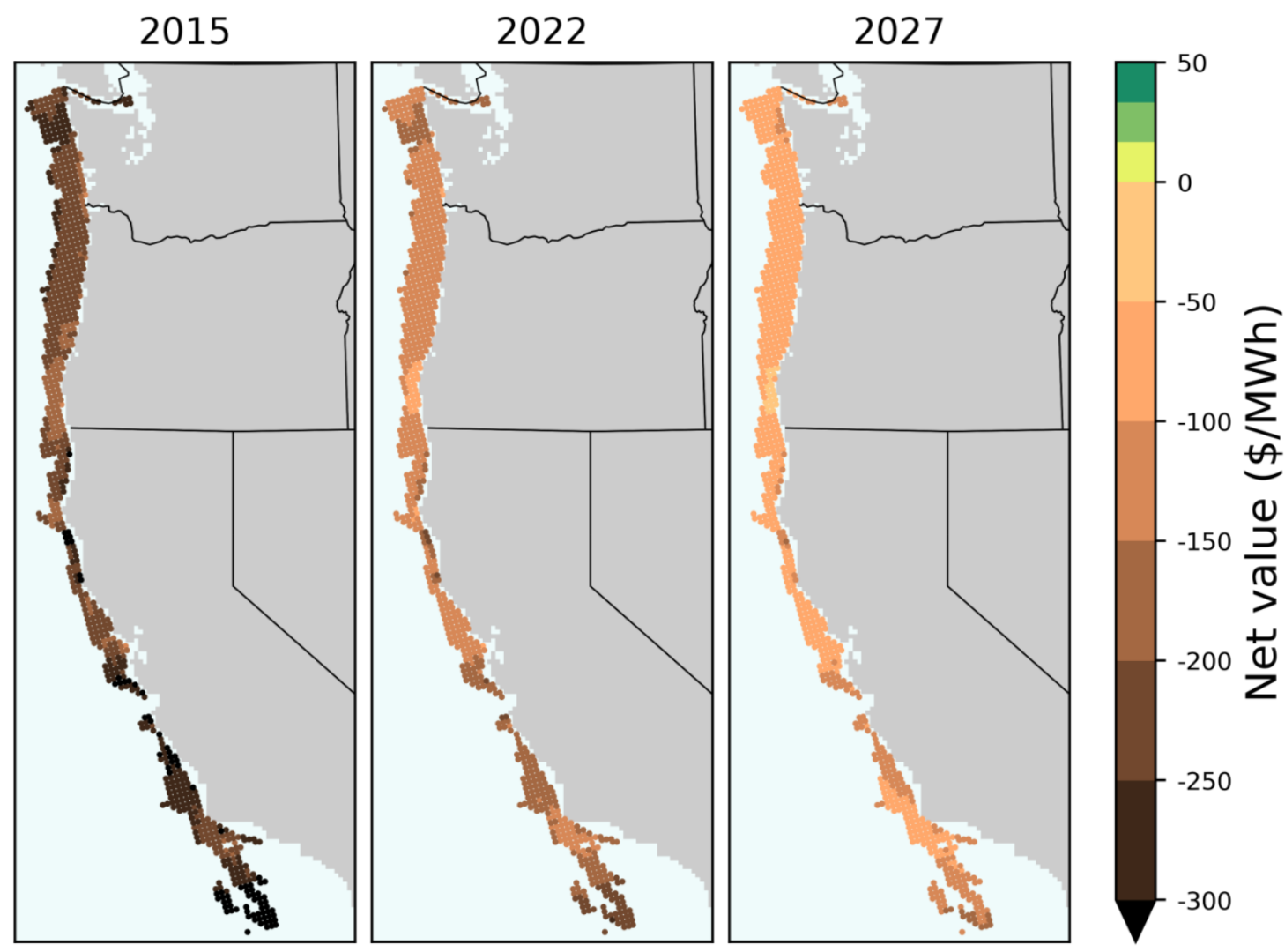

Figure 27. Pacific Coast spatial net value distribution (2015-2027)

Note: Sites with economic potential (net value $>0$ ) are depicted in shades of green.

\subsection{Gulf Coast}

\subsubsection{Levelized Cost of Energy}

\subsubsection{Spatial Distribution}

Offshore wind resource studies conducted by NREL in 2016 calculated the technical offshore wind resources for each state and found that the Gulf states had among the highest quantity of offshore wind resource in the United States. However, the quality of that resource was found to be lower as most of the sites are below a 8-m/s average wind speed (Musial et al. 2016a). Nevertheless, the resource assessment shows that Florida, Louisiana, and Texas rank second, third, and fourth nationally in terms of total offshore wind resource, with significant area in shallow water. Shallow water may be an advantage to help sites in some of these areas achieve competitive LCOE levels.

Figure 28 depicts the spatial distribution of LCOE in the Gulf Coast region between 2015 and 2027. In 2015, LCOE ranges from $\$ 140$ to $\$ 385 / \mathrm{MWh}$, led by locations in Texas and Louisiana. By 2022, this range declines to $\$ 105-260 / \mathrm{MWh}$. By 2027, this range declines further to $\$ 90$ 185/MWh. The influence of water depth and distance from shore seems clearly distinguishable in the Gulf Coast with the highest-cost sites farther from shore. The Gulf states all have areas where 
LCOE drops below $\$ 125 / \mathrm{MWh}$. In particular, Louisiana and Texas both have significant resources below \$100/MWh by 2027.

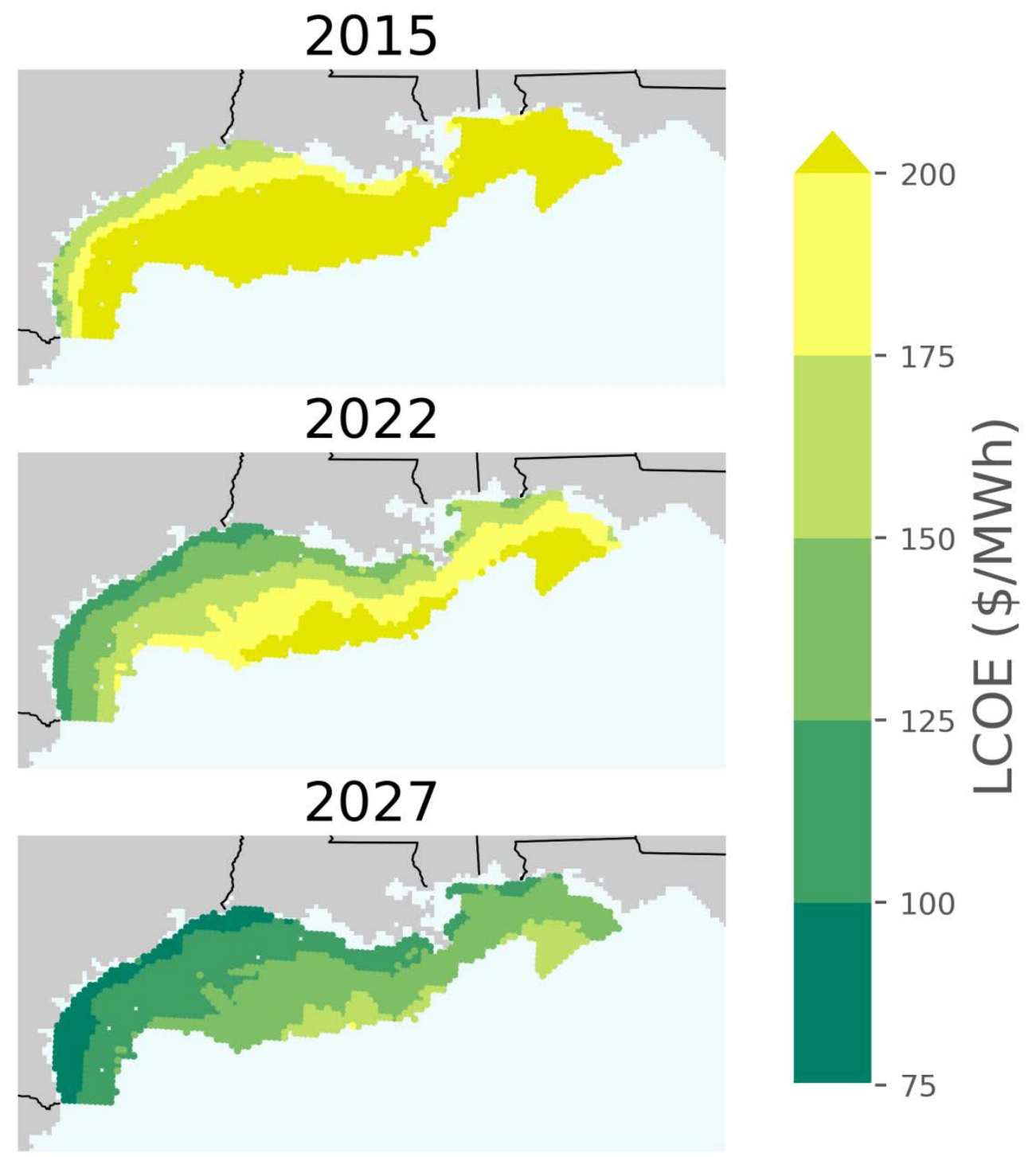

Figure 28. Gulf Coast spatial LCOE distribution (2015-2027) 


\subsubsection{Supply Curves}

With nearly $600 \mathrm{GW}$ of technical offshore wind energy resource potential, the Gulf Coast is the second largest coastal region after the Atlantic Coast region. In 2015, nearly $3 \mathrm{GW}$ of capacity are estimated to be available at LCOE levels less than \$150/MWh and approximately $50 \mathrm{GW}$ are available at LCOE less than $\$ 175 / \mathrm{MWh}$. Fixed-bottom technology is predominant among leastcost sites. In 2015, Figure 29 shows that fixed-bottom technology comprises nearly all of the capacity at LCOE levels below $\$ 200 / \mathrm{MWh}$. Over time, as floating technology costs decrease, the share of floating technology increases. In 2027, Figure 30 shows that in 2027, 75\% of the sites that are below an LCOE of $\$ 100 / \mathrm{MWh}$ are still fixed-bottom sites.

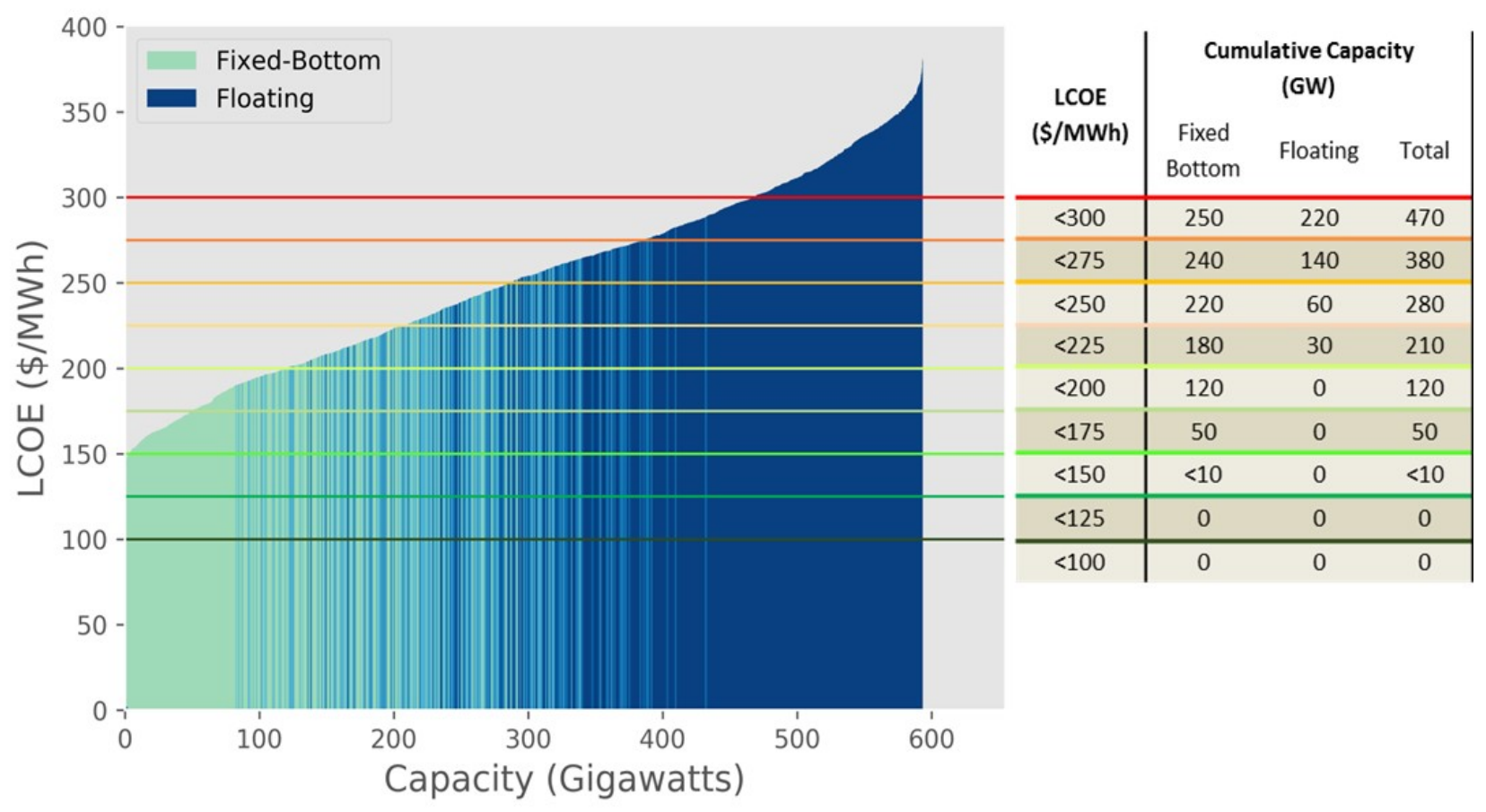

Figure 29. 2015 Gulf Coast supply curve

Note: Cumulative capacity in table rounded to the nearest 10 (LCOE $<\$ 300 / \mathrm{MWh}$ ) and one (LCOE<150\$/MWh). 


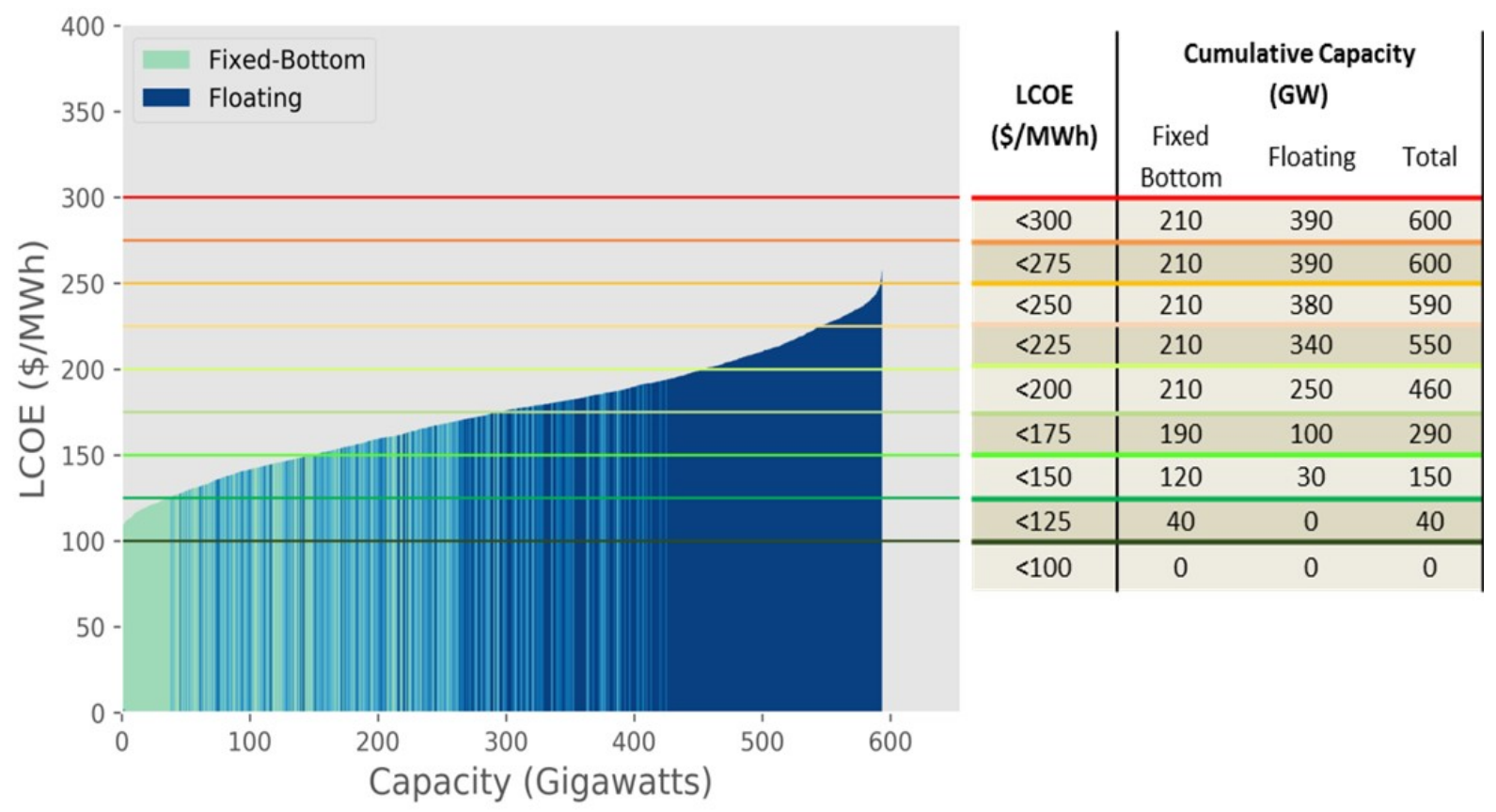

Figure 30. 2022 Gulf Coast supply curve

Note: Cumulative capacity in table rounded to the nearest 10.

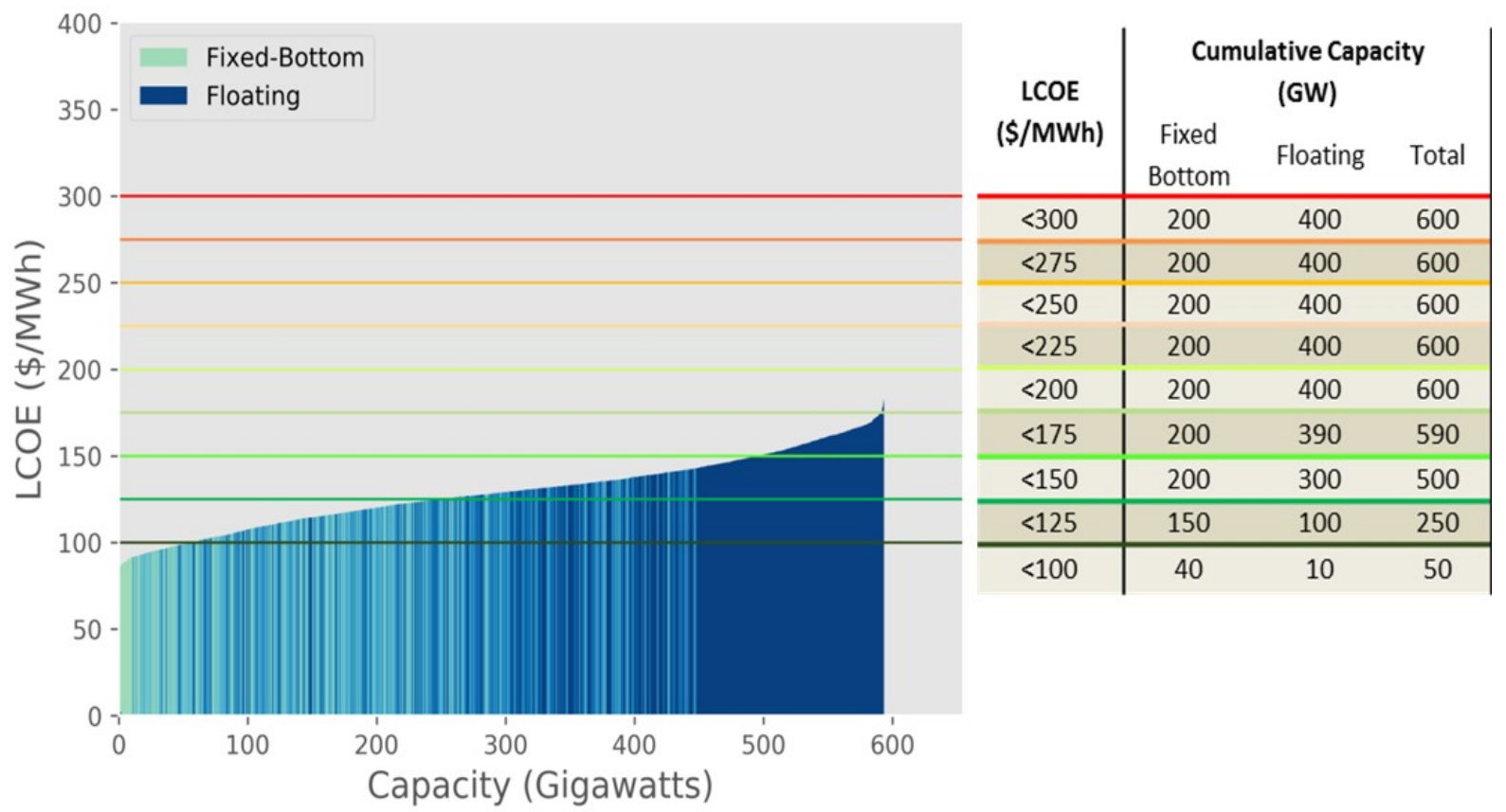

Figure 31. 2027 Gulf Coast supply curve

Note: Cumulative capacity in table rounded to the nearest 10.

This report is available at no cost from the National Renewable Energy Laboratory at www.nrel.gov/publications. 


\subsubsection{Levelized Avoided Cost of Energy}

In 2015, LACE in the Gulf Coast is lowest around Florida (\$39-43/MWh) and Texas (\$44$62 / \mathrm{MWh}$ ) with Alabama, Louisiana, and Mississippi ranging between $\$ 39$ and $\$ 50 / \mathrm{MWh}$. These ranges generally increase, although some EIA estimates suggest that some areas might decrease in marginal generation prices through 2027 (EIA 2016). By 2027, the LACE range for the Gulf states is estimated to be between $\$ 36$ and $\$ 71 / \mathrm{MWh}$.

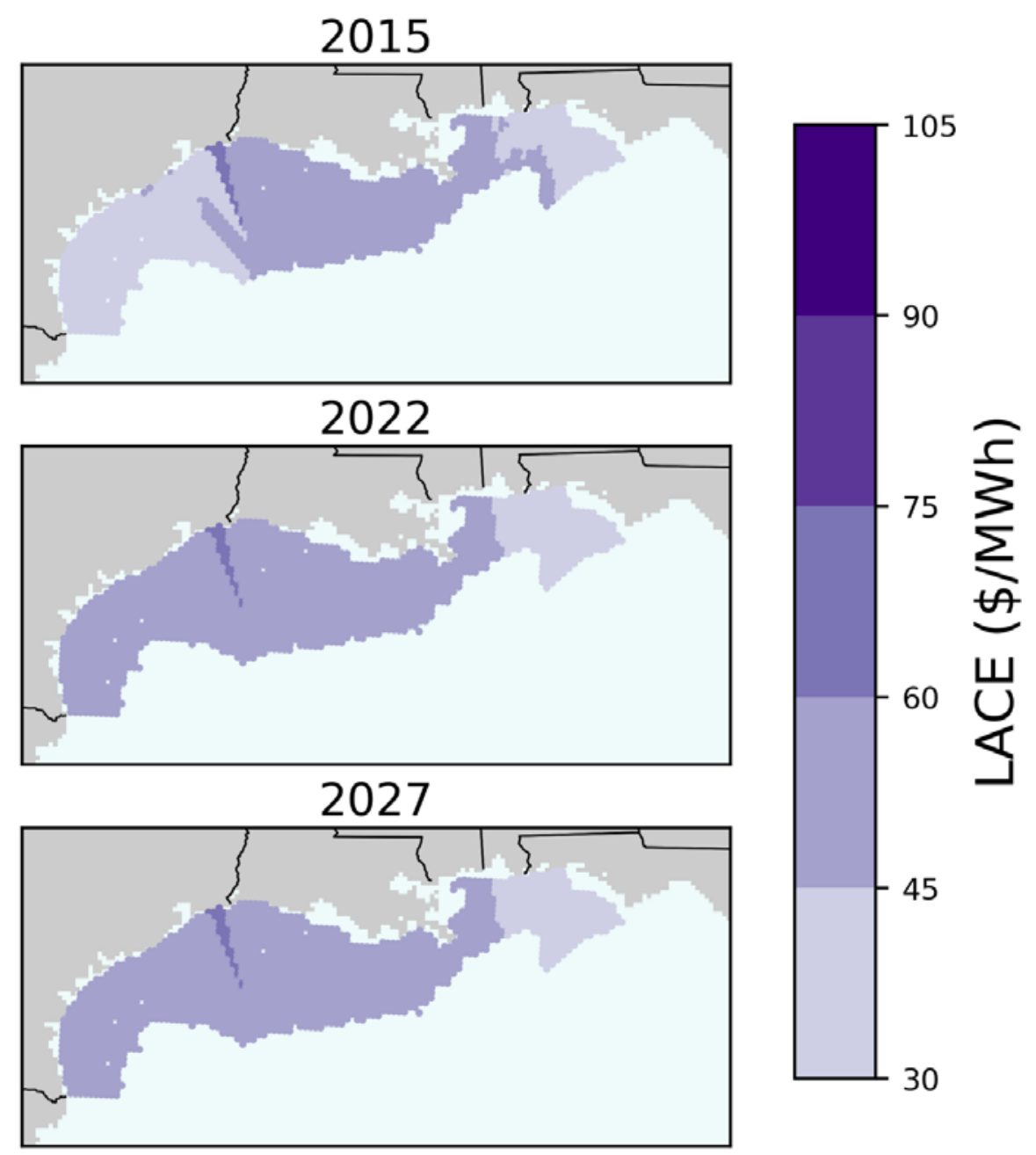

Figure 32. Gulf Coast spatial LACE distribution (2015-2027)

\subsubsection{Net Value and Economic Potential}

Figure 33 shows the net value of offshore wind sites in the Gulf of Mexico from 2015 through 2027. The maps show that regions far from shore, which also have deeper water, have a lower net value. In 2015, the figure shows a wide region with a net value less than $-300 \$ / \mathrm{MWh}$ (in dark brown), whereas those sites closest to shore range between $-\$ 90 / \mathrm{MWh}$ and $-\$ 110 / \mathrm{MWh}$. By 2027 , the net value of the region increases with some sites reaching $-\$ 19 / \mathrm{MWh}$. These sites are located over wide areas of Texas and western Louisiana near the shore. Although none of the 
sites in the Gulf Coast exceed a net value of zero (i.e., no economic potential was estimated within the time frame considered) many sites are close to the zero-net-value threshold, which should be evaluated in context of the general uncertainties related to the assumptions and data used in this assessment.

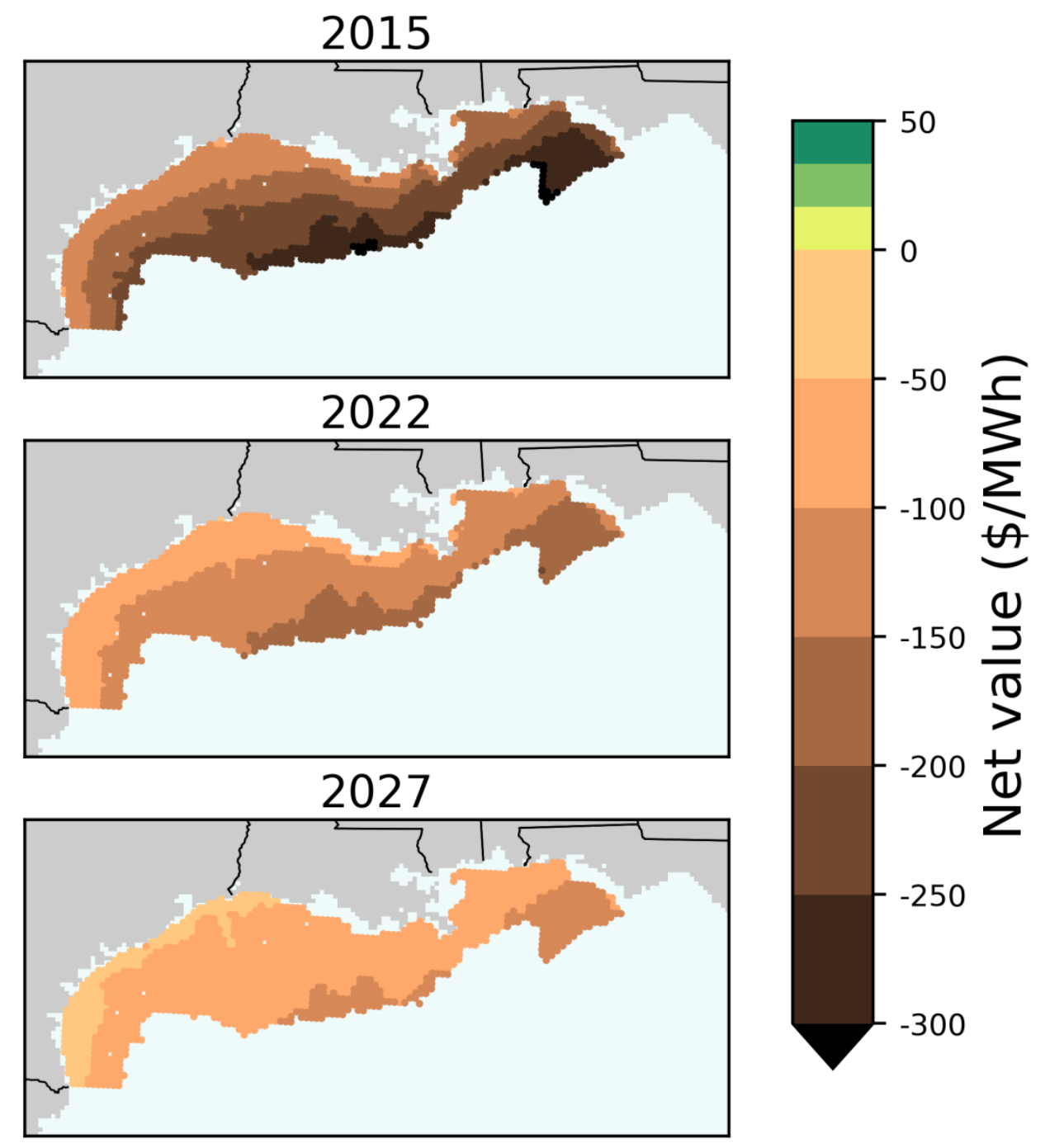

Figure 33. Gulf Coast spatial net value distribution (2015-2027)

Note: Sites with economic potential (net value $>0$ ) are depicted in shades of green. 


\subsection{Great Lakes}

\subsubsection{Levelized Cost of Energy}

\subsubsection{Spatial Distribution}

The 2016 Offshore Wind Energy Resource Assessment for the United States report (Musial et al. 2016) found that the Great Lakes had about $136 \mathrm{GW}$ of technical resource capacity; a low quantity because of a conservative assumption that none of the water above $60 \mathrm{~m}$ in depth would be feasible for development due to formation of lake ice. ${ }^{35}$ The quality of the offshore wind resource for the Great Lakes region was found to be very good and the general absence of extreme meteorological ocean events (wind and waves) helps keep costs low. The unique design concern is with the presence of lake ice, which can add structural load burdens and hence cost. However, because of their engineering design, fixed-bottom structures are considered to be managed well in this environment. States such as Michigan, Ohio, and Wisconsin have the top resource capacity in this region.

Figure 34 shows modeled data with LCOE variations between \$130/MWh and \$270/MWh in 2015 across locations in the Great Lakes. In 2022, the figure shows that this range reduces to $\$ 95 / \mathrm{MWh}$ and $\$ 180 / \mathrm{MWh}$ and, by 2027 , from $\$ 75 / \mathrm{MWh}$ to $\$ 135 / \mathrm{MWh}$. The Great Lakes are relatively homogenous with respect to the physical variables considered in this assessment that might influence cost. The variability of the wind resource within the region seems to explain the majority of the variations in LCOE. The least-cost locations found are in Lake Erie, Lake Michigan, and Saginaw Bay in Lake Huron, which have multiple sites with strong wind resources that are close to shore. Note that the cost model has not yet been upgraded to include cost adders that may be needed to account for the impacts of ice exposure to the substructure, increased operating costs that may be required for accessibility in the winter, or technical availability impacts. If these cold weather variables are included, it is likely that the LCOEs for the region may increase.

\footnotetext{
${ }^{35}$ If the deep water exclusion were removed for the Great Lakes region, $519 \mathrm{GW}$ of technical resource capacity would be available (Musial et al. 2016).
} 


\section{5}
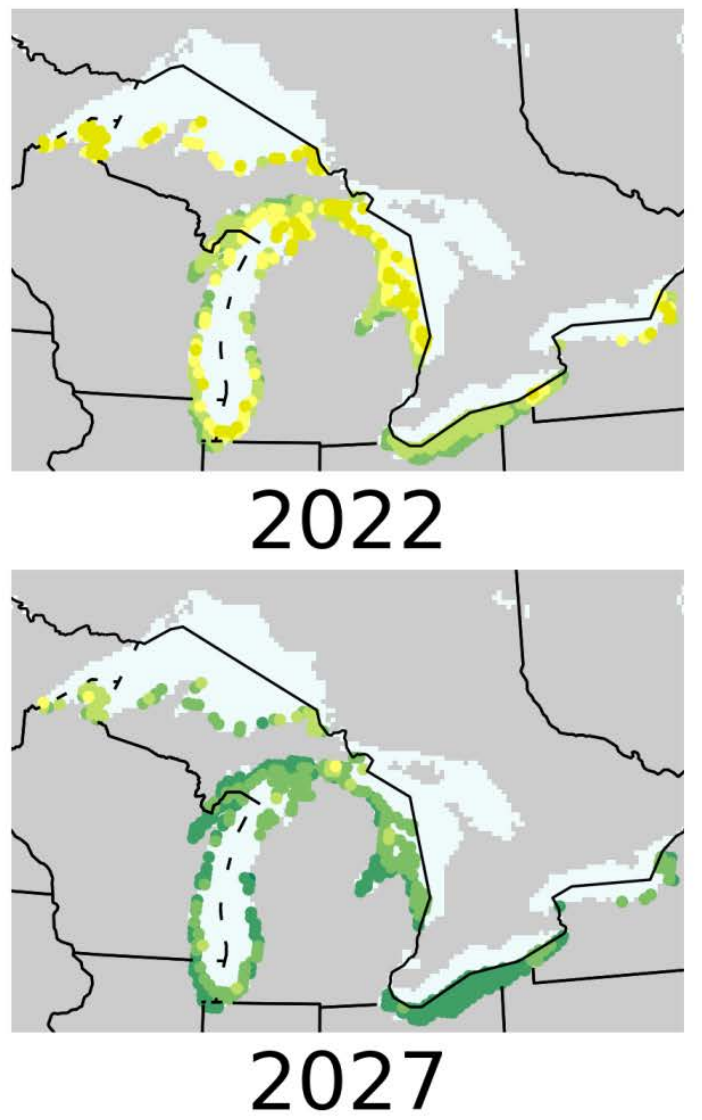

$-200$
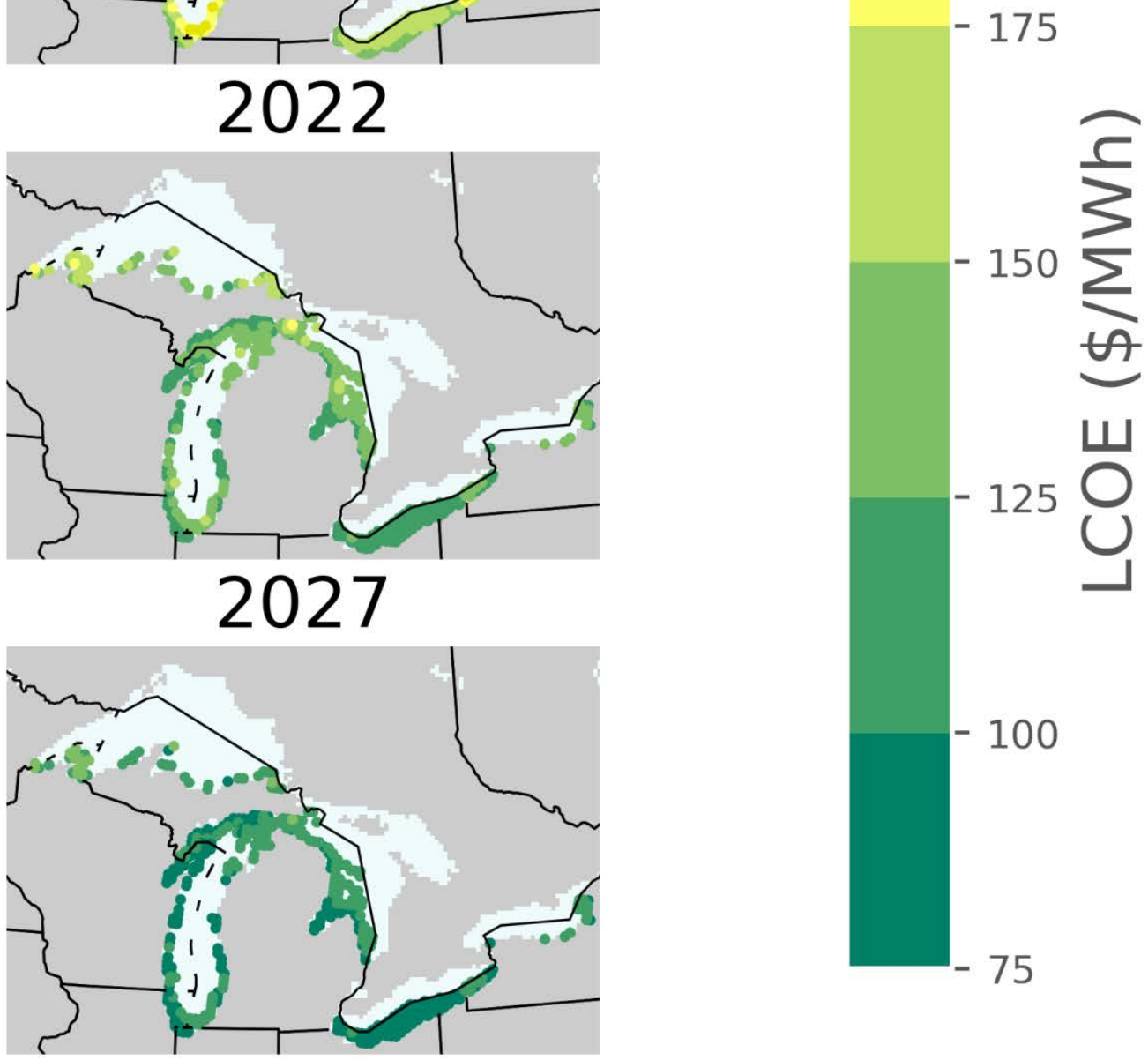

Figure 34. Great Lakes spatial LCOE distribution (2015-2027) 


\subsubsection{Supply Curves}

Approximately $100 \mathrm{GW}$ of offshore wind energy capacity was estimated for the Great Lakes area as shown in Figures 3537. Because of the uncertainty of floating offshore wind technology's ability to survive freshwater ice floes, ice regions of the Great Lakes where depths are greater than $60 \mathrm{~m}$ were excluded. As a result, fixed-bottom technology comprises all of the available resource in the Great Lakes shown in these figures. Figure 35 shows that in 2015, approximately $20 \mathrm{GW}$ are available below an LCOE of $\$ 150 / \mathrm{MWh}$. By 2027, Figure 37 shows that areas in the Great Lakes are among those in the United States with the lowest LCOE, with $60 \mathrm{GW}$ (over half) below $\$ 100 / \mathrm{MWh}$ and all of the resource area below $\$ 125 / \mathrm{MWh}$.

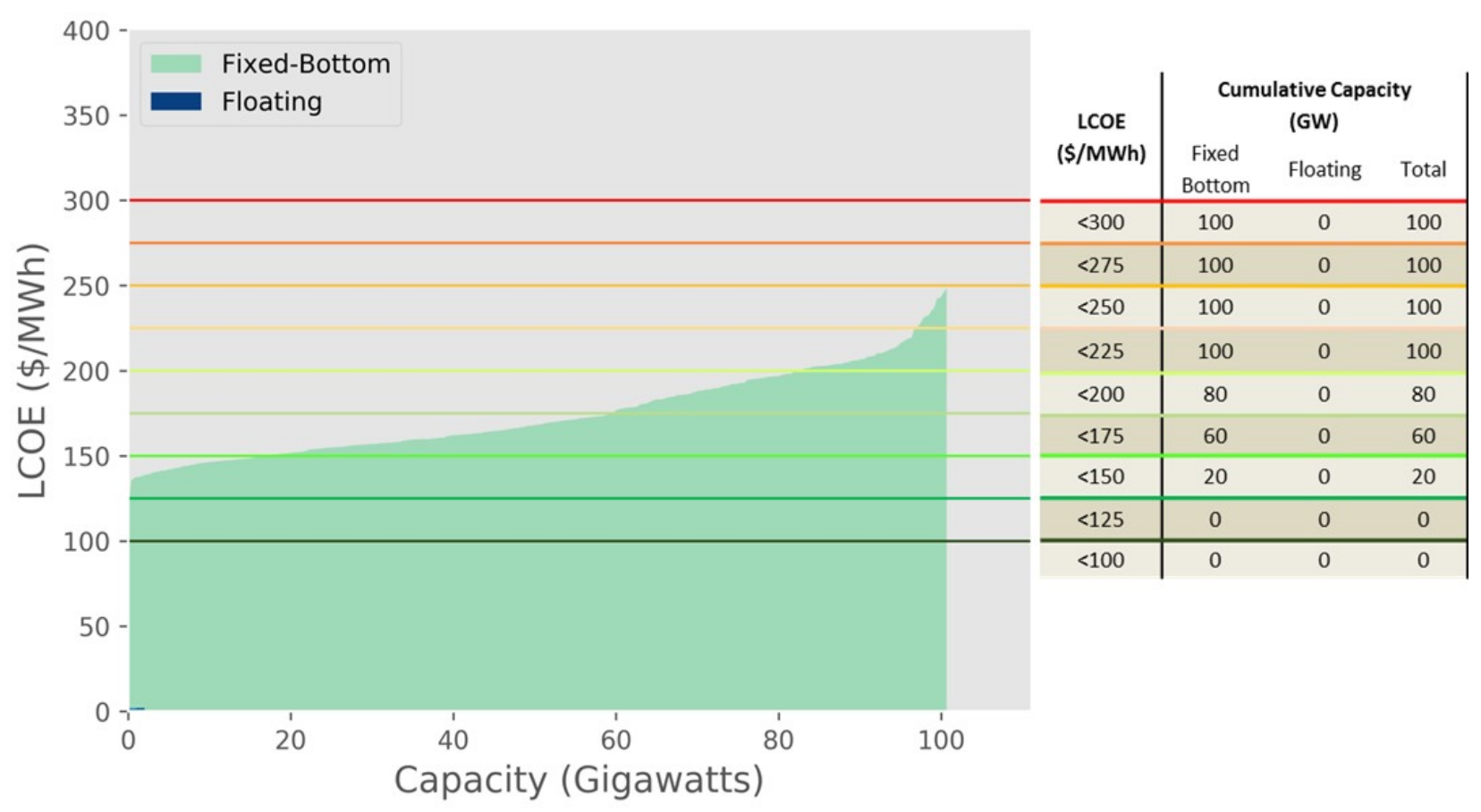

Figure 35. 2015 Great Lakes supply curve

Note: Cumulative capacity in table rounded to the nearest 10. 


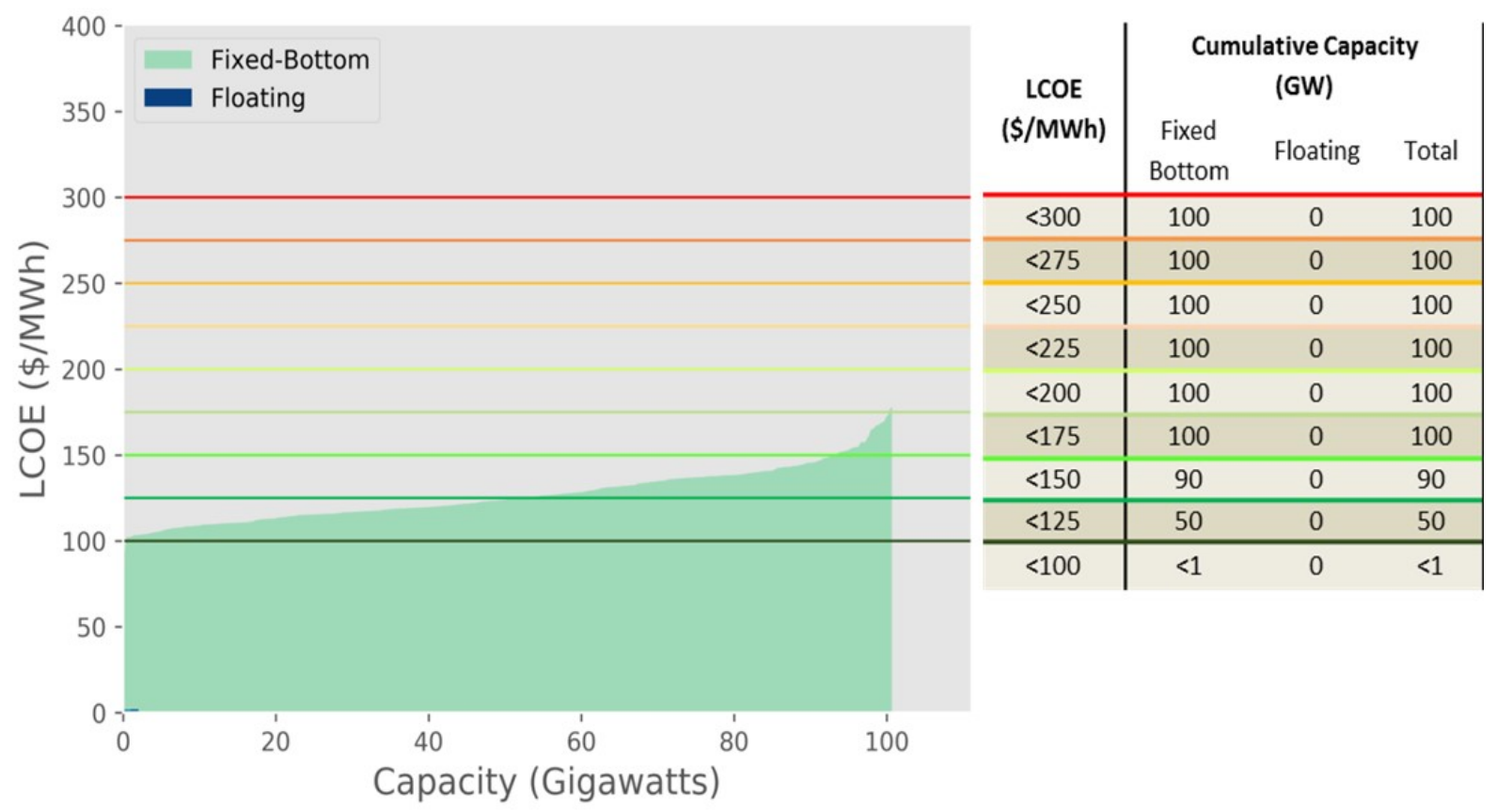

Figure 36. 2022 Great Lakes supply curve

Note: Cumulative capacity in table rounded to the nearest 10.

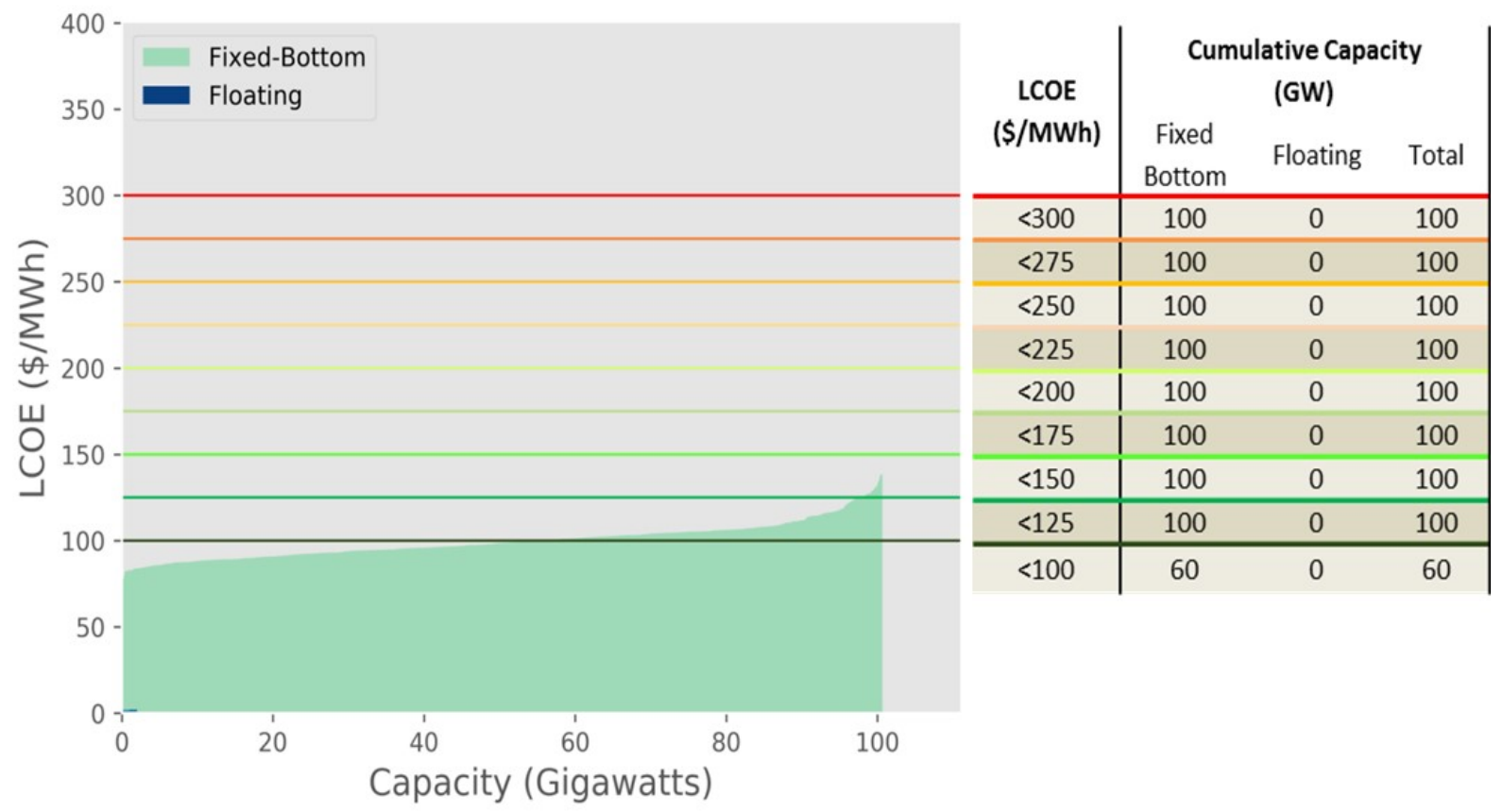

Figure 37. 2027 Great Lakes supply curve

Note: Cumulative capacity in table rounded to the nearest 10. 


\subsubsection{Levelized Avoided Cost of Energy}

The range of LACE increases from $\$ 42-65 / \mathrm{MWh}$ in 2015 to $\$ 42-72 / \mathrm{MWh}$ by 2027 . Areas with higher levels of LACE are located in the northern parts of Lake Michigan and Lake Erie. The western parts of Lake Superior and Lake Huron are among those with relatively low LACE estimates.

\section{5}

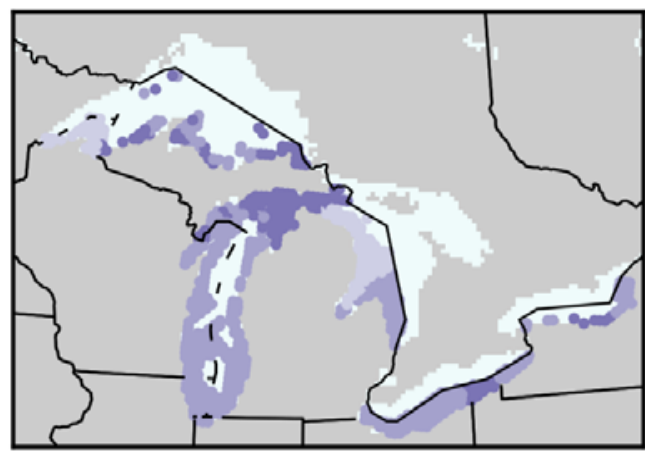

2022

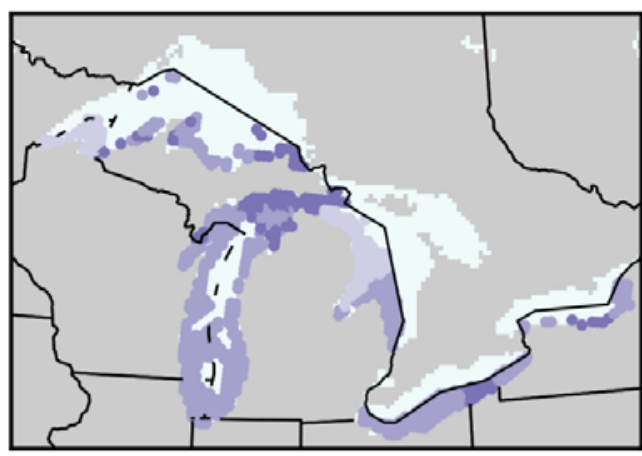

2027
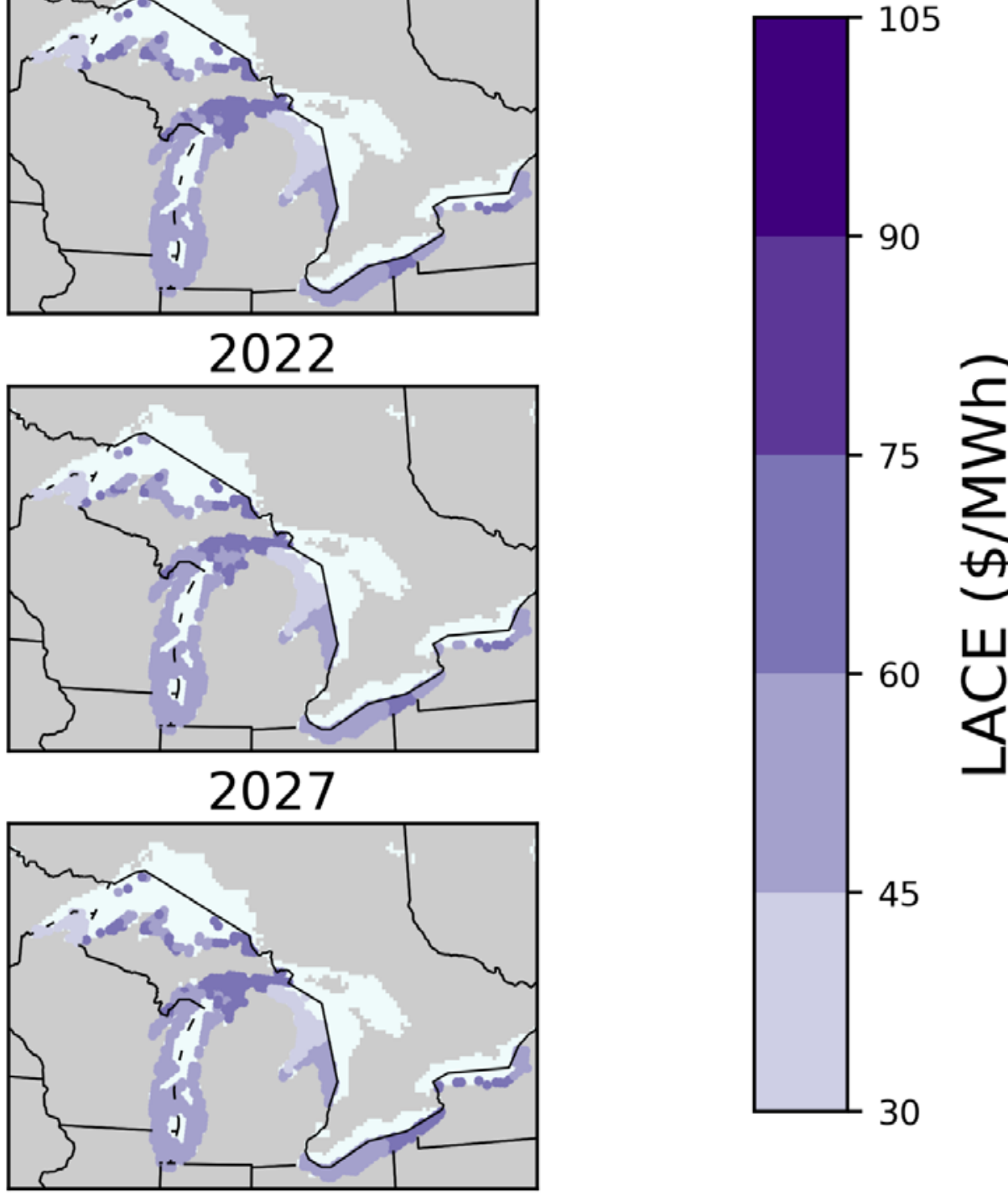

Figure 38. Great Lakes spatial LACE distribution (2015-2027) 


\subsubsection{Net Value and Economic Potential}

Although the Great Lakes region has some of the least-cost offshore wind locations estimated in this assessment as a result of relatively high wind speeds close to shore, in the time frame considered it does not show any sites with a net value greater than zero (i.e., lack of economic potential). However, by 2027, $75 \mathrm{GW}$, or three-quarters of the available $100 \mathrm{GW}$ in the Great Lakes, has a net value between $-\$ 50 / \mathrm{MWh}$ and $-\$ 19 / \mathrm{MWh}$, which is nearing the threshold of economic viability for some sites without considering policy incentives.
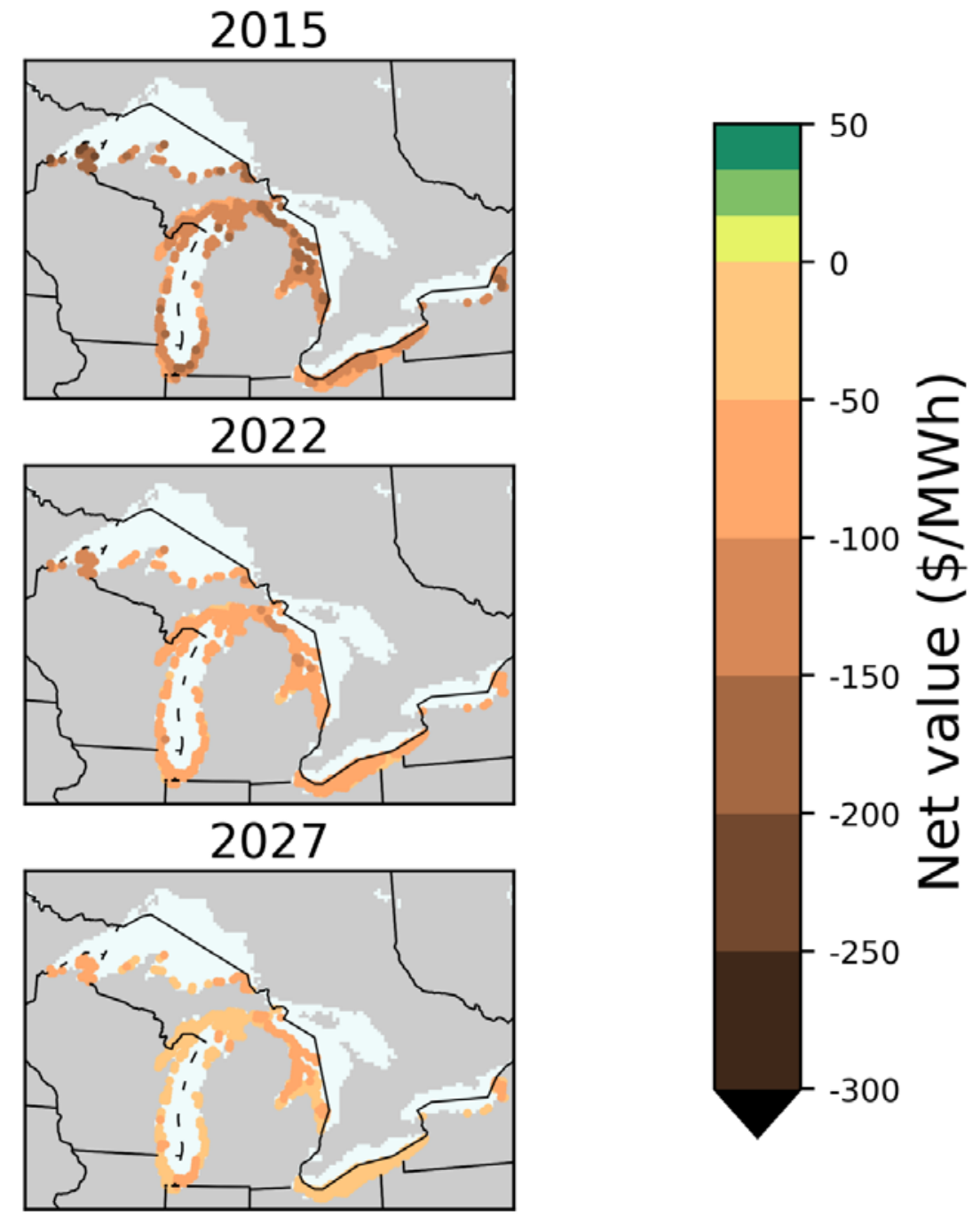

Figure 39. Great Lakes spatial net value distribution (2015-2027)

Note: Sites with economic potential (net value $>0$ ) are depicted in shades of green. 


\subsection{Hawaii}

\subsubsection{Levelized Cost of Energy}

\subsubsection{Spatial Distribution}

The Hawaiian Islands are surrounded by 1,001,486 $\mathrm{km}^{2}\left(386,676 \mathrm{mi}^{2}\right)$ of gross offshore wind resource area, but most of that resource is unsuitable for offshore wind development because of excessive water depths, low wind speeds, or inaccessibility to load. NREL's 2016 resource study (Musial et al. 2016) estimates that the technical resource area that could actually be developed for offshore wind is $15,225 \mathrm{~km}^{2}\left(5,878 \mathrm{mi}^{2}\right)$. According to that study, Hawaii has a technical resource of about $29 \mathrm{GW}$, or nearly 100 terawatt-hours per year.

Figure 39 shows the LCOE's modeled for Hawaii from 2015 through 2027. In Hawaii, the LCOE range lies between $\$ 200 / \mathrm{MWh}$ and $\$ 265 / \mathrm{MWh}$ in 2015. By 2022, this range falls in between $\$ 130 / \mathrm{MWh}$ and $\$ 175 / \mathrm{MWh}$. Additional technology improvements and cost reduction strategies lead to an LCOE range of \$100/MWh and \$125/MWh by 2027.

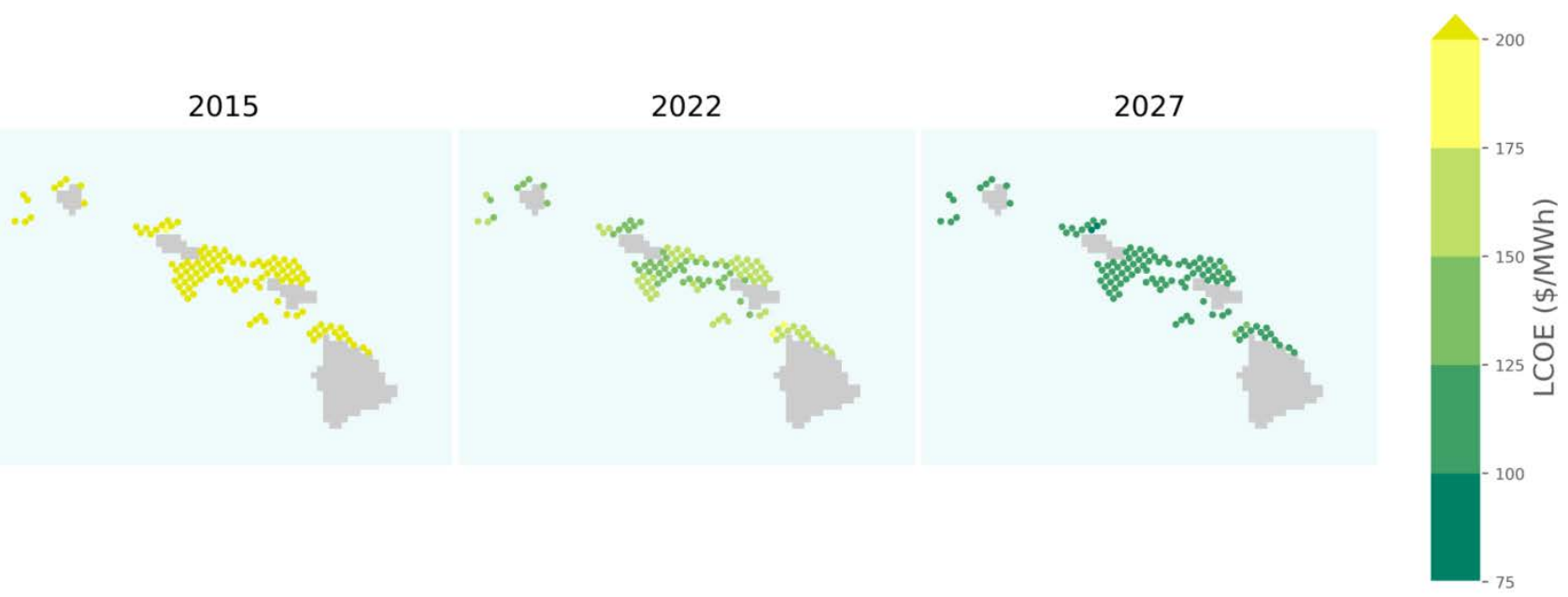

Figure 40. Hawaii spatial LCOE distribution (2015-2027)

\subsubsection{Supply Curves}

The smallest among the coastal regions considered in this analysis, Hawaii has an offshore wind technical resource of approximately $27 \mathrm{GW}$. Because $80 \%$ of the electricity in Hawaii is consumed on the island of Oahu, offshore wind may only be practical in locations that can access that load, which is about 6,782 gigawatt-hours/year (Hawaii 2016). For reference, NREL estimates that the output of a 1-GW wind plant offshore Oahu would be over 3,000 gigawatthours/yr.

Figures 41-43 show the offshore wind energy supply curves for Hawaii from 2015 to 2027. In this area, LCOE decreases significantly between 2015 and 2027. In 2015, only a few selected sites are available at LCOE levels below \$200/MWh. By 2027, approximately 0.5 GW are estimated to be below $\$ 100 / \mathrm{MWh}$, and nearly all of the other Hawaiian sites have LCOE values below \$125/MWh. As seen in the Pacific Coast region, almost all of the viable sites for offshore wind in Hawaii are in deeper waters where floating technology is selected by the model. The 
quantity of fixed-bottom sites that are represented in the supply curves in Figures $41-43$ is negligible with respect to the total resource available.

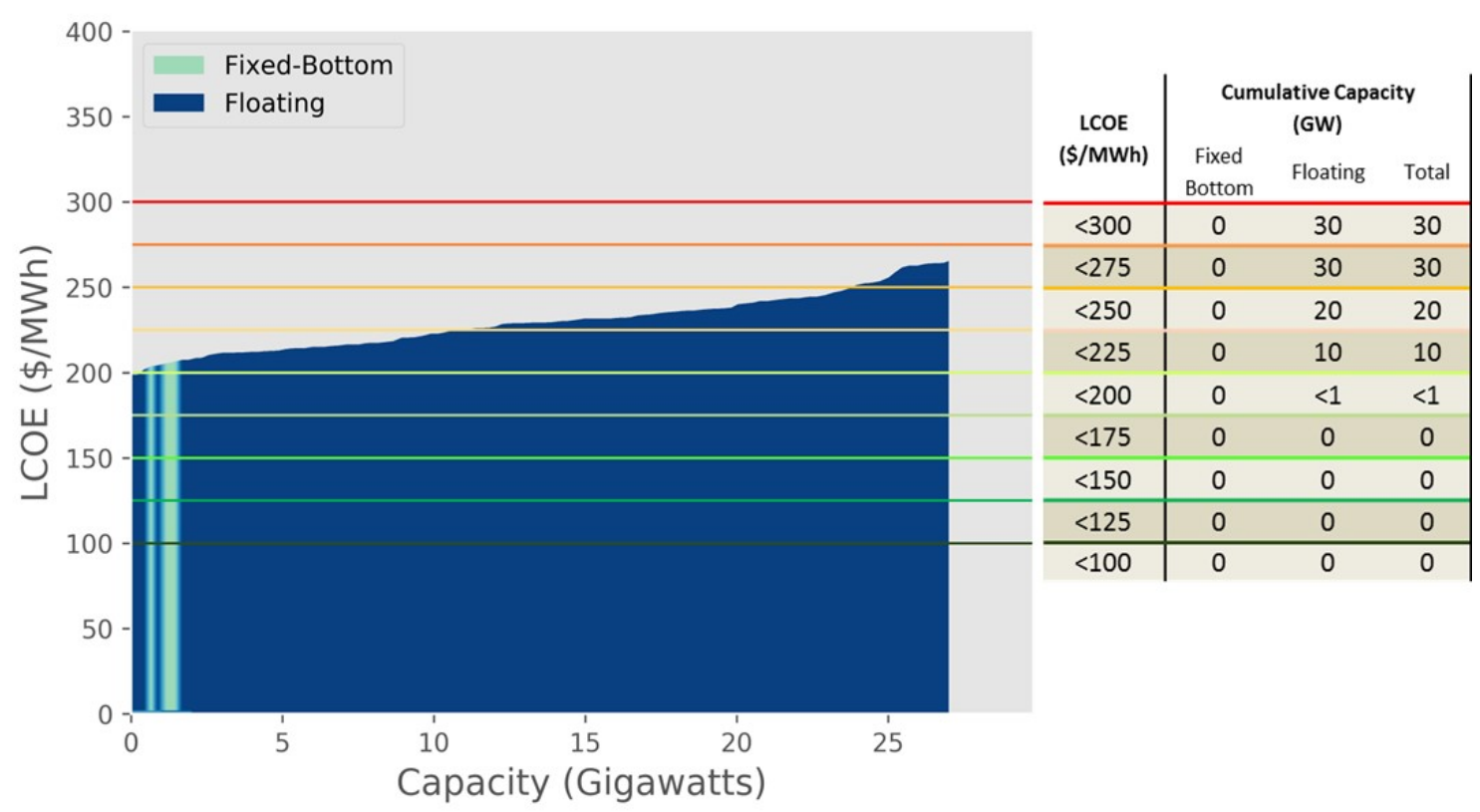

Figure 41. 2015 Hawaii supply curve

Note: Cumulative capacity in table rounded to the nearest $10(\mathrm{LCOE}<\$ 300)$ and one $(\mathrm{LCOE}<\$ 225)$.

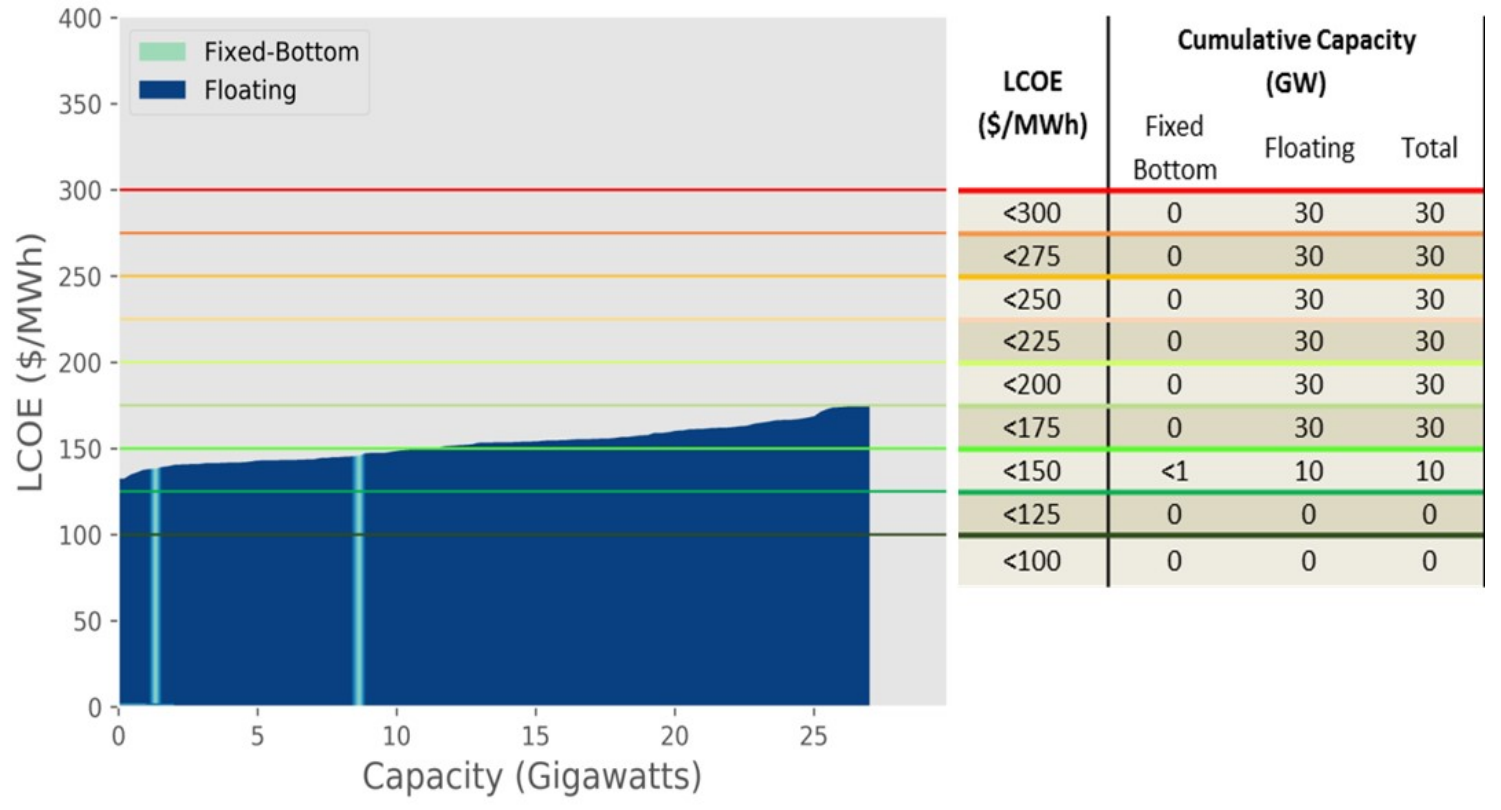

Figure 42. 2022 Hawaii supply curve

Note: Cumulative capacity in table rounded to the nearest 10 (LCOE $<\$ 300 / \mathrm{MWh}$ ) and one (LCOE<\$150/MWh).

This report is available at no cost from the National Renewable Energy Laboratory at www.nrel.gov/publications. 


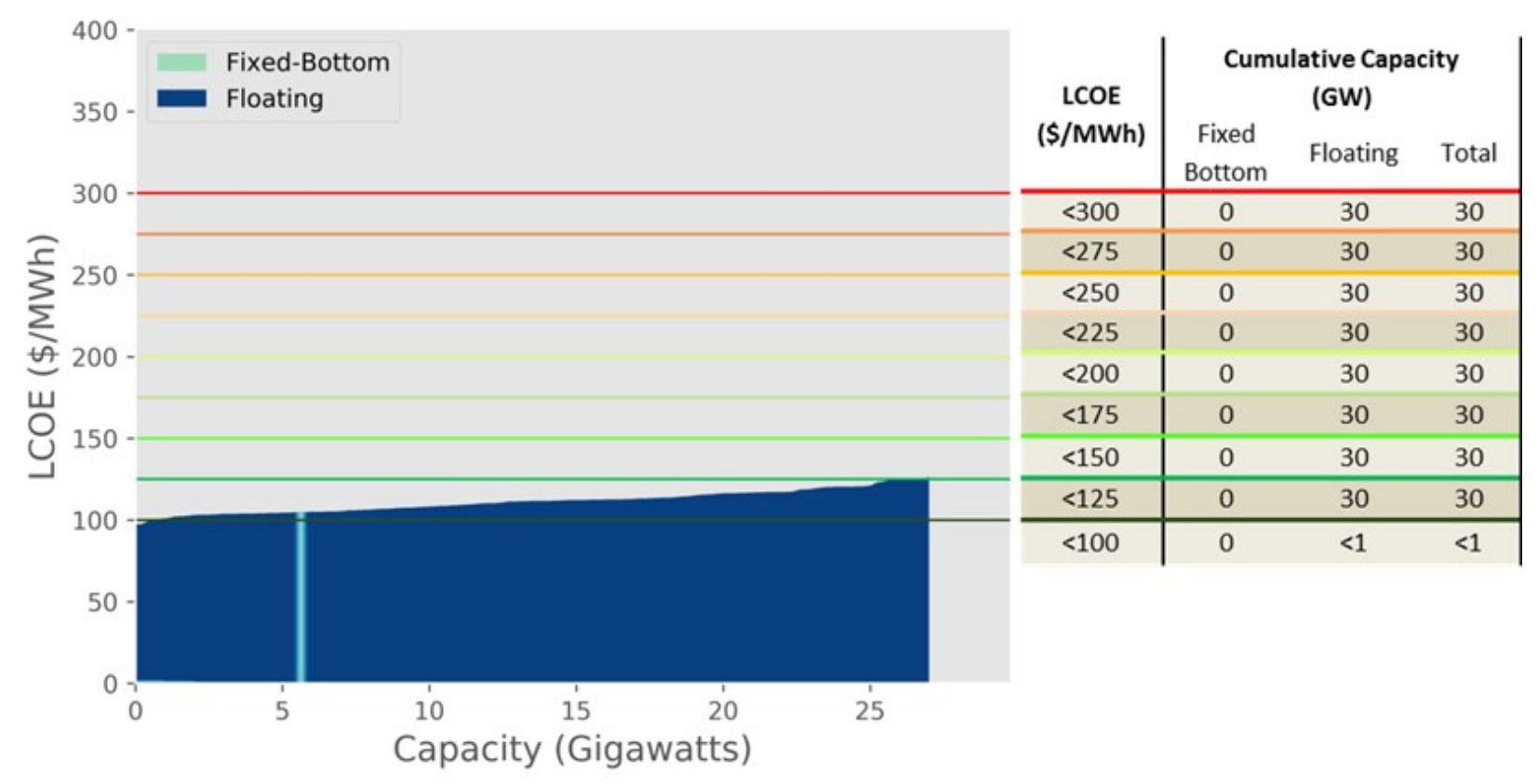

Figure 43. 2027 Hawaii supply curve

Note: Cumulative capacity in table rounded to the nearest 10.

Hawaii has the highest retail electricity prices in the United States (EIA 2017; Musial and Ram 2010), but achieving a good translation from those prices to wholesale electricity was beyond the scope of this study. 


\section{Conclusions and Next Steps}

In this analysis, the economic potential of offshore wind was assessed for more than 7,000 U.S. coastal sites between 2015 and 2027. The assessment includes the use of high-resolution heat maps of LCOE, LACE, and net value, and a set of associated descriptive statistics.

It was observed that the estimated reductions in LCOE over the next decade coincide with relatively high levels of LACE in some U.S. regions. By 2027, a considerable amount of economic potential was estimated for the Northeast and the Eastern shore of Virginia. It was also revealed that the supply and net value curves were relatively flat, indicating that even a small change in LCOE or LACE has the potential to trigger significant changes in the amount of economic potential calculated. This effect would be most relevant in regions that have significant quantities of net value sites close to zero, such as in the Northeast, mid-Atlantic, Great Lakes, and Gulf Coast in 2027. The flat shape of the supply curve also cautions to re-evaluate this assessment as market conditions or costs change.

Some general observations from this work include:

- The offshore wind sites with economic potential are located predominantly in the Northeast and Eastern shore of Virginia

- Across regions, the number of sites with a positive net value (or a value close to a positive net value) increase over the time period considered in this analysis

- State policies have driven offshore wind development recently (e.g., in New York and Massachusetts); these policies may play a key role in increasing the economic viability of offshore wind but are not considered in this analysis

- Further technology improvements are likely needed to achieve cost reductions

- Offshore wind development in different regions will likely require varying technology solutions (e.g., to address low wind speeds in the Gulf, icing in the Great Lakes, deepwater floating solutions in the Pacific and Hawaii).

A number of limitations and opportunities for further work were indicated throughout this report. Because Beiter et al. (2016) discusses improvements with regards to the LCOE assessment and cost-reduction pathways in detail, this section will focus on further work to improve LACE. Additional research could improve this metric in the following areas:

- Consider the competition among available technologies by comparing the net value of offshore wind to other technologies at a high geospatial resolution

- Estimate LACE by taking into account the coincidence of hourly marginal generation price data and hourly offshore wind production profiles 
- Investigate the availability of additional generation and wholesale price electricity data, particularly for the Pacific Northwest, Mountain region, and Southeast

- Conduct an analysis that takes into account the distribution of LCOE and LACE, and perform an analysis that would redefine economic potential based on thresholds of LCOE and LACE distributions (e.g., compare $50^{\text {th }}$ percentiles of LCOE and LACE for assessing economic potential)

- An additional metric that may be considered to further validate the findings from this assessment is a comparison of offshore wind LCOE with the least-cost option from other new build generation (e.g., natural gas, land-based wind, solar photovoltaic) as part of a merit order analysis

- Assess capacity credit and capacity payment specific to different U.S. coastal regions to more accurately represent the amount of firm capacity offshore wind can provide in various regions and at different times

- Perform additional studies that further develop the metrics from this report to explore their use in evaluating appropriate subsidy levels and site development prioritization

- Conduct an assessment of economic resource potential for Hawaii ${ }^{36}$ and Alaska (Draxl et al. [forthcoming]).

${ }^{36}$ This study only assessed the LCOE in Hawaii but not LACE and economic potential because of data limitations. 


\section{References}

ABB/Ventyx. 2015. Velocity Suite Database. Atlanta, GA: Ventyx/ABB.

American Wind Energy Association (AWEA). 2017. U.S. Wind Industry Fourth Quarter 2016 Market Report. Released January 26, 2017. http://www.awea.org/4q2016.

Bird, L., M. Milligan, D. Lew. 2013. Integrating Variable Renewable Energy: Challenges and Solutions (Technical Report). NREL/TP-6A20-60451. National Renewable Energy Laboratory (NREL), Golden (US). www.nrel.gov/docs/fy13osti/60451.pdf.

Beiter, P., W. Musial, A. Smith, L. Kilcher, R. Damiani, M. Maness, S. Sirnivas, T. Stehly, V. Gevorgian, M. Mooney, and G. Scott. 2016. A Spatial-Economic Cost Reduction Pathway Analysis for U.S. Offshore Wind Energy Development from 2015-2030 (Technical Report). NREL/TP-6A20-66579. National Renewable Energy Laboratory (NREL), Golden, CO (US). www.nrel.gov/docs/fy16/66579.pdf.

Beiter, P., and T. Tian. 2016. 2015 Renewable Energy Data Book. U.S. Department of Energy, Office of Energy Efficiency and Renewable Energy. Accessed December 2016. www.nrel.gov/docs/fy17osti/66591.pdf.

Brown, A., P. Beiter, D. Heimiller, C. Davidson, P. Denholm, J. Melius, A. Lopez, D. Hettinger, D. Mulcahy, and G. Porro. 2015. Estimating Renewable Energy Economic Potential in the United States: Methodology and Initial Results (Technical Report). NREL/TP-6A20-64503. National Renewable Energy Laboratory (NREL), Golden, CO (US). http://www.nrel.gov/docs/fy15osti/64503.pdf.

California Energy Commission. "Renewables Portfolio Standard (RPS).” http://www.energy.ca.gov/portfolio/. 2017.

Canada Department of Environment and Climate Change. 2017. "Met 101: National Marine Weather Guide. Chapter 3: Sea State." Accessed March 2017. https://www.ec.gc.ca/meteoweather/default.asp?lang=En\&n=279AC7ED-1\&offset=3\&toc=show.

Catapult. 2015. Cost Reduction Monitoring Framework 2015. Qualitative Summary Report to the Offshore Wind Programme Board. Swindon, U.K.: Innovate UK Technology Strategy Board. Accessed May 2016. https://ore.catapult.org.uk/wp-content/uploads/2016/05/Cost-ReductionMonitoring-Framework-2015.-Qualitative-report.pdf.

DOE (U.S. Department of Energy). 2013. Report to Congress on Renewable Energy Resource Assessment Information for the United States (Legislation). Washington, D.C.: Office of Energy Efficiency and Renewable Energy.

DOE. 2015. Wind Vision: A New Era for Wind Power in the United States. U.S. Department of Energy Office of Energy Efficiency and Renewable Energy. DOE/GO-102015-4557. Washington, D.C. http://www.energy.gov/sites/prod/files/WindVision_Report_final.pdf. 
DOE. 2016. National Offshore Wind Strategy. U.S. Department of Energy and U.S. Department of the Interior. DOE/GO-102016-4866. September 2016. Washington, D.C. https://energy.gov/eere/wind/downloads/national-offshore-wind-strategy-facilitatingdevelopment-offshore-wind-industry.

Draxl, C., L. Kilcher, G. Scott, W. Musial, P. Beiter. Forthcoming. 2017 Offshore Wind Energy Resource Assessment for Alaska. National Renewable Energy Laboratory (NREL), Golden, CO (US).

E.C. Harris. 2012. Offshore Wind Cost Reduction Pathways: Supply Chain Work Stream. London, U.K.: The Crowne Estate. http://www.thecrownestate.co.uk/media/5614/ei-echarrisowcrp-supply-chain-workstream.pdf.

Energy Information Administration (EIA). 2013. "Levelized Cost of Electricity and Levelized Avoided Cost of Electricity Methodology Supplement." Presented at the Workshop on Assessing the Economic Value of New Utility-Scale Renewable Generation Projects Using Levelized Cost of Electricity and Levelized Avoided Cost of Electricity, Washington, D.C. July 25. Accessed May 2016. http:/www.eia.gov/renewable/workshop/gencosts/pdf/methodology supplement.pdf.

EIA. 2014. EIA Annual Energy Outlook 2014. Washington, D.C.: Energy Information Administration. Accessed May 2015. http://www.eia.gov/forecasts/aeo/pdf/0383(2014).pdf.

EIA. 2015. Annual Energy Outlook 2015 with Projections to 2040 (Technical Report, DOE/EIA0383(2015). Washington, D.C. Accessed July

2015. http://www.eia.gov/forecasts/aeo/pdf/0383(2015).pdf.

EIA. 2016. "Levelized Cost and Levelized Avoided Cost of New Generation Resources in the Annual Energy Outlook 2015." Washington, D.C. Accessed March 2016. https://www.eia.gov/forecasts/aeo/pdf/electricity generation.pdf.

EIA. 2017. Energy Information Agency State Electricity Profiles: Hawaii. Data for 2015. Release Date: January 17, 2017. https://www.eia.gov/state/?sid=HI.

Ensslin, C., M. Milligan, H. Holttinen, M. O’Malley, A. Keane. 2008. “Current Methods to Calculate Capacity Credit of Wind Power, IEA Collaboration." Paper presented at the Power and Energy Society General Meeting - Conversion and Delivery of Electrical Energy in the 21st Century, Pennsylvania, July 20-24, 2008). https://www.researchgate.net/

publication/4361034_Current_methods to calculate_capacity_credit_of_wind power._IEA_ collaboration.

Eurek, K., W. Cole, D. Bielen, N. Blair, S. Cohen, B. Frew, J. Ho, V. Krishnan, T. Mai, B. Sigrin, D. Steinberg. 2016. Regional Energy Deployment System (ReEDS) Model

Documentation: Version 2016 (Technical Report). NREL/TP-6A20-67067. National Renewable Energy Laboratory (NREL), Golden, CO (US). Accessed March 2017. www.nrel.gov/docs/fy17osti/67067.pdf. 
European Commission. 2016. "SET-Plan-Declaration on Strategic Targets in the Context of an Initiative for Global Leadership in Offshore Wind." Paper presented by the SET Plan Secretariat, Brussels, Belgium, January 20. Accessed June 2016. https://setis.ec.europa.eu/system/files/declaration_of_intent_offshore_wind.pdf.

Federal Energy Regulatory Commission. 2010. "ISO/RTO Performance Metrics," Commission Staff Report AD10-5-000, Accessed May 29, 2015.http://www.ferc.gov/legal/staff-reports/1021-10-rto-metrics.pdf.

Garlick, R., R. Aukland, B. Zhang. 2017. "Market Overview Report - February 2017." 4COffshore Wind Farm Subscription (February 14, 2017). Accessed February 2017.

GE Power. 2010. New England Wind Integration Study. Prepared for ISO New England. GE Energy, Schenectady, New York (US). http://www.uwig.org/newis_es.pdf.

"Governor Cuomo Announces Establishment of Clean Energy Standard that Mandates 50 Percent Renewables by 2030," New York State Governor's Office. Accessed February 15, 2017. https://www.governor.ny.gov/news/governor-cuomo-announces-establishment-cleanenergy-standard-mandates-50-percent-renewables.

Hawaii Department of Business, Economic Development \& Tourism. 2016. Hawaii, Monthly Energy Trends, Research \& Economic Analysis, Department of Business, Economic Development \& Tourism, Hawaii.gov. Accessed September 21, 2016. http://dbedt.hawaii.gov/economic/energy-trends-2/.

Hirth, L. 2013. "The Market Value of Variable Renewables: The Effect of Solar Wind Power Variability on their Relative Price." Energy Economics 38:218-236. doi:10.1016/j.eneco.2013.02.004.

Independent System Operator of New England. (2015). "Locational Marginal Pricing (FAQ)" Accessed May 29, 2015. http://www.iso-ne.com/participate/support/faq/lmp.

Jenkin, T., P. Beiter, R. Margolis. 2016. Capacity Payments in Restructured Markets under Low and High Penetration Levels of Renewable Energy. Golden, CO: National Renewable Energy Laboratory. NREL/TP-6A20-65491.

Lopez, A., B. Roberts, D. Heimiller, N. Blair, and G. Porro. 2012. U.S. Renewable Energy Technical Potentials: A GIS-Based Analysis (Technical Report). NREL/TP-6A20-51946. National Renewable Energy Laboratory (NREL), Golden, CO (US). http://www.nrel.gov/docs/fy12osti/51946.pdf.

Maness, M., B. Maples, A. Smith. 2017. NREL Offshore Balance-of-System Model (Technical Report). NREL/TP-6A20-66874. National Renewable Energy Laboratory (NREL), Golden, CO (US). www.nrel.gov/docs/fy17osti/66874.pdf. 
Massachusetts Institute of Technology. 2015. The Future of Solar Energy. An Interdisciplinary MIT Study (Technical Report). Accessed June

2016. http://mitei.mit.edu/system/files/MIT\%20Future $\% 20$ of $\% 20$ Solar $\% 20$ Energy $\% 20$ Study co mpressed.pdf.

McClellan, S., D. Ozkan, W. Kempton, A. Levitt, and H. Thomson. 2015. New York Offshore Wind Cost Reduction Study (Technical Report). Newark, DE: University of Delaware, Special Initiative on Offshore Wind. https://www.ceoe.udel.edu/File\%20Library/About/SIOW/2016-06ny-offshore-wind-cost-reduction-study-ff8.pdf.

Milligan, M., and K. Porter. 2008. Determining the Capacity Value of Wind: An Updated Survey of Methods and Implementation (Technical Report). NREL/CP-500-43433. National Renewable Energy Laboratory (NREL) Golden, CO (US). Accessed July 2014. http://www.nrel.gov/docs/fy08osti/43433.pdf.

Mills, A., R. Wiser. 2012. Changes in the Economic Value of Variable Generation at High Penetration Levels: A Pilot Case Study of California. Lawrence Berkeley National Laboratory (LBNL). https://emp.lbl.gov/sites/all/files/lbnl-5445e.pdf.

Moné, C., T. Stehly, B. Maples, and E. Settle. 2015. 2014 Cost of Wind Energy Review (Technical Report). NREL/TP-6A20-64281. National Renewable Energy Laboratory (NREL), Golden, CO (US). http://www.nrel.gov/docs/fy16osti/64281.pdf.

Musial, W., P. Beiter, D. Heimiller, and G. Scott. 2016. 2016 Offshore Wind Energy Resource Assessment for the United States (Technical Report). NREL/TP-5000-66599. National Renewable Energy Laboratory (NREL), Golden, CO (US). http://www.nrel.gov/docs/fy16osti/66599.pdf.

Musial, W. and B. Ram. 2010. Large-Scale Offshore Wind Power in the United States: Assessment of Opportunities and Barriers (Technical Report). NREL/TP-500-40745. National Renewable Energy Laboratory (NREL), Golden, CO (US). http://www.nrel.gov/docs/fy10osti/40745.pdf.

Namovicz, C. 2013. "Assessing the Economic Value of New Utility-Scale Renewable Generation Projects." Paper presented at the EIA Energy Conference, Washington, D.C., June 17. Accessed May 2015. http://www.eia.gov/conference/2013/pdf/presentations/namovicz.pdf.

Navigant. 2013. “U.S. Offshore Wind Manufacturing and Supply Chain Development”. Prepared for U.S. Department of Energy. www.osti.gov/scitech/servlets/purl/1087161.

Sigrin, B., P. Sullivan, E. Ibanez, R. Margolis. 2014. Representation of Solar Capacity Value in the ReEDS Capacity Expansion Model (Technical Report). NREL/TP-6A20-61182. National Renewable Energy Laboratory (NREL), Golden, CO (US). www.nrel.gov/docs/fy14osti/61182.pdf. 
Short, W., D. J. Packey, and T. Holt. 1995. A Manual for the Economic Evaluation of Energy Efficiency and Renewable Energy Technologies (Technical Report). NREL/TP-462-5173. National Renewable Energy Laboratory (NREL), Golden, CO (US).

Smith, A., T. Stehly, and W. Musial. 2015. 2014-2015 Offshore Wind Technologies Market Report (Technical Report). NREL/TP-5000-64283. National Renewable Energy Laboratory (NREL), Golden, CO (US). http://www.nrel.gov/docs/fy15osti/64283.pdf.

Stoutenburg, E., N. Jenkins, and M. Z. Jacobson. 2010. "Power output variations of co-located offshore wind turbines and wave energy converters in California," Renewable Energy 35 (2010): 2,781-2,791, accessed March 12, 2016, doi: 10.1016/ j.renene.2010.04.033.

Tegen, S., D. Keyser, F. Flores-Espino, J. Miles, D. Zammit, D. Loomis. 2015. Offshore Wind Jobs and Economic Development Impacts in the United States: Four Regional Scenarios (Technical Report). National Renewable Energy Laboratory (NREL), Golden, CO (US). www.nrel.gov/docs/fy15osti/61315.pdf.

The Crown Estate. 2012. Offshore Wind Cost Reduction Pathways Study. London, U.K. http://www.thecrownestate.co.uk/media/5493/ei-offshore-wind-cost-reduction-pathwaysstudy.pdf.

The Crown Estate. 2015. Cost Reduction Monitoring Framework: Summary Report to the Offshore Wind Programme Board. Glasgow: Catapult Offshore Renewable Energy. https://ore.catapult.org.uk/documents/10619/110659/ORE+Catapult+report+to+the+OW $\underline{\mathrm{PB} / \mathrm{a} 8 \mathrm{c} 73 \mathrm{f} 4 \mathrm{e}-\mathrm{ba} 84-493 \mathrm{c}-8562-\mathrm{acc} 87 \mathrm{~b} 0 \mathrm{c} 2 \mathrm{~d} 76 .}$

The General Court of the Commonwealth of Massachusetts. Bill H.4568; An Act to Promote Energy Diversity. 2017. https://malegislature.gov/Bills/189/House/H4568.

Valpy, B., P. English, A. Martínez, and E. Simonot. 2014. Future Renewable Energy Costs: Offshore Wind (Technical Report). Cricklade, U.K.: BVG Associates. http://www.kicinnoenergy.com/wpcontent/uploads/2014/09/KIC IE OffshoreWind anticipated innovations i mpact1.pdf. 


\section{Appendix A. Descriptive Statistics}
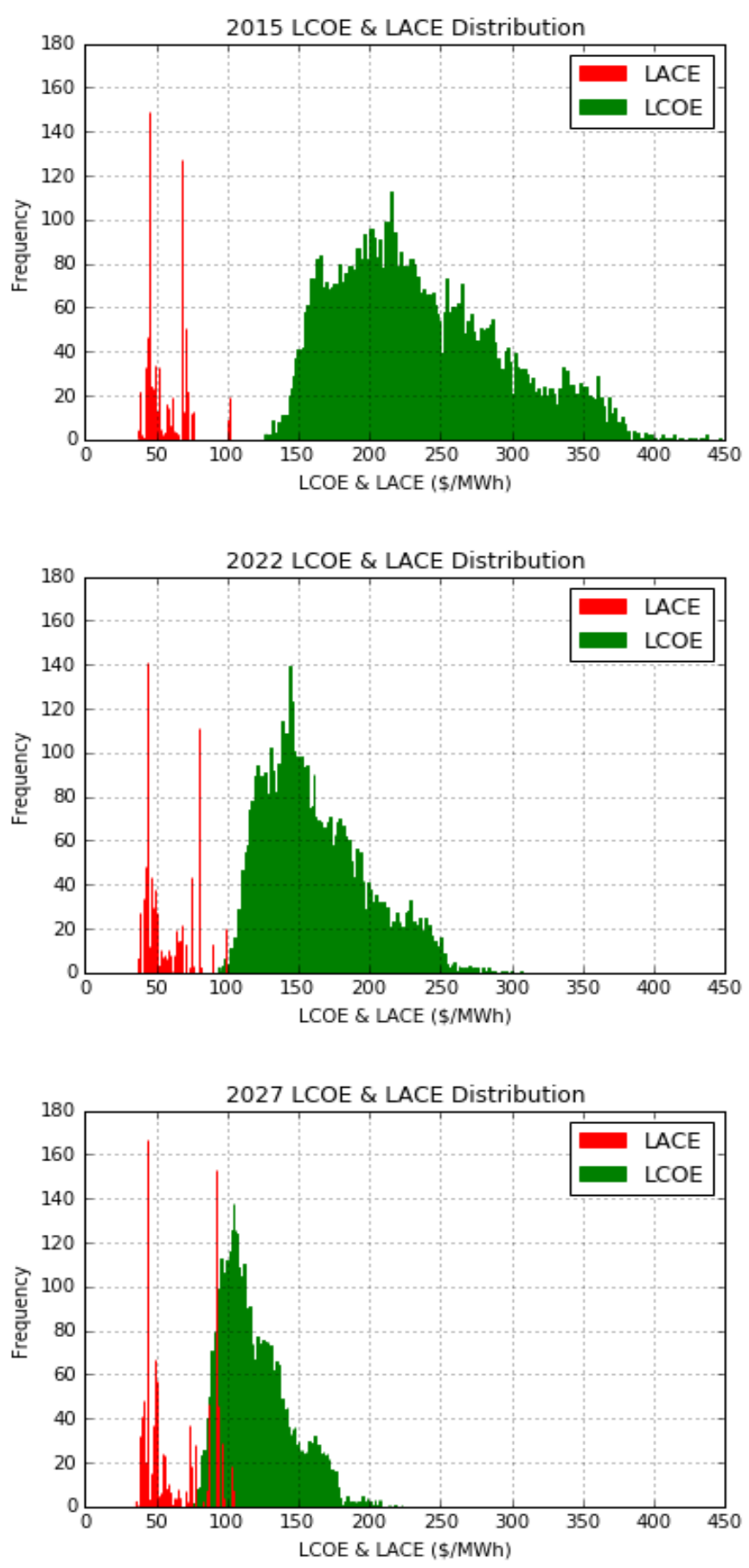

Figure A-1. National LCOE and LACE distribution (2015-2027) 


\section{Appendix B. Detailed Formulas}

The calculation of a location-specific LACE value follows this general form:

$L A C E$

$=\frac{\text { Average Marginal Generation Price } * \text { Escalation Factor } * \text { Capacity Factor } * 8760 h+\text { Capacity Payment } * \text { Capacity Credit }}{}$ Capacity Factor $* 8760 \mathrm{~h}$

Where:

\begin{tabular}{|c|c|c|}
\hline Variable & Description & $\begin{array}{l}\text { Assumption under } \\
\text { Primary Cases }\end{array}$ \\
\hline $\begin{array}{l}\text { Average Marginal } \\
\text { Generation Price }\end{array}$ & 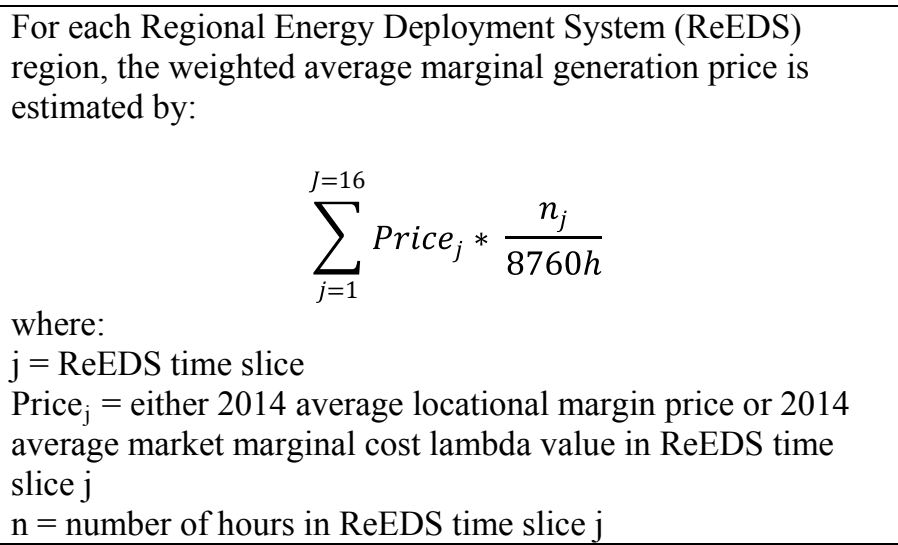 & $\begin{array}{l}\mathrm{j}=16 \text { (number of } \\
\text { ReEDS time slices) }\end{array}$ \\
\hline Escalation Factor & $\begin{array}{l}\text { For each Energy Information Administration (EIA) Annual } \\
\text { Energy Outlook (2015) market region, the escalation factor is } \\
\text { estimated by: } \\
\text { where: } \\
\mathrm{t}=\text { year } \\
\begin{array}{l}\text { Y }=\text { generation price (from EIA } 2015 \text { Annual Energy Outlook, } \\
\text { EIA 2015) } \\
\mathrm{i}=\text { discount rate }\end{array}\end{array}$ & $\begin{array}{l}\mathrm{t}=20 \text { (project } \\
\text { lifetime) } \\
\mathrm{i}=7 \%\end{array}$ \\
\hline Capacity Payment & $\begin{array}{l}\text { Capacity payments capture the value a generation project can } \\
\text { offer to the system in meeting reliability reserve margins (EIA } \\
2013 \text { ). } \\
\text { The Overnight capital cost of an advanced natural gas-fired } \\
\text { combustion turbine (NGCT) plant, } \$ 682 / \mathrm{kW} \text { (consistent with } \\
\text { AEO } 2015 \text { in EIA } 2015 \text { ), is used as proxy for capacity } \\
\text { payment. }\end{array}$ & \\
\hline Capacity Credit & $\begin{array}{l}\text { Capacity credit captures "the ability of a unit to provide system } \\
\text { reliability reserves" (EIA } 2013, \text { p. } 3 \text { ) }\end{array}$ & $25 \%$ \\
\hline
\end{tabular}

Source: Brown et al. (2015) 